Louisiana State University

LSU Digital Commons

2014

\title{
A thermographic method for remaining fatigue life prediction of welded joints
}

Paul Thomas Williams

Louisiana State University and Agricultural and Mechanical College

Follow this and additional works at: https://digitalcommons.Isu.edu/gradschool_theses

Part of the Mechanical Engineering Commons

\section{Recommended Citation}

Williams, Paul Thomas, "A thermographic method for remaining fatigue life prediction of welded joints" (2014). LSU Master's Theses. 2189.

https://digitalcommons.Isu.edu/gradschool_theses/2189

This Thesis is brought to you for free and open access by the Graduate School at LSU Digital Commons. It has been accepted for inclusion in LSU Master's Theses by an authorized graduate school editor of LSU Digital Commons. For more information, please contact gradetd@lsu.edu. 


\title{
A THERMOGRAPHIC METHOD FOR REMAINING FATIGUE LIFE PREDICTION OF WELDED JOINTS
}

\author{
A Thesis \\ Submitted to the Graduate Faculty of the \\ Louisiana State University and \\ Agricultural and Mechanical College \\ in partial fulfillment of the \\ requirements for the degree of \\ Master of Science in Mechanical Engineering \\ in
}

The Department of Mechanical and Industrial Engineering

by

Paul Thomas Williams

MEng University of Sheffield, 2010

May 2014 


\section{Acknowledgements}

I would like to thank my wife Emily for her endless support throughout my time at LSU, and all my friends and family here, and back home in the UK. Further I would like to thank my advisor Professor Khonsari for his considerable time and knowledge contributions to this work, my advisory committee members Professor Meng and Professor Wahab. Finally thank you to all my friends and colleagues at the CeRoM lab at LSU, for their support and advice throughout this work. This work was funded in part by Cameron International. Thanks to Omar Kabir for his contributions and support throughout this work. 


\section{Table of Contents}

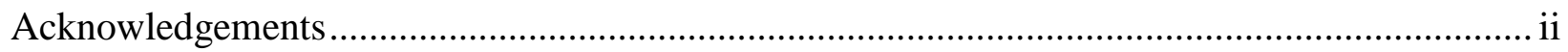

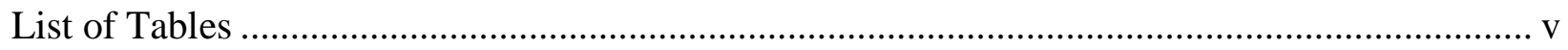

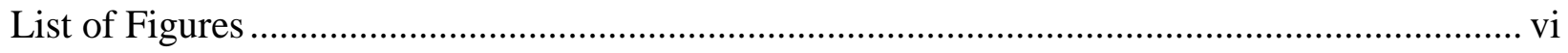

Nomenclature ................................................................................................................... vii

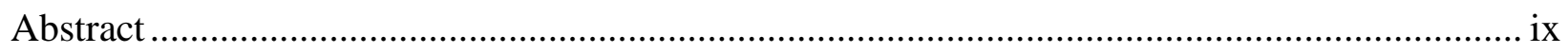

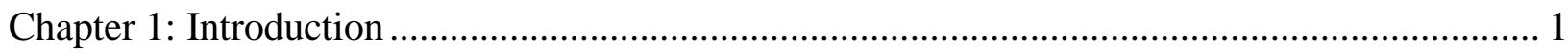

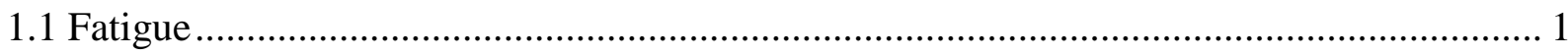

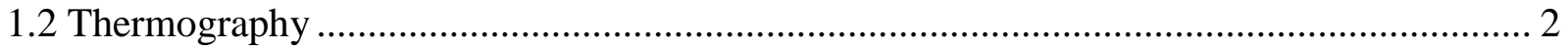

1.3 Developments in Fatigue Prediction Methods .......................................................... 4

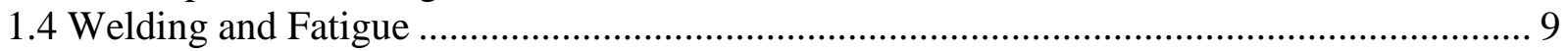

1.5 Buckingham Pi Theorem........................................................................................... 11

1.6 Continuum Damage Mechanics (CDM) ................................................................ 16

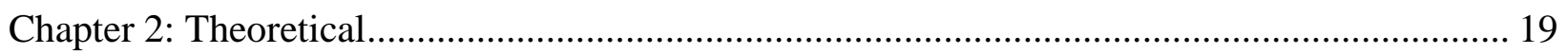

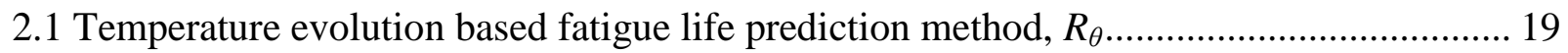

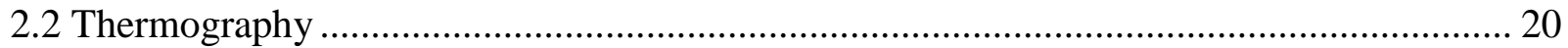

2.3 Buckingham Pi Theorem....................................................................................... 20

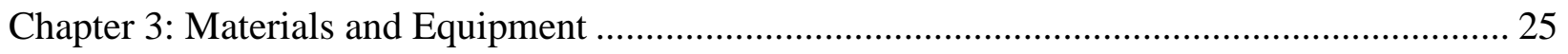

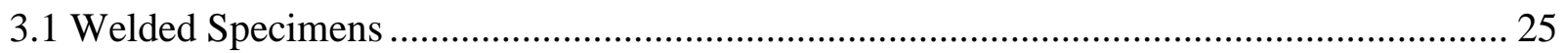

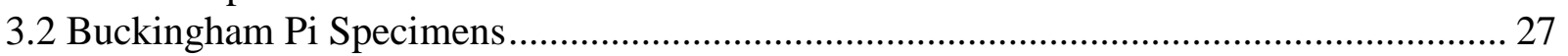

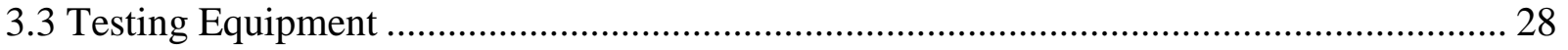

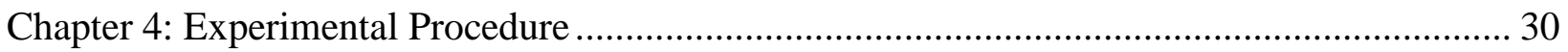

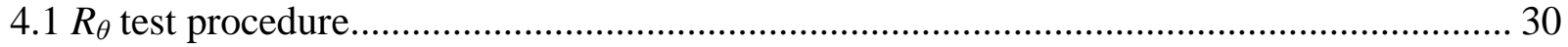

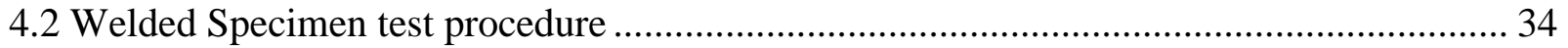

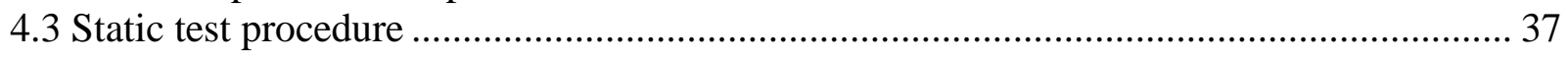

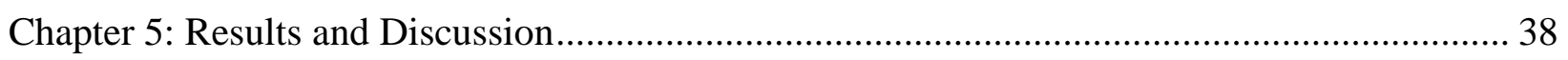

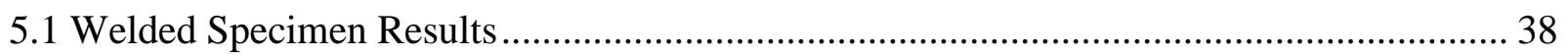

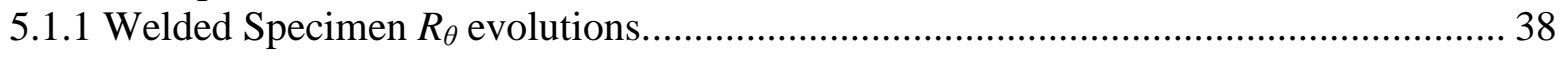

5.1.2 Welded Specimen Verification Results............................................................ 41

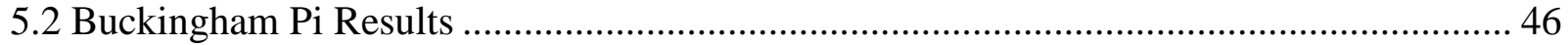

5.2.1 Buckingham Pi $R_{\theta}$ evolutions .......................................................................... 46

5.2.2 Application of Results to Pi Theorem ..................................................................... 50

5.2.3 Predictions for previously untested $R_{r}$ evolutions .............................................. 53

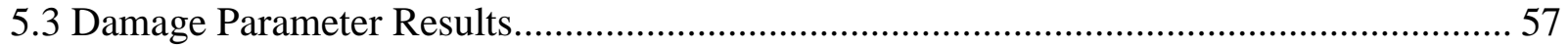

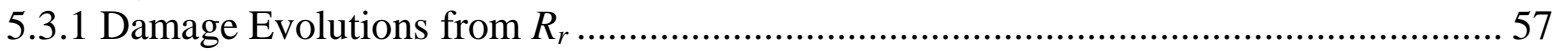




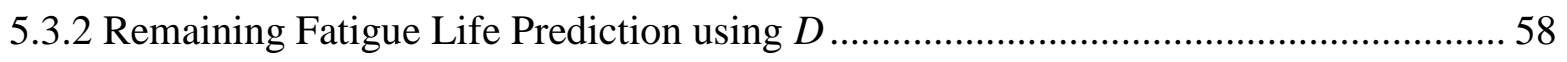

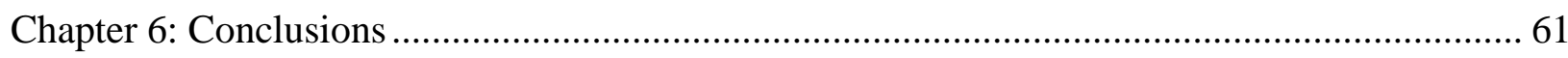

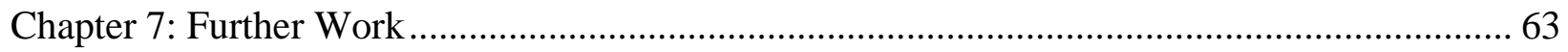

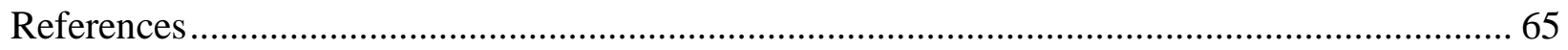

Appendix A: Additional Experimental Data for welded $R_{\theta}$ testing and Buckingham Pi testing.. 72 Appendix B: Letter of permission for reuse of images and text ....................................... 75

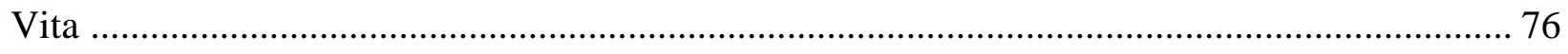




\section{List of Tables}

Table 1: Parameters used in Buckingham Pi Analysis. .................................................... 21

Table 2: Material Properties for Pristine and Welded 1018 Carbon Steel................................. 26

Table 3: Carbon Steel Material Properties................................................................................ 27

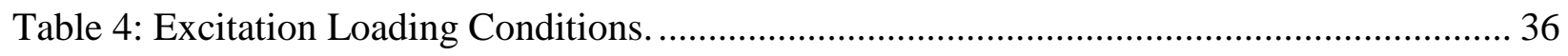

Table 5: Verification Test Results for Welded 1018 Specimens............................................ 39

Table 6: Verification Test Results for Welded API5LX52 Specimens. ................................... 45

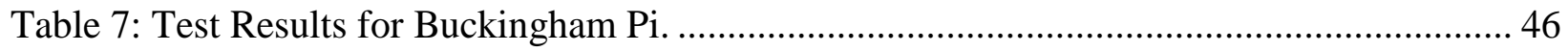

Table 8: Coefficients for Carbon Steel. ........................................................................ 51

Table 9: Damage Verification Test Results for Welded API5LX52 Specimens........................ 59 


\section{List of Figures}

Figure 1: Diagram of Tubular 1018 Carbon Steel Specimen. …………………………................. 25

Figure 2: Photo of a Welded Specimen, prior to application of black paint................................. 25

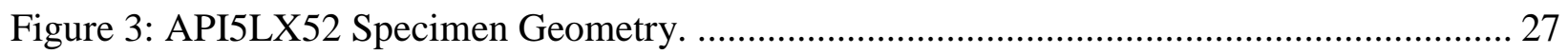

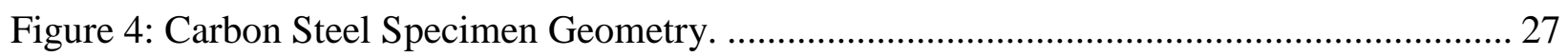

Figure 5: Painted Buckingham Pi Specimens with varying gauge lengths. ................................ 28

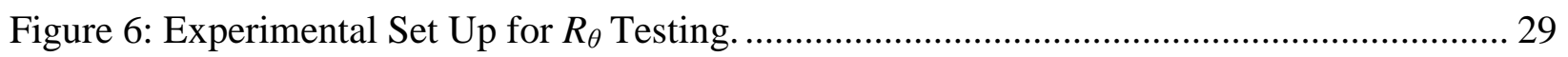

Figure 7: Visualization of the Fatigue and Excitation Testing conditions.................................... 31

Figure 8: Idealized temperature evolutions during Fatigue and Excitation loading..................... 31

Figure 9: Temperature averaging line on a thermographic Specimen image.............................. 32

Figure 10: Temperature vs. Frame Number data from the IR Camera software.......................... 33

Figure 11: Measurement of $R_{\theta}$ from the thermographic data. ................................................... 33

Figure 12: $R_{\theta}$ evolution variation with ROI Marker shape ..................................................... 35

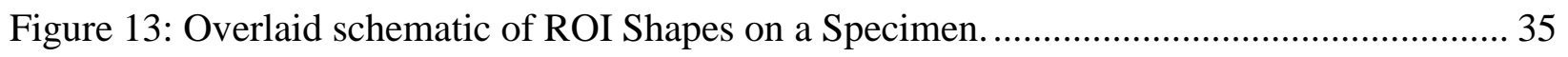

Figure 14: Example of hotspot motion during fatigue loading.................................................... 36

Figure 15: $R_{\theta}$ evolutions for the 1018 Carbon Steel Welded Specimens. ..................................... 38

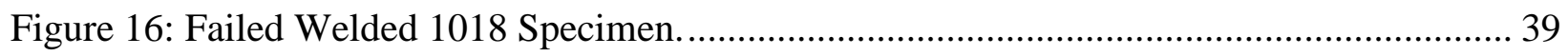

Figure 17: S-N Curve for both Welded and Pristine 1018 Specimens. ........................................ 40

Figure 18: Performance curve for a Welded Specimen, including the $R_{\theta 0}$ value. ......................... 41

Figure 19: Performance curve for a Welded Specimen with no $R_{\theta 0}$ value.................................... 41

Figure 20: Welded Specimen fracture surface showing apparent flaws....................................... 43

Figure 21: $R_{\theta}$ evolutions for the API5LX52 welded specimens................................................. 44

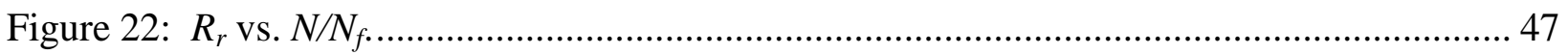


Figure 23: $R_{r}$ vs. Maximum Applied Stress/ Ultimate Tensile Strength. 48

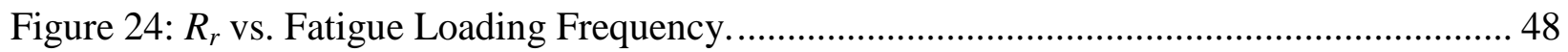

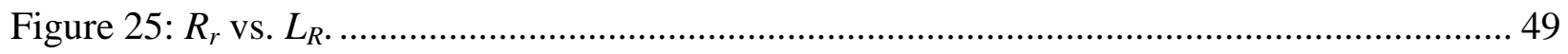

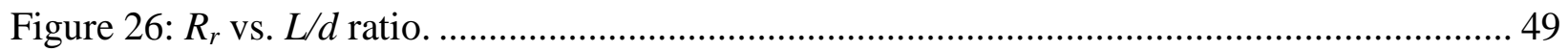

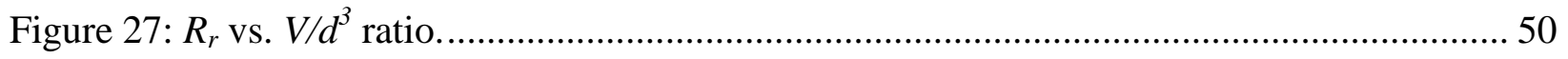

Figure 28: Comparison of Experimental and Predicted $R_{r}$ evolutions and different stress levels.52

Figure 29: Comparison of Experimental and Predicted $R_{r}$ evolutions at different load ratios..... 52

Figure 30: Comparison of Experimental and Predicted $R_{r}$ evolutions at different $V / d^{3}$ ratios.... 53

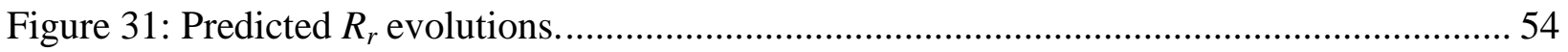

Figure 32: Comparison of Predicted and Experimental $R_{r}$ evolutions. .......................................... 54

Figure 33: $R_{r}$ vs. maximum applied stress/ ultimate tensile strength ratio for Welded API5LX52

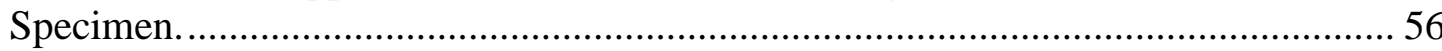

Figure 34: Damage Evolution for API5LX52 Welded Specimens................................................... 58

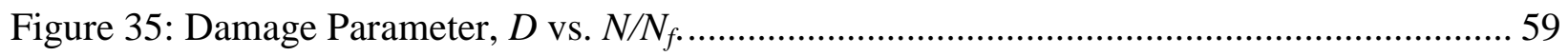

Figure A-1: $S-N$ curve for Welded and Pristine API5LX52 ...................................................... 72

Figure A-2: S-N Curve for Buckingham Pi Specimens. ........................................................... 72

Figure A-3 $L_{R}-N$ Curve for Buckingham Pi Specimens................................................... 73

Figure A-4: $f-N$ Curve for Buckingham Pi Specimens. ........................................................ 73

Figure A-5: Volume Ratio - N Curve for Buckingham Pi Specimens........................................... 74

Figure A-6: $R_{r}$ vs. Maximum Applied Stress/ Ultimate Tensile Strength for API5LX52............ 74

Figure B-1: Letter of permission for reuse of images and text from the paper "A thermographic method remaining fatigue life prediction of welded joints"........................................ 75 


\section{Nomenclature}

\begin{tabular}{|c|c|c|}
\hline$a$ & unit balance exponent & - \\
\hline$b$ & unit balance exponent & - \\
\hline$c$ & unit balance exponent & - \\
\hline$d$ & unit balance exponent & - \\
\hline$d$ & specimen gauge section diameter & $\mathrm{m}$ \\
\hline$D$ & damage parameter & - \\
\hline$E$ & elastic Modulus & $\mathrm{GPa}$ \\
\hline$f$ & fatigue loading frequency & $\mathrm{Hz}$ \\
\hline$h$ & heat transfer coefficient & $\mathrm{W} / \mathrm{m}^{2} \mathrm{~K}$ \\
\hline$i$ & counting index & - \\
\hline$L$ & specimen gauge length & $\mathrm{m}$ \\
\hline$L$ & base unit of length & - \\
\hline$L_{R}$ & load ratio & - \\
\hline$n$ & slope of $R_{\theta}$ curve & ${ }^{\circ} \mathrm{C} / \mathrm{s}$ \\
\hline$N / N_{f}$ & fraction of fatigue life & - \\
\hline$Q_{i}$ & quantity to be varied experimentally in Pi group & - \\
\hline$\widetilde{R}_{r}$ & relative temperature rise & ${ }^{\circ} \mathrm{C} / \mathrm{s}$ \\
\hline$R_{\theta}$ & temperature rise during excitation testing & ${ }^{\circ} \mathrm{C} / \mathrm{s}$ \\
\hline$R_{\theta 0}$ & Initial $R_{\theta}$ measurement & ${ }^{\circ} \mathrm{C} / \mathrm{s}$ \\
\hline$R_{\theta 0}{ }^{\prime}$ & $\mathrm{Y}$ axis intercept of $R_{\theta}$ curve & ${ }^{\circ} \mathrm{C} / \mathrm{s}$ \\
\hline$t$ & base unit of time & - \\
\hline$V$ & specimen gauge section volume & $\mathrm{m}^{3}$ \\
\hline$x$ & total number of variables & - \\
\hline$y$ & number of repeating variables & - \\
\hline$z$ & Pi group exponent & - \\
\hline$\alpha$ & thermal diffusivity & $\mathrm{m}^{2} / \mathrm{sec}$ \\
\hline$\theta$ & base unit of temperature & - \\
\hline$\Pi_{i}$ & non-dimensional group & - \\
\hline$\sigma_{\max }$ & applied fatigue stress & $\mathrm{MPa}$ \\
\hline$\sigma_{U T S}$ & ultimate tensile strength & $\mathrm{MPa}$ \\
\hline$\varphi$ & function relating a combination of $\mathrm{Pi}$ groups & - \\
\hline$\psi$ & function relating all non-dimensional Pi groups & - \\
\hline
\end{tabular}




\begin{abstract}
A non-destructive thermographic technique is adapted and applied to study the fatigue life and behavior of welded specimens made from two different materials. Results show good agreement between experimental predictions of consumed fatigue life and predicted fatigue life. Further, the thermal evolution of the specimens is used to calculate Damage Parameter, which is also used to make fatigue life predictions with promising results.

To gain further insight Buckingham Pi theorem is also applied to determine the role of the important parameters involved in a dimensionless form. For this purpose, a series of experiments were performed and used for the analysis of Pi groups. The non-dimensional Pi groups show variation caused by changes in material properties, and loading conditions used in determining temperature evolutions.
\end{abstract}




\section{Chapter 1: Introduction}

\subsection{Fatigue}

Material Fatigue is a significant issue in all areas of engineering structures and machinery components. Scientific understanding of the nature of fatigue and the ability to appropriately manage maintenance and repair is thus of great importance, for fatigue failure has enormous economic and safety implications. Recent examples with disastrous consequences are the Kiellend incident [1] which killed 123 people, and the DeHavailland Comet disasters [2], where unexpectedly high fatigue stresses causes by window geometry led to several failures of the aircraft fuselage in flight. These are just two prominent examples of failures caused by fatigue. There are a number of techniques to monitor the health of structures and components and methods to make predictions of the remaining fatigue life. The National Bureau of standards presented a special report, estimating the cost of fatigue at approximately 4\% GNP ( $\$ 119$ billion dollars in 1982) [3]. In an effort to reduce the vast expenditure on fatigue and failures caused by fatigue, the report suggests that significant economic savings of around $\$ 35$ billion dollar per year could be made through appropriate implementation of innovative technology, and additional saving could be found through research into fracture [3]. Bhaumik et al., [4] estimated that $60 \%$ of failures found in aircraft components could be related to fatigue. These startling statistics emphasize the motivation for further research into fatigue and fracture.

Traditionally, the Stress vs. Number of cycles to failure (S-N) curves have been the standard strategy for making general predictions and planning of maintenance. However these curves only consider single loading scenarios, and without directly applicable data, they do not provide accurate analysis of any engineering situation. 
A Review of the open literature reveals that a significant portion of fatigue modelling or predictions is based on phenomenological approaches to fatigue, such as the Paris crack law [5], which studies the cyclic growth of a crack, and well known S-N curves, where the loading stress is plotted against the number of fatigue cycles to failure, under constant cyclic loading, which date as far back as works by Wöhler, 1870 [6] and Basquin in 1910 [7]. While progress has been made in further understanding fatigue behavior and failure, the traditional approaches previously listed are limited in their scope and range of applicability. For example S-N curves are only valid under particular loading conditions; however, real applications will rarely have a constant loading or frequency. Further material variations and other complexities caused by variations in geometry make the applicability of these approaches questionable. Stephens et al., 2001 [8] discussed the synergistic complexities of applying these approaches in engineering applications. It, therefore, comes as no surprise that engineers tend to resort to large safety factors in their designs and analyses.

\subsection{Thermography}

Before continuing to discuss some of the novel approaches for fatigue analysis developed in recent years, a brief discussion of thermography is presented to aid in understanding the wide applications of the technique and how it has opened new research avenues in the studying fatigue. Since the discovery of infra-red (IR) radiation [9] by Sir William Herschel, and the advent of IR cameras, thermography has become a popular technique due to the increased versatility of this non-contact analysis method. Prior to the use of IR camera, thermocouples were used to measure local temperature differences in specimens. However many novel techniques in materials and stress analysis take advantage of the modern, high resolution IR cameras. 
Meola [10] provides an in depth summary and explanation of the key theory behind thermography, and Maldague [11] presented the developments up to the state of the art in 1994. Throughout its history, thermography has been applied to a wide range of different applications including stress analysis $[12,13]$, crack growth and fracture mechanics studies [14-16], materials and fatigue analysis [17-19] including composites [20, 21] and civil materials [22-24], weld inspection and monitoring [25] and diverse areas such as studying integrated electric circuits [26] and medical applications [27]. Of particular interest from those applications listed is fatigue analysis. The general principle of fatigue analysis using thermography is to study the hysteresis energy released by a specimen when it is cyclically loaded. The foundation of this theory is thermoelasticity, which was discussed as early as 1853 [28] and 1857 [29] by Lord Kelvin and also considered by noted physicist Biot in 1956 [30]. The use of thermography for thermoelastic stress analysis, TSA, began in the 1970's. Thermographic stress relies on the use of a small applied stress, to generate small fluctuations in temperature. Generally the stress applied is below the endurance limit, the stress at which a material can survive at least one million cycles. As the material is expanded and compressed, the temperature rises and falls. If the cycling is at a high enough frequency, the specimen effectively becomes an adiabatic system. This allows for hotspots in the images to analyzed, as the signal picked up by an IR camera can be related to principal stresses in the material, and areas of the specimens that show particularly increased temperatures can be analyzed for a stress concentration effect on the component.

The fatigue analysis applications of IR thermography use a similar concept; however, the loading is no longer required to be below the endurance limit. When a strain gauge or extensometer is applied to a specimen undergoing cyclic loading, a hysteresis loop can be measured - the area of while is equal to the amount of energy released by the specimen - which 
can be measured using IR thermography. Hysteresis loops have been studied by several researchers, including Morrow [31] who developed an equation for predicting hysteresis energy. Later works have used hysteresis energy as a method for predicting fatigue life and studying cyclic loading [32-36]. Some modern techniques have been developed which will be discussed in greater detail in Section 1.3.

\subsection{Developments in Fatigue Prediction Methods}

Many testing methodologies used to study fatigue require instrumentation to be attached to the component, and to ensure that the component only undergoes an exact set of loading conditions, which is required for traditional S-N curve based predictions. To apply existing methodologies and gain a full understanding of a materials behavior could potentially require many hours of testing, under a range of loading conditions.

To help improve fatigue analysis and life predictions, many avenues of research have been explored. One area of particular interest has been thermodynamic based approaches, through the application of irreversible thermodynamics to the degradation of a material. The use of entropy for studying the fatigue and failure phenomenon is a powerful technique, as entropy is known to always increase for a closed system until equilibrium is reached. Due to this behavior entropy has been described as the "arrow of time", and as such is a useful technique for analyzing cyclic techniques. Prigogine covered the theory of irreversible thermodynamics in his 1967 publication, where he described the variation in entropy of a system as a sum of two terms: the entropy generated by the system and the entropy supplied to the system [37].

A novel procedure developed at the Center for Rotating Machinery laboratory (CeRoM) at Louisiana State University (LSU) presents a method to study the fatigue life of a specimen that is not restricted by geometry, or specimen loading. Naderi and Khonsari [19, 38] utilized 
thermodynamic entropy to study the degradation of a material throughout fatigue loading. Fracture Fatigue Entropy (FFE) uses a temperature reading at each cycle of loading captured by an IR camera, and the released hysteresis energy per cycle to calculate the final value of entropy. The results found from this technique showed a relatively constant final value of FFE, therefore allowing it be considered as a material constant, and that when the value was reached, failure would occur.

It has also been shown that FFE is not only applicable to metals undergoing fatigue loading, but also composite materials [21]. For the experiments, a woven glass fiber composite material was subjected to tension-tension loading and fully reversed bending, where the results presented show the FFE values for the composite materials to be relatively constant, though composite specimens produced smaller FFE values than metal specimens. The application of the FFE concept to composite metals emphasizes the utility of entropy as a damage measure, as regardless of the damage mechanisms in materials, the entropy is still generated and allows for characterization of fatigue.

Naderi and Khonsari [38] presented an in-depth experimental investigation using thermodynamic entropy to develop a fatigue failure criterion. Through a range of experiments, including variable loading, hysteresis energy and generated entropy were studied an indexes for fatigue analysis. Of all the plots shown, the entropy vs. fatigue cycles shows the best trend, suggesting it had the most potential for further development.

Naderi and Khonsari also presented an approach for studying damage accumulation under variable loading [40]. Many techniques for studying for fatigue rely on materials undergoing constant fatigue loading, thus variable loading poses a more difficult problem. The technique presented uses damage accumulation and the critical damage, the value of 
accumulated damage when macro-cracks initiate to study variable loading in materials. The results from the experiments measured the damage accumulation effectively in materials tested, under various loading methods, proving the technique to be robust and widely applicable.

A further development using thermography was shown by Naderi and Khonsari [39], applying damage mechanics to study low-cycle fatigue using thermodynamic entropy. Through experimentation, using a range of different loading methods, it was shown that the entropy-based formulation provided good evolutions of damage through the fatigue life of the specimens, and matched well with evolutions calculated using other approaches found in literature.

Naderi et al. [41] also used the entropy flow during fatigue to determine the critical damage parameter for a material, when macro-crack initiation began. The experimental data showed that at approximately $89 \%$ of the consumed fatigue life of a specimen, the entropy flow increased significantly from a relatively steady state condition, signaling the beginning of failure in the specimen. This increase in entropy flow was also mirrored in the temperature measured on the surface of the specimen. The presented results and damage parameter evolutions determined from this entropy relation showed good agreements other approaches.

The generation of damage in a composite material was also studied by Naderi et al. [42], with an approach that also included the study of acoustic emission combined with thermographic temperature measurements. The cooling rate of the specimen was measured to study to the dissipated thermal energy, as well as the temperature throughout loading. The temperature evolution throughout loading showed a three-phase trend: an initial increase, a steady state region, followed by a further increase closer to failure. This trend was also revealed the number of acoustic counts, showing that the acoustic counts can be utilized to assess to the damage in the 
specimen and that results of acoustic emission corroborate those obtained from the dissipated thermal energy.

Another novel technique of particular interest is a life prediction technique developed by Amiri and Khonsari [43]. Through the measurement of the initial temperature rise, called $R_{\theta}$ and comparing the value of this parameter at different load levels a methodology was developed to make fatigue life predictions. The results presented show a relation between $R_{\theta}$ and $N_{f}$ related by some coefficients that must be determined from experiments.

Continuing from the work on predicting fatigue life, temperature evolution in fully reversed bending loading was also studied by Amiri and Khonsari [44]. Aluminum 6061 and Stainless Steel 304 were both tested in this loading, and the previously discussed parameter $R_{\theta}$ was used to make predictions for the total fatigue life. The results showed the $R_{\theta}$ was able to be successfully implemented to predict the fatigue life, allowing for a rapid prediction based on the initial temperature rise.

Further expanding on the previous works using the parameter $R_{\theta}$, Amiri and Khonsari [45] presented a mapping concept to make fatigue life predictions for specimens that had already undergone fatigue loading. Using short tests to generate small temperature rises in the specimens - which were measured with an IR camera - a map was created plotting $R_{\theta}$ against fatigue cycles completed. The results showed a linear progression of these plots, which could then be used to make fatigue life predictions, by completing a short time excitation test (STE) on a pre-fatigued specimen and comparing the $R_{\theta}$ with the map. The predictions showed good accuracy with the experimental results with great promise for further implementation.

Liakat and Khonsari [46] utilized the technique presented by Amiri to study a subsea jumper material, API5LX52, and Carbon Steel 1018. In addition to being different materials, 
different geometries were also examined, with the Carbon Steel 1018 specimens being tubular. Due to differences in material properties, different loading conditions were used for the STE tests used to generate the $R_{\theta}$ maps. The predictions presented showed good agreement with the experimental data. This implies that the technique is not limited by geometry or material, allowing for a wider application of the technique.

From the developments using IR thermography in the study of fatigue behavior, Amiri and Khonsari [47] presented the underlying theory for analyzing degradation theory behind irreversible thermodynamics. Through the study of these techniques further advances can be made into study of these processes and new methodologies to study and analyze fatigue phenomena.

Meneghetti [48] applied IR thermography to study the energy released by a specimen undergoing fatigue loading, and presented an energy release based parameter to study fatigue. The published experimental results agreed well with the theoretical model developed in the paper, and model was also shown to provide promising results for variable fatigue loading. Another use of thermography for characterizing fatigue by dissipated heat energy is presented by Rösner et al. [49].

In addition to solely relying on thermography, some researchers have approached the study of materials by combining non-destructive techniques. Matsumoto [50] combined three separate approaches to study fatigue; IR thermography, Magnetic leakage flux and Acoustic impedance. Each of the methods individually showed progressive trends as the fatigue continued and degradation of the material increased, proving the powerful potential of combining different analysis techniques for improved understanding of fatigue processes. 


\subsection{Welding and Fatigue}

Welding is one of the most commonly used methods joining different metals. However, proper welding of metals requires consideration of many factors such as residual stresses, consistent weld qualities, and changes in material properties in the heat affected zone (HAZ). All of these factors can significantly affect the quality of a weld. Welding has been investigated in detail by the scientific community to examine the issues of reduction in strength and fatigue life.

A variety of different approaches have been considered for studying welded joints under fatigue loading, and Crupi et al. [51] present a summary of the more commonly used procedures. The approaches discussed include a modified Linear Elastic Fracture Mechanics approach (LEFM), Stress Averaging Approach (SAA), Notch Stress Intensity Factor (NSIF) and Critical Distance method (CD). The authors state that all the methods discussed are applicable to cruciform specimens with fillet welds, and partial penetration butt welds. Throughout the paper four methods are considered, Crack Modeling Method (CMM) as well as CD, SAA and NSIF approaches. The accuracy of these different methods is compared with CMM appearing the most consistent and SAA tending to the least accurate of the methodologies presented.

Bilous and Lagoba [52] used geometry and microstructural variations created by welding to define a stress concentration factor, equivalent to a notch in a specimen. The reported stress concentration factor $K_{f}$ varied throughout the life of the specimen, generally increasing then decreasing prior to failure; however, some tests showed continuous increases in the value of $K_{f}$. This variation in $K_{f}$ was discussed and determined to be material dependent, as the change in $K_{f}$ was different between high and medium strength structural steels.

Alam et al. [53] have utilized finite element techniques to study the fatigue behavior of welded joints, considering both experimental and theoretical laser welded geometries. The 
presented results showed the importance of the weld geometry in determining the values and locations of the peak stresses in the joints, in addition to highlighting geometries which should be avoided for maximum fatigue life of welded joints. Jiang et al. [54] also used finite element to examine the effect of heat input during welding, and number of welding passes on the residual stresses. The presented works emphasize the complexities which must be considered in the study of welded joints, due to the large number of variables affecting the strength of the joints.

Equivalent structural stress approach, based on Von Mises equivalent stress equation has been used by Kang [55], who provided a comparison between theoretical results and experimental results of spot welded joints. Both tensile-shear, and multiaxial loading were tested, and the experimental and theoretical data showed a good correlation for both loading methods. Another approach considered by Park and Kang [56] utilized Back propagation Neural Networks (BNN) to further examine spot welds. A number of variables were considered such as load ratio, weld nugget size and loading angle to create a single output of the predicted fatigue life. The key feature of the methodology is the ability to combine multiple inputs and determine a value for the fatigue life. Experimental data for tension, shear and tensile-shear loading was presented, showing reasonable agreement with the theoretical results.

Lock-in thermography has also been used to study fatigue in welded joints by Fan et al. [57], and shows predictions of fatigue lives, with reasonable accuracy. In addition the paper addressed other energetic approaches to prediction the lives of welded specimens with a variety of different load sequences. The thermographic results presented agree well with the traditional S-N approach to fatigue life prediction.

Crupi et al. [58] completed a thermographic study of specimens containing welded joints undergoing low-cycle fatigue (LCF). The results for the tested flat, stress relieved specimens 
showed a difference between the base metal and weld metal when plotted on a temperature vs. cycle plot. Both base and welded material showed a three phase temperature profile, with an initial rise, a flat, relatively steady state region and a rapid increase close to failure, which has also been shown in other thermographic studies of pristine specimens such as those carried out by Amiri and Khonsari [45].This provides further evidence that due to a similar thermal response, the $R_{\theta}$ technique could be applied to welded specimens. Also of note is the utilization of heat treatment of the specimen as a basis for the stress relief procedure applied to welded specimens described in section 3.1 .

\subsection{Buckingham Pi Theorem}

In 1914, Buckingham presented a theorem to aid in the understanding of a range of phenomena [59], which has since been utilized across engineering disciplines. It has been applied in a wide range of fields in engineering from fluid flow, with well-known dimensionless numbers such as the Reynolds Number [60] to fracture mechanics and crack propagation [61]. The basic concepts behind dimensional analysis have been considered by some of the most famous minds in physics and engineering including, Sir Isaac Newton [62], Euler [63] and Fourier [64].

A further method of dimensional analysis was presented by Lord Rayleigh in 'Theory of Sound' [65]. From this initial statement of the methodology, he continued to apply it to a range of different problems [66]. Lord Rayleigh felt the technique was not applied in as many situations as it could have been, and suggested that some early users of the technique did not apply it enough [67]. The Rayleigh method is fairly well-known as a method of dimensional analysis. Nevertheless, it is not without its limitations, such as not defining the number of non- 
dimensional groups for a problem. This can create difficulties if not all the variables for a problem are known or fully understood.

In 1914 Buckingham [59] presented a theorem for studying the dimensions of an equation, and reducing the number of variables by creating non-dimensional groups. This work went on to be considered as the Buckingham Pi Theorem, one of the most commonly used methods of dimensional analysis. The application of the method to break down the original equations is straight forward, and can be applied very generally to different fields of engineering. In his paper Buckingham provides several detailed examples of his theorem showing the wide range of applicability that makes the method so popular.

Mayo Hersey, a prominent tribology researcher, discussed the importance of dimensional analysis and contributed different approaches and extension to Buckingham's Pi theorem, particularly application of the derivatives to the method [68]. As a corollary to Buckingham's Pi theorem work [59, 69] the approach developed in his paper uses the derivatives of Pi groups to relate different quantities to each other, and determine the relationship between them. This provides a useful addition to dimensional analysis should there be a quantity that is difficult to vary. In which case, it may be possible to change another, and through the derivative relation find the effect. Further to his work on the derivatives of dimensional quantities, Hersey also considered a dimensional analysis approach to the study of plastic flow [70]. Through the use of Pi theorem, plastic flow is broken down to provide an easier to analysis set of groups, which are then used to further analysis this complex problem, including the study of rotational resistance and turbulent motion in plastic flow.

Percy Bridgman completed a full text book, titled 'Dimensional Analysis' [71] covering the Rayleigh and Buckingham Pi approaches to dimensional analysis, and some applications of 
the concept. Throughout this text book, the work by Buckingham, Hersey and several other previously mentioned proponents of the dimensional analysis methodology was referenced, to show the strength of the technique.

A review of available literature shows a range of application of dimensional analysis to variety of fatigue problems. However, currently no attempts appear to have been made to nondimensionalize a "thermal fatigue parameter". Studying previous work regarding the use of dimensional analysis provides a useful insight into dimensional effects in fatigue and fracture.

Scaling Phenomena in Fatigue and Fracture by Barenblatt [72], presents an overview of the effect of scaling in fatigue, covering the development of scaling laws and applications of $\mathrm{Pi}$ theorem before continuing to discuss complete and incomplete self-similarity. Show in detail as an example of incomplete self-similarity, was the dimensional analysis of Paris Law.

Paris law is defined as:

$$
\frac{d a}{d N}=C \Delta K^{m}
$$

where $a$ is the crack length, $N$ is the number of fatigue cycles and $C$ and $m$ are material constants.

From this development it is shown that some parameters in Paris law are not directly material constant but significantly dependent upon the specimen geometry. Since most correlations and relations found in experiments use standard specimens, this scale factor is significant issue with regard to applying these laws to real life components.

Shirani and Härkegård [73] conducted experimental research into the size effect on fatigue properties of steels used in wind turbine construction. Weibull analysis was also applied to the experimental data to create Probability - Stress - Number of Cycles graph (P-S-N) to analyze the scatter, and further in-depth studying of the size effect was carried out using 
Weibull's weakest link method. The tested material, a ductile cast iron, shows a slight reduction in fatigue life on the standard S-N curves for larger specimens compared the smaller test specimens. The P-S-N curves generated from the experimental data also showed promise for accurately representing the statistical distribution of data points of the larger specimens.

Further work on specimen size and the effect on fatigue properties has also been conducted by Nakai et al. [74]. The experimental work carried out in this paper uses extremely small specimens varying from $0.2 \mathrm{~mm}$ to $0.6 \mathrm{~mm}$ diameter of both pure aluminum and pure iron. The presented results showed that the fatigue strength of the pure aluminum specimens changed very little when the specimen diameter was varied. However, number of cycles to failure varied greatly. Pure iron specimens showed different behavior with variations in both fatigue strength and fatigue life being reported when the specimen diameter was changed. Fracture morphology of the specimens were also studied, with three different morphologies seen in aluminum and two in pure iron; however, only a weak correlation was identified between fracture morphology and fatigue life.

Flaceliere and Morel, surface and volume effects in high-cycle, multiaxial fatigue [75], also considers the weakest link theory previously utilized in [79]. A brief summary of the theory suggests that an increased volume of material under the same loading, has a higher chance of encountering a critical defect, and could reduce the fatigue strength. The work presented focuses mainly on high-cycle fatigue using Weibull analysis and probability. The results show a reasonable agreement between a theoretical model based on volume integrating over the volume, a theoretical model based on the surface area modified by the hydrostatic stress gradient and the experiment results. However, there are some discrepancies between the data sets. 
Ciavarella et al. [76] continued to generalize the dimensional analysis shown by Barenblatt and Botvina [62] and showed the most deviations from Paris Law can be explained through the unified approach presented combining both complete and incomplete self-similarity. The original work used as the basis for this paper discusses Paris Law as a weak scaling law, and Pi theorem was used to break down Paris Law in nine different Pi groups, which are studied in depth. The relationship between the constants $C$ and $m$ in the Paris Law are also studied which allows for the more generalized approach.

Paggi [77] utilized dimensional analysis to study fatigue in quasi-brittle materials, considering the crack-size and size-scale effects on Paris Law, following dimensional analysis on Paris law carried out by Barenblatt and Botvina [62]. The paper combines the nondimensionalized Paris law and the Wöhler equation to create an analytical framework, and determine theoretical trends. The results of the theoretical trends compare favorably with experimental results obtained from other literature, showing the strength and utility of the Pi theorem technique.

Further work into dimensional effects on Paris law and Wöhler equation have been carried out by Plekhov et al. [78], in particular studying the dependency of grain size and frequency on fatigue life. The Hall Petch describes the relationship between yield strength and grain size, and so comparing these results to the effect of the grain size provides useful information, particularly with ultra-fine grain materials being developed. The presented results show good agreement between the groups developed through Buckingham Pi theorem. However, the author does note some difficulties with a lack of data in determining some exponents for Pi groups. 
Chou and Croman studied the effect of scale on the fatigue of composite materials [79]. Fatigue tests were carried out on composite specimens containing either one or three holes. The results from these tests were studied using the statistical weakest link theory and the authors determined that for this series of the tests, the variation in strength and fatigue data due to scale was accounted for by statistical scatter.

The study of weld geometry has also included dimensional analysis as shown by Nguyen and Wahab [80]. Due to the large amount of variables that can affect the fatigue of welded joints, the application of this technique allows for the study of both geometry of the welded joints, and the residual stresses left by the welding process. Through the plotting of $\mathrm{S} \cdot K_{f}$ against $\mathrm{N}$, the fatigue data shows a significantly decreased amount of scatter, which the author suggests could be used to improve the standard procedure for fatigue testing.

Hirose et al. studied size effect on the fatigue properties of welded steels used in the nuclear industry through experiment [81]. Both strain and load-controlled fatigue tests were carried out on irradiated specimens, with two different specimen sizes. For small and large specimens it was found that the number of cycles to failure, plastic strain range and the applied stresses did not vary significantly with specimen geometry. The welded material had a shorter fatigue life than the base metal, and this was also found to be independent of the size of the specimen.

\subsection{Continuum Damage Mechanics (CDM)}

Continuum Damage Mechanics (CDM) allows for a different approach to the study of material degradation. A variety of different approaches have been used to study fatigue damage [82 - 85]. Damage parameter has been briefly mentioned previously in Section 1.3, this section aims to provide a small insight into the work developing the theory, and its application. 
One of the earlier works on the subject of material damage was presented by Hashin and Rotem [82]. The key development in his paper was showing that specimens under different loading conditions could reach the same level of damage. The endurance limit of the materials tested was used to determine the progression of damage and experimental results showed reasonably good agreement with the theoretical development in his paper.

Lemaitre and Dufailly [83] described eight different methodologies for measuring damage. Their paper also defined damage in a material as the effective density of micro-crack and voids within a volume element. Direct techniques such as micrographic examination of fracture to surfaces were used to determine the density of cracks, as well as indirect methods such as studying elastic modulus variation and variation of micro hardness variation. This progression into the study of material parameter variation due to damage accumulation would significantly aid in development of later works such as that of Duyi and Zhenlin $[\mathbf{8 5}, \mathbf{8 6}]$.

Cheng et al. [84] used the concept of ductility to deflection to define a new measure of fatigue damage in a specimen. The deflection of ductility is calculated from material parameters, and measured experimentally, and showed a trend of gradual increase, followed by a significant rise defined as the critical point at which a macro-crack is formed. The critical point in damage evolution has also been studied by Naderi et al. [41].

Recently work by Duyi and Zhenlin [86] presented a viable, and relatively simple to apply method to study the progression of damage throughout the fatigue life of a specimen. The equation for calculating the damage parameter presented by Duyi and Zhenlin was:

$$
D_{N}=-\frac{D_{\left(N_{f}-1\right)}}{\ln \left(N_{f}\right)} \ln \left(1-\frac{N}{N_{f}}\right)
$$

This equation was later adapted by Naderi et al. [39] to determine the damage evolution based on a thermodynamic entropy approach. Naderi suggested that as $D$ was a function of 
consumed fatigue life $N / N_{f}$ as was thermodynamic entropy, the following relation could be applied:

$$
\frac{S_{e}}{S_{f}} \cong \frac{N}{N_{f}}
$$

Thus applying this relation to the damage parameter equation developed by Duyi and Zhenlin [86]:

$$
D=\frac{-1}{\ln \left(S_{f}\right)} \ln \left(1-\frac{S_{e}}{S_{f}}\right)
$$

Thermodynamic methods to study damage parameter and the critical damage for a material have been mentioned previously [39-42], showing good agreement with other published results such as those by Duyi and Zhenlin [86]. Liakat et al. [87] presented a further framework using temperature data captured from an IR camera to calculate the damage parameter, $D$. Using the $R_{\theta}$ approach developed by Amiri [45], an equation for $D$ is developed, and the results show good agreement with entropy based $D$ evolutions reported by Naderi [39]. Also presented in this work is the effect of variable loading on $D$ and $R_{\theta}$ evolutions. Both plots show changes when the loading is changed. However, when $D$ is plotted with normalized fatigue life, the results collapse to a single trend, potentially allowing for predictions to be made of the consumed fatigue life. 


\section{Chapter 2: Theoretical}

\subsection{Temperature evolution based fatigue life prediction method, $R_{\theta}$}

A thermographic technique for fatigue life prediction was presented by Amiri and Khonsari [45]. A temperature is measured when as specimen undergoes loading, and the slope of this initial temperature is defined as $R_{\theta}$. Meyendorf et al. [88] discussed the factors affecting the cyclic temperature rise of a material. As $R_{\theta}$ is a temperature over several cycles, similar principles are applicable, and Williams et al. [89] presented the following development relating $R_{\theta}$ to loading conditions.

$R_{\theta}=\boldsymbol{F} \sigma_{a}{ }^{m+1}$

where $\boldsymbol{F}$ is a function related to material microstructure, loading frequency and temperature, and $\mathrm{m}$ is an empirically determined material constant.

$\boldsymbol{F}=\boldsymbol{F}$ (microstructure, loading frequency, load amplitude, temperature)

The temperature rise experienced by specimens under excitation loading conditions is relatively small, due to the short loading time of the excitation test, thus temperature does not have a significant effect on the function $\boldsymbol{F}$. Therefore:

$\boldsymbol{F} \cong \boldsymbol{F}$ (microstructure, loading frequency, load amplitude)

Loading frequency and load amplitude used to obtain $R_{\theta}$ are defined as the excitation loading conditions:

$\boldsymbol{F} \cong \boldsymbol{F}$ (microstructure, excitation loading conditions)

Amiri and Khonsari [43] described the increase of material degradation throughout fatigue loading, therefore relating material microstructure to $N$, the number of fatigue cycles.

$\boldsymbol{F} \cong \boldsymbol{F}(N$, excitation loading conditions $)$ 
At the onset of cyclic loading $(N=0)$ a pristine specimen is ideally assumed to be defect free. This initial temperature rise is defined as $R_{\theta 0}$. From equations 5 and 8 , it can be written as:

$R_{\theta 0}=\boldsymbol{F}$ (excitation loading conditions)

where $\boldsymbol{F}_{\boldsymbol{0}}$ is function obtained when $(N=0)$. All excitation loading parameters (load ratio, frequency and stress amplitude) are kept constant throughout a test series. Therefore, $\boldsymbol{F}_{\boldsymbol{0}}$ has an effect on all values of $R_{\theta}$ :

$R_{\theta}=F_{N} \sigma_{a}^{m+1}+R_{\theta 0}$

with $\boldsymbol{F}_{N}=\boldsymbol{F}(N)$. As excitation test parameters remain constant throughout a test series, function $\boldsymbol{F}$ varies only with number of fatigue cycles.

\subsection{Thermography}

To utilize thermographic methods for fatigue life predictions, it is important to understand the methodology for obtaining the experimental data. For the tests, the IR camera captures 1 frame per second during the short time excitation tests. The specimen is excited for 10-15 seconds or 100-150 cycles. Once captured the data is post processed using a short data marker, or region of interest (ROI), approximately $10 \mathrm{~mm}$ long, placed vertically on the hotspot which appears in the center of the pristine specimen. The camera software averages the temperature along the pixels in this line and outputs the average temperature into an Excel file. To determine the temperature rise required for fatigue life predictions the first 10 points of the temperature rise from the ambient temperature are collected, and a curve fit applied to determine the value of $\mathrm{R}_{\theta}$. Diagrams showing the procedure in greater detail are included in Section 4.1.

\subsection{Buckingham Pi Theorem}

To study the proportionality of fatigue loading parameters with respect to $R_{\theta}$ ideally the relation should go through the origin. The evolution of $R_{\theta}$ against Number of cycles, $N$ has a relation of the form: 


$$
R_{\theta}=n \frac{N}{N_{f}}+R^{\prime}{ }_{\theta 0}
$$

This can be used to determine a further parameter $R_{r}$, which is the relative temperature rise, defined as:

$$
R_{r}=R_{\theta}-R_{\theta 0}^{\prime}=n \frac{N}{N_{f}}
$$

The use of $R_{r}$ as a parameter for calculations based on the fatigue behavior was first shown by Liakat and Khonsari [87]. Plotting these values against normalized fatigue life provides a relation between the fraction of fatigue life $N / N_{f}$ and the relative temperature rise $R_{r}$ which will be discussed in more detail further on in this paper.

Buckingham Pi theorem can be applied fairly simply to a range of problems. The first part of the analysis is to consider all the key variables for the problem, and the parameter that is to be studied, in this case $R_{r}$. Table 1 below shows the parameters affecting the temperature evolution, and the relevant base units of Mass, $M$, Length, $L$, Time, $t$ and Temperature, $\theta$.

Table 1: Parameters used in Buckingham Pi Analysis.

\begin{tabular}{ccc}
\hline Parameter & Units (SI) & Base Units (MLt $\theta)$ \\
\hline$\alpha$ & $\mathrm{m}^{2} / \mathrm{s}$ & $\mathrm{L}^{2} \mathrm{t}^{-1}$ \\
$\sigma_{\max }$ & $\mathrm{MPa}$ & $\mathrm{ML}^{-1} \mathrm{t}^{-2}$ \\
$\sigma_{U T S}$ & $\mathrm{MPa}$ & $\mathrm{ML}^{-1} \mathrm{t}^{-2}$ \\
$d$ & $\mathrm{~m}$ & $\mathrm{~L}^{-1}$ \\
$f$ & $\mathrm{~Hz}$ & $\mathrm{t}^{-1}$ \\
$h$ & $\mathrm{~W} / \mathrm{m}^{2} \mathrm{~K}$ & $\mathrm{Mt}^{-3} \theta^{-1}$ \\
$L$ & $\mathrm{~m}$ & $\mathrm{~L}^{-}$ \\
$L_{R}$ & Unitless & - \\
$N / N_{f}$ & Unitless & - \\
$R_{\theta}$ & ${ }^{\circ} \mathrm{C} / \mathrm{s}$ & $\theta \mathrm{t}^{-1}$ \\
$V$ & $\mathrm{~m}^{3}$ & $\mathrm{~L}^{3}$ \\
\hline
\end{tabular}

From the parameters shown in Table 1 above, was selected to represent each of the 4 base units, and these selected parameters are called repeating variables. The total number of variables, 
$x$ minus the number of repeating variables, $y$, gives the number of dimensionless Pi groups that will be determined through the analysis. 11 total parameters minus 4 repeating parameters shows that $7 \mathrm{Pi}$ groups will be created. To determine the individual Pi groups a unit balance is carried out using the 4 repeating parameters, and 1 of the remaining 7 parameters, thus creating the 7 groups. The following equations provide an example of a unit balance and creation of a Pi group.

$$
Q_{1} \cdot \sigma_{U T S}^{a} \cdot d^{b} \cdot \alpha^{c} \cdot h^{d}=M^{0} L^{0} t^{0} \theta^{0}
$$

Equation 13 shows that any quantity to be studied combined with the 4 repeating parameters must be equal to the 4 base units with exponents of $0 . R_{\theta}$ is the first parameter to study, as it is the measured quantity used to make predictions of remaining fatigue life (RFL).

$$
R_{\theta} \cdot \sigma_{U T S}^{a} \cdot d^{b} \cdot \alpha^{c} \cdot h^{d}=M^{0} L^{0} t^{0} \theta^{0}
$$

Substituting in the base units listed previously in Table 1, Equation 14 becomes:

$$
\left(\theta t^{-1}\right)^{1}\left(M L^{-1} t^{-2}\right)^{a}(L)^{b}\left(L^{2} t^{-1}\right)^{c}\left(M t^{-3} \theta^{-1}\right)^{d}=M^{0} L^{0} t^{0} \theta^{0}
$$

From this equation it is now possible to balance each of the base units individually with the parameters and non-dimensional side, and then solving the equations for the exponents $a, b, c$ and d.

$$
\begin{gathered}
M \text { balance: } 0=a+d \\
L \text { balance: } 0=-a+b+2 c \\
t \text { balance: } 0=-1-2 a-c-3 d \\
\theta \text { balance: } 0=1-d
\end{gathered}
$$

From the base unit balancing equations above, the 4 exponents can be determined, in the case shown, $a=-1, b=3, c=-2, d=1$. Applying these values back into Equation 14 creates the Pi group from the studied quantity and the four repeating parameters.

$$
R_{r} \cdot \sigma_{U T S}^{-1} \cdot d^{3} \cdot \alpha^{-2} \cdot h^{1}=M^{0} L^{0} t^{0} \theta^{0}
$$


This can be simplified and finally written as:

$$
\Pi_{1}=\frac{R_{r} \cdot h \cdot d^{3}}{\sigma_{U T S} \cdot \alpha^{2}}
$$

Following the same procedure the remaining pi groups can also be determined:

$$
\begin{gathered}
\Pi_{2}=\frac{\sigma_{\max }}{\sigma_{U T S}} \\
\Pi_{3}=L_{R} \\
\Pi_{4}=\frac{N}{N f} \\
\Pi_{5}=\frac{f d^{2}}{\alpha} \\
\Pi_{6}=\frac{L}{d} \\
\Pi_{7}=\frac{V}{d^{3}}
\end{gathered}
$$

From Buckingham's 1914 paper [59], it is stated that these groups are related and the relation can be described by equations 21 and 22 below:

$$
\begin{gathered}
\psi\left(\Pi_{1}, \Pi_{2}, \Pi_{3}, \Pi_{4}, \Pi_{5}, \Pi_{6}, \Pi_{7}\right)=0 \\
\Pi_{1}=\varphi\left(\Pi_{2}, \Pi_{3}, \Pi_{4}, \Pi_{5}, \Pi_{6}, \Pi_{7}\right)
\end{gathered}
$$

For investigating how $R_{r}$ varies with respect to the individual pi groups, one group must be varied at a time, by changing one parameter within the pi group. In addition to maintaining all other parameters, using a constant geometry is important in studying the physical behavior. Once this has been studied and an equation determined the scaling effects from geometry changes can be studied. Therefore, initially in the Buckingham Pi analysis the geometry will not change and so the last two pi groups consisting of only geometry parameters will utilized later in the analysis. 
For the purpose of studying the effect of the pi groups on $R_{r}$ with constant specimen geometry, the pi groups are put in the form of Equation 23:

$$
\frac{R_{r} \cdot h \cdot d^{3}}{\sigma_{U T S} \cdot \alpha^{2}}=\varphi\left(\frac{\sigma_{\max }}{\sigma_{U T S}}, L_{R}, \frac{N}{N f}, \frac{f d^{2}}{\alpha}\right)
$$




\section{Chapter 3: Materials and Equipment}

\subsection{Welded Specimens}

In order to study the fatigue behavior and thermal response of welded joints, specimens needed to be designed. Figure 1 shows a schematic of the tubular welded 1018 specimens, and Figure 2 shows a photo of a fully machined, and heat treated specimens prior to the application of black paint, used to improve thermal emissivity.

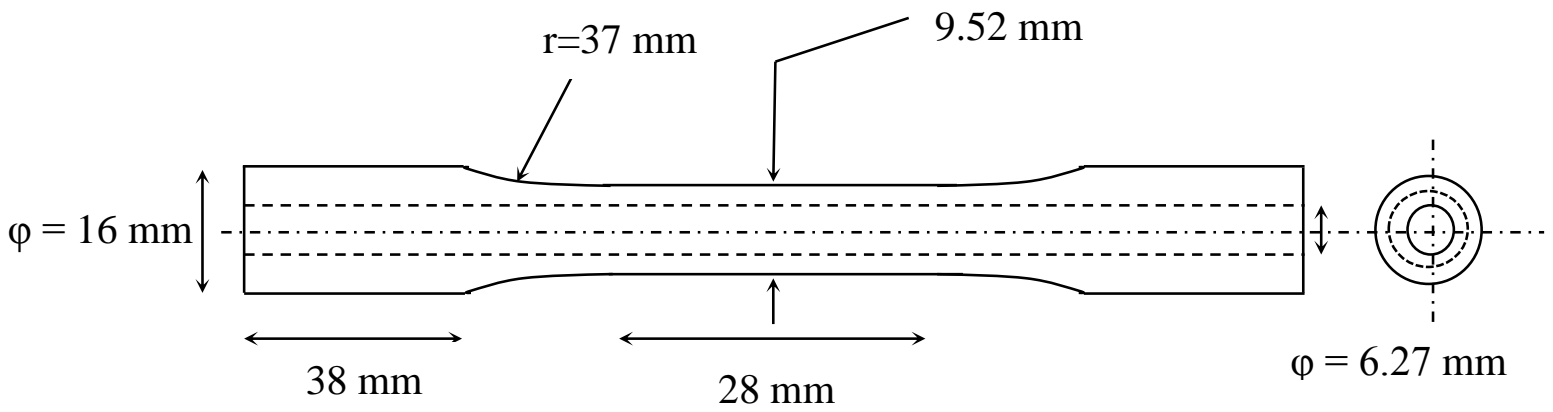

Figure 1: Diagram of Tubular 1018 Carbon Steel Specimen.

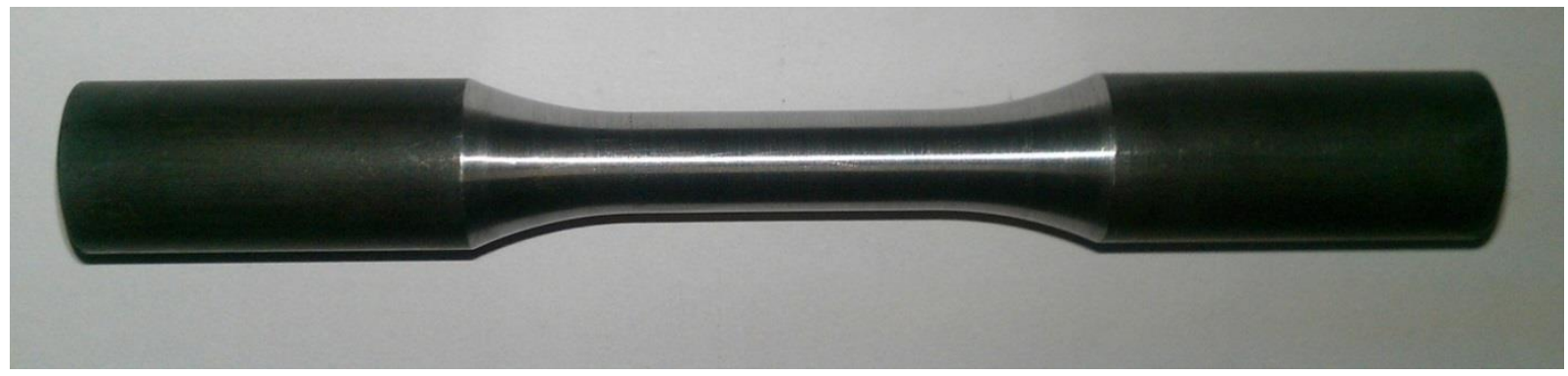

Figure 2: Photo of a Welded Specimen, prior to application of black paint.

Prior to fatigue testing, a static test was performed on a welded specimen to determine important material properties, carried out according to ASTM: E8, which are listed in Table 2. The hardness of the specimen was also measured as it provides a comparison point for any further specimens that are made to ensure similar specimen behavior. 
Table 2: Material Properties for Pristine and Welded 1018 Carbon Steel.

\begin{tabular}{lllll}
\hline & Yield Stress, & Tensile Strength, & Elastic Modulus, & Hardness, \\
& $\sigma_{y}(\mathrm{MPa})$ & $\sigma_{U T S}(\mathrm{MPa})$ & $E(\mathrm{GPa})$ & HRB \\
\hline Pristine & 305 & 575 & 140.8 & 71 \\
Welded & 295 & 429.3 & 193.5 & 60.9 \\
\hline
\end{tabular}

The material used in the manufacture of the specimens was tubular 1018 carbon steel, cut into a dog bone shape according to the instructions from ASTM: E-466-07. For the butt welded joint in the center of the specimen gauge section, a $60^{\circ}$ degree angle was required to allow for space for the weld material. To create an accurate angle between the halves of the specimen to be joined were cut into two using a thread tapping cutter. Following this the specimens were welded back together using Titanium Inert Gas (TIG) welding with ER708-2 filler material, using a variable voltage controlled by the welder to ensure good quality. Once the welding was completed the specimen was machined to remove the weld bead from the outside of the specimen, and bored to remove any from the inside as these have been shown to lead to early failure [58], and then heat treated. The heat treatment procedure was determined using literature from Crupi [58] and recommendations from ASTM. The treatment consisted of heat at a rate of $200^{\circ} \mathrm{C}$ per hour up to $650^{\circ} \mathrm{C}$, holding at this temperature for 4 hours and then cooled at a rate of $200^{\circ} \mathrm{C}$ per hour [58]. Finally the specimen was polished to remove any nicks and scratches on the gauge section and sprayed with a thin layer of black paint to improve emissivity.

Additional welded specimens were provided by Cameron International for further testing and verification of the procedure. The specimens were made from solid API5LX52, containing a weld in the center of the gauge section, however little else was known about the specimens. Based on the information provided by the Cameron representative, the specimens had not undergone and stress relieving procedures, and that prior to the machining operations to make 
the specimens, the welds had been inspected and judged to contain no flaws. The specimen geometry is shown below in Figure 3.

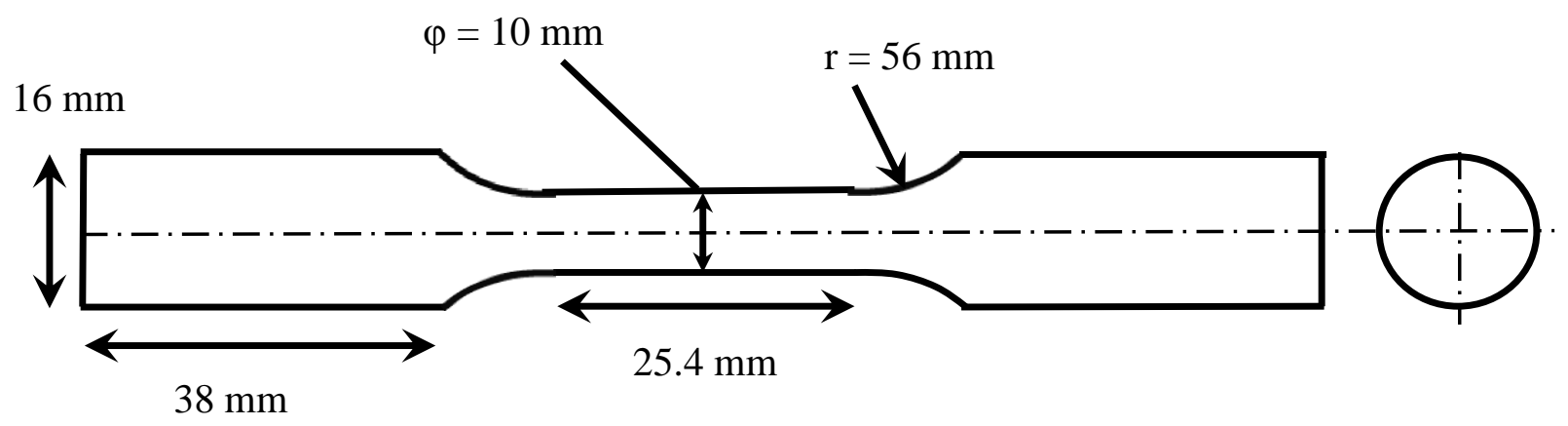

Figure 3: API5LX52 Specimen Geometry.

\subsection{Buckingham Pi Specimens}

For the Buckingham Pi theorem testing to analyze the proportionality of $R_{\theta}$ with respect to other variables, cylindrical specimens were designed following ASTM standard E-466-07, and made from solid Carbon Steel rods. The geometry is shown below in Figure 4 with the appropriate material properties in Table 3.

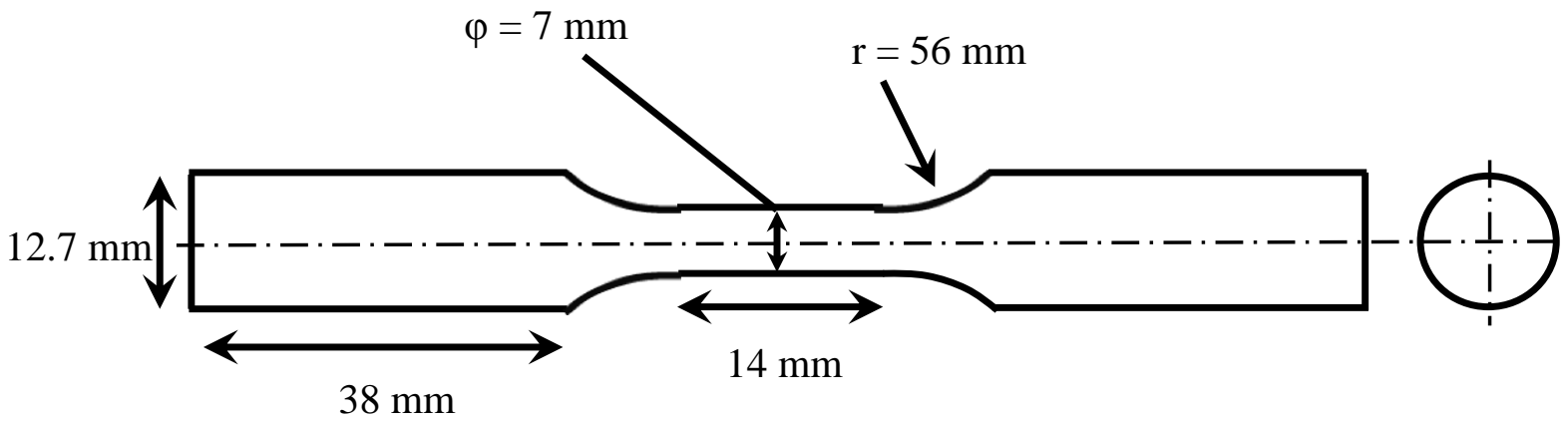

Figure 4: Carbon Steel Specimen Geometry.

Table 3: Carbon Steel Material Properties.

\begin{tabular}{ccc}
\hline Yield Strength, $\sigma_{\mathrm{y}}$ & Ultimate Tensile Strength, $\sigma_{\mathrm{UTS}}$ & Elastic Modulus, E \\
\hline $655 \mathrm{MPa}$ & $704.32 \mathrm{MPa}$ & $205 \mathrm{GPa}$ \\
\hline
\end{tabular}

The specimens were machined from $12.7 \mathrm{~mm}$ (1/2”) Carbon Steel rods. To study the geometry effect on $R_{r}$, further specimens were manufactured with a different gauge length, but a 
constant diameter of $7 \mathrm{~mm}$. The gauge section for these additional specimens varies between 5 $\mathrm{mm}$ and $25 \mathrm{~mm}$, varying the pi groups $L / d$ and $V / d^{3}$ by changing only a single parameter as recommended by Buckingham [59]. Specimens were polished with varying grades of sandpaper after the machining processes were completed and a thin coating of paint was applied to the gauge section to improve the thermal emissivity during loading. Figure 5 shows finished specimens, after spraying with black paint.

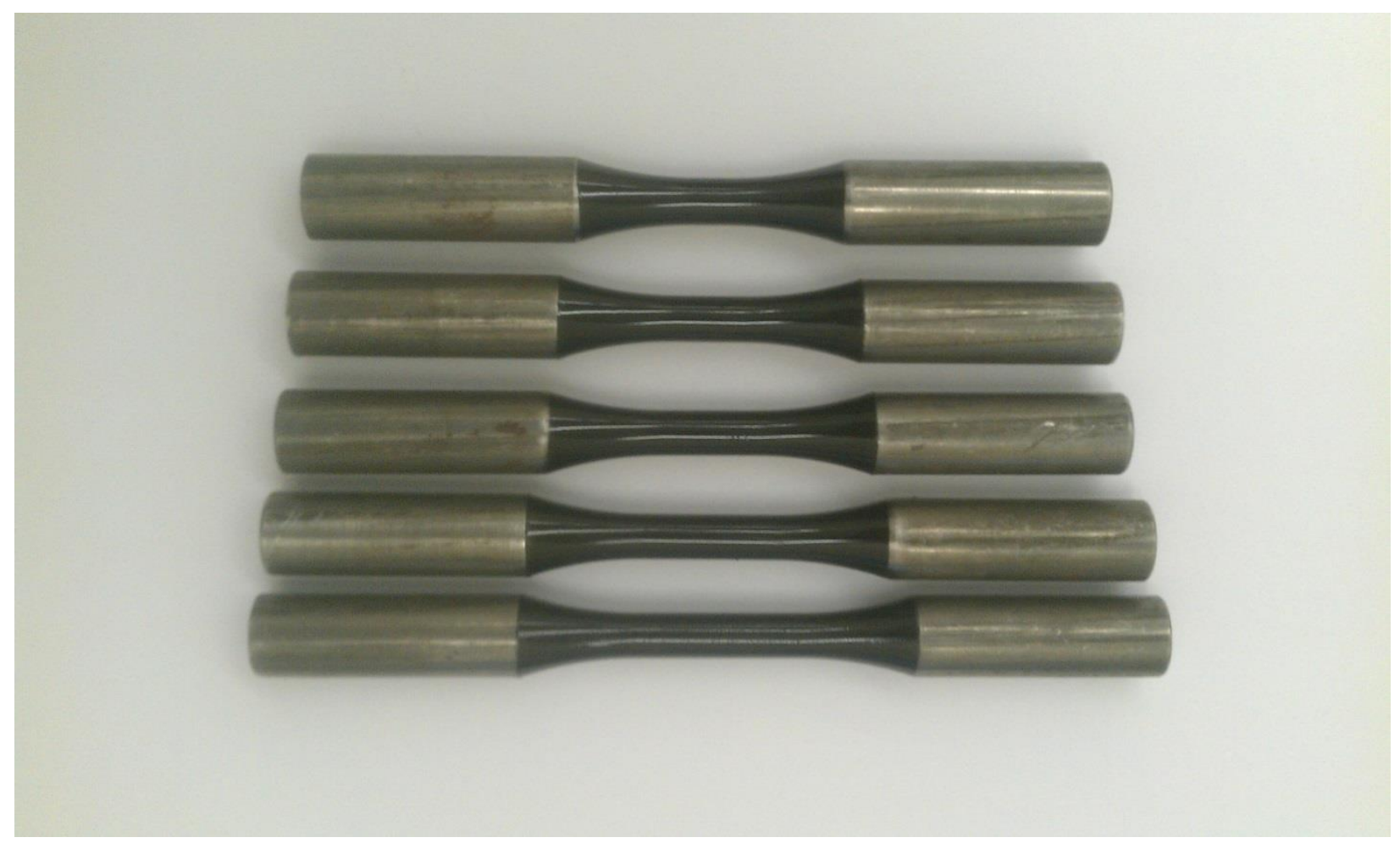

Figure 5: Painted Buckingham Pi Specimens with varying gauge lengths.

\subsection{Testing Equipment}

The tests carried out were uniaxial tension-compression tests, and throughout the series of the tests, various parameters were varied, frequency, maximum applied stress, load ratio (minimum stress/ maximum stress) and fatigue loading frequency. The tests were carried out using a TestResources axial-torsion servo-hydraulic fatigue tester. For the determination of the fatigue parameter $R_{\theta}$ thermal data was captured with an infra-red (IR) camera. The model used 
was a Mikron 7500 , with a temperature range of $0^{\circ} \mathrm{C}$ to $500^{\circ} \mathrm{C}, 320 \times 240$ pixel resolution, sensitivity of $0.08^{\circ} \mathrm{C}$ at $30^{\circ} \mathrm{C}$, and accuracy of $\pm 2 \%$. Figure 6 below shows the experimental set up used to collect the thermographic data.

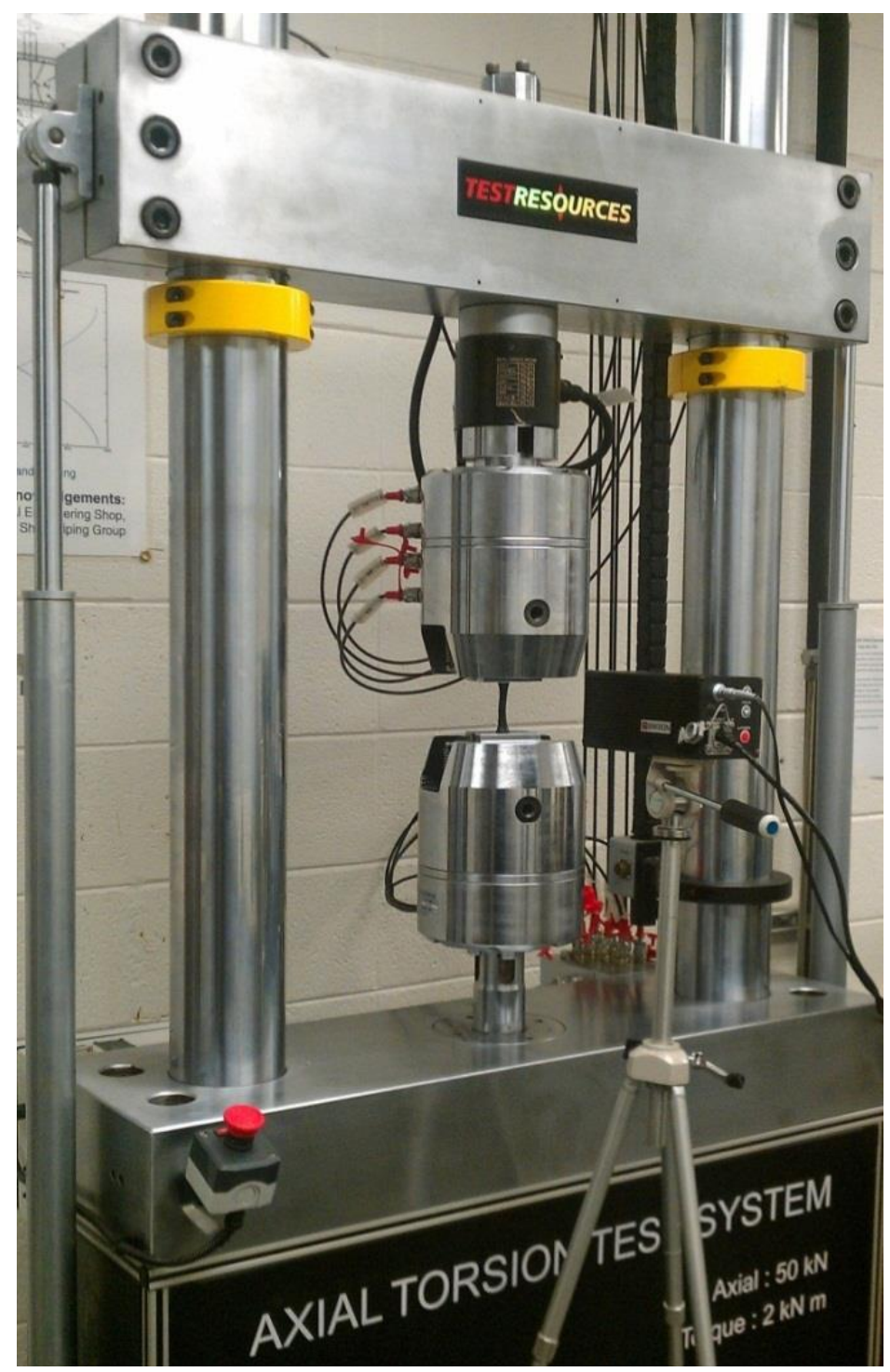

Figure 6: Experimental Set Up for $R_{\theta}$ Testing. 


\section{Chapter 4: Experimental Procedure}

\section{1 $R_{\theta}$ test procedure}

To measure $R_{\theta}$ and generate the performance curve used to make remaining fatigue life predictions, a test procedure has been developed by researchers from the CeRoM lab [43-45]. The testing consists of two different loading conditions, a Normal Fatigue Test (NFT) and a Short Time Excitation (STE). The majority of the tests were carried out under the fatigue loading conditions, and to create different performance curves, these parameters were varied. The STE tests run for approximately 10-15 seconds, normally at a slightly higher load ratio. The STE tests were used to create and measure the temperature rise defined as $R_{\theta}$, and these tests were carried out at various points throughout the fatigue life. Plotting the $R_{\theta}$ value against the fraction of consumed fatigue life allows the creation of the performance curves. Figures 7 and 8 below illustrate the difference between NFT and STE tests, and show how the temperature generated by the specimen varies between the two loading conditions. For a test series STE loading conditions are kept constant with regard to maximum applied stress, frequency and load ratio. The load applied for the excitation is determined from a static test performed with the material. To ensure a measurable temperature rise a negative load ratio is selected, generally less than $R=-0.5$, and the applied stress is below the yield strength, so as to not reduce the fatigue life of the specimen. This point is especially important as the STE are designed in a manner not to significantly affect the fatigue life of a specimen by damaging it during loading, and the total number of STE cycles throughout a test is, thus, a small fraction of the overall life. 


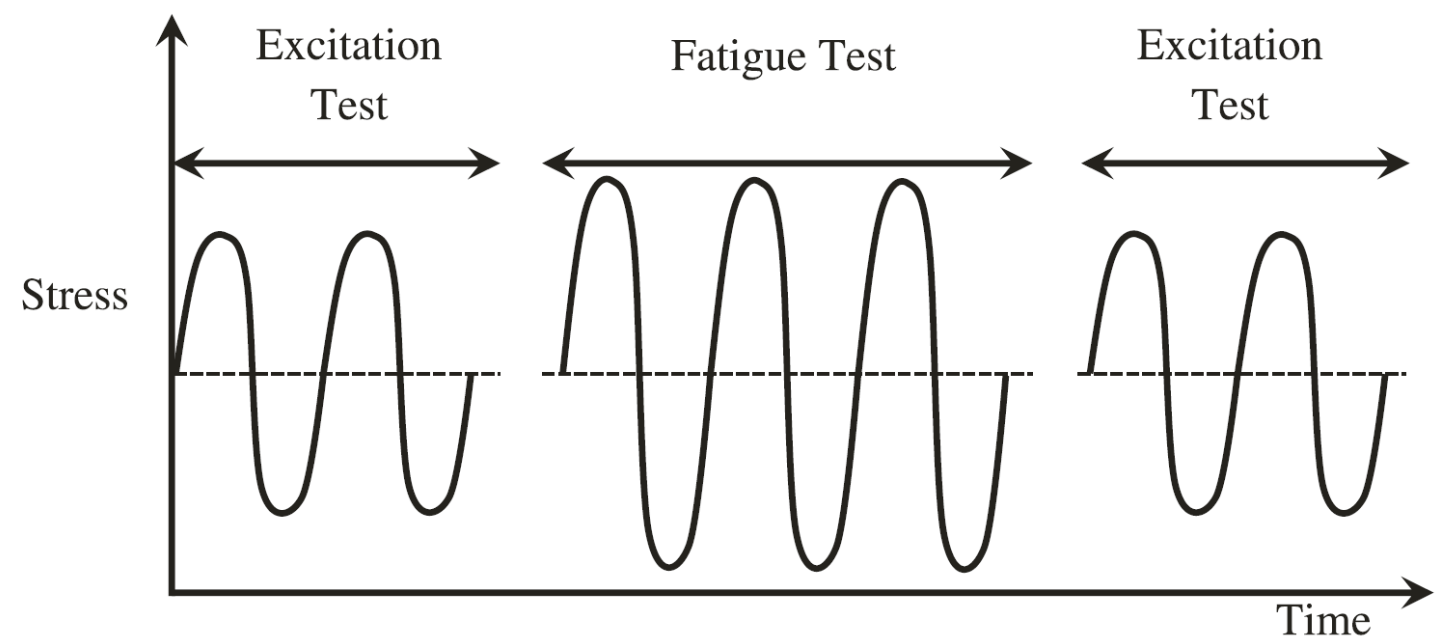

Figure 7: Visualization of the Fatigue and Excitation Testing conditions.

As shown in Figure 8, the STE test cannot be run until the specimen returns to ambient temperature. This cooling process is accelerated using fan-assisted cooling. Once the temperature returns to room temperature, the IR camera is used to capture images of the specimen surface during the STE test.

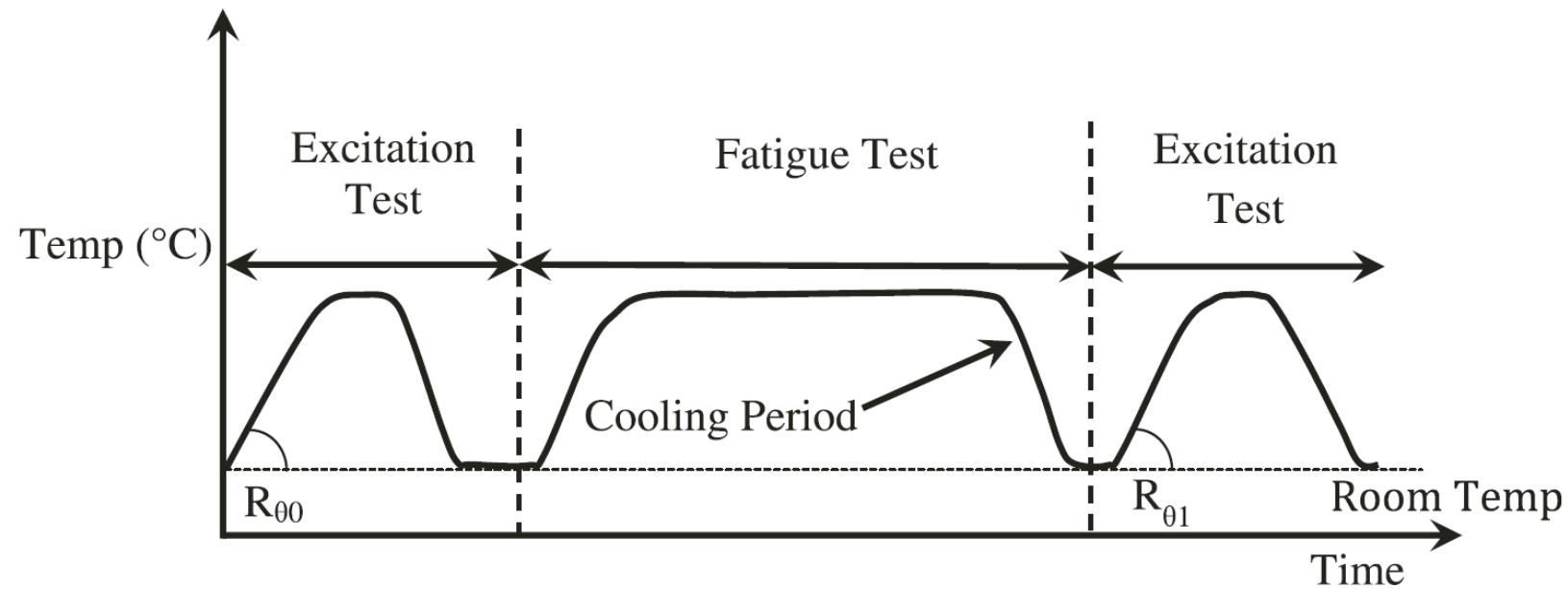

Figure 8: Idealized temperature evolutions during Fatigue and Excitation loading.

To maximize the emissivity of the specimen surface, a thin layer of black paint is sprayed on the gauge section prior to testing. The camera settings are kept constant for all the STE tests, 
using a capture interval of $1 \mathrm{~Hz}$. The emissivity of the paint on the specimen is also input to ensure that accurate temperatures are measured. This value is provided in a data-book supplied with the IR camera with a value of 0.98 [90]. Before the images are captured, the camera is refreshed using an internal blackbody source with the Manual NUC command (Non-uniformity correction). All these functions ensure that accurate comparable data can be obtained from all experiments regardless of material or loading conditions.

Once the data has been collected it must be analyzed to obtain a value for $R_{\theta}$. To collect the data from the camera, a temperature averaging line is drawn on the specimen in the IR camera software as shown in Figure 9, then as the video is replayed through the software, the average temperature is plotted against the frame number from the video, creating a plot like that shown in Figure 10.

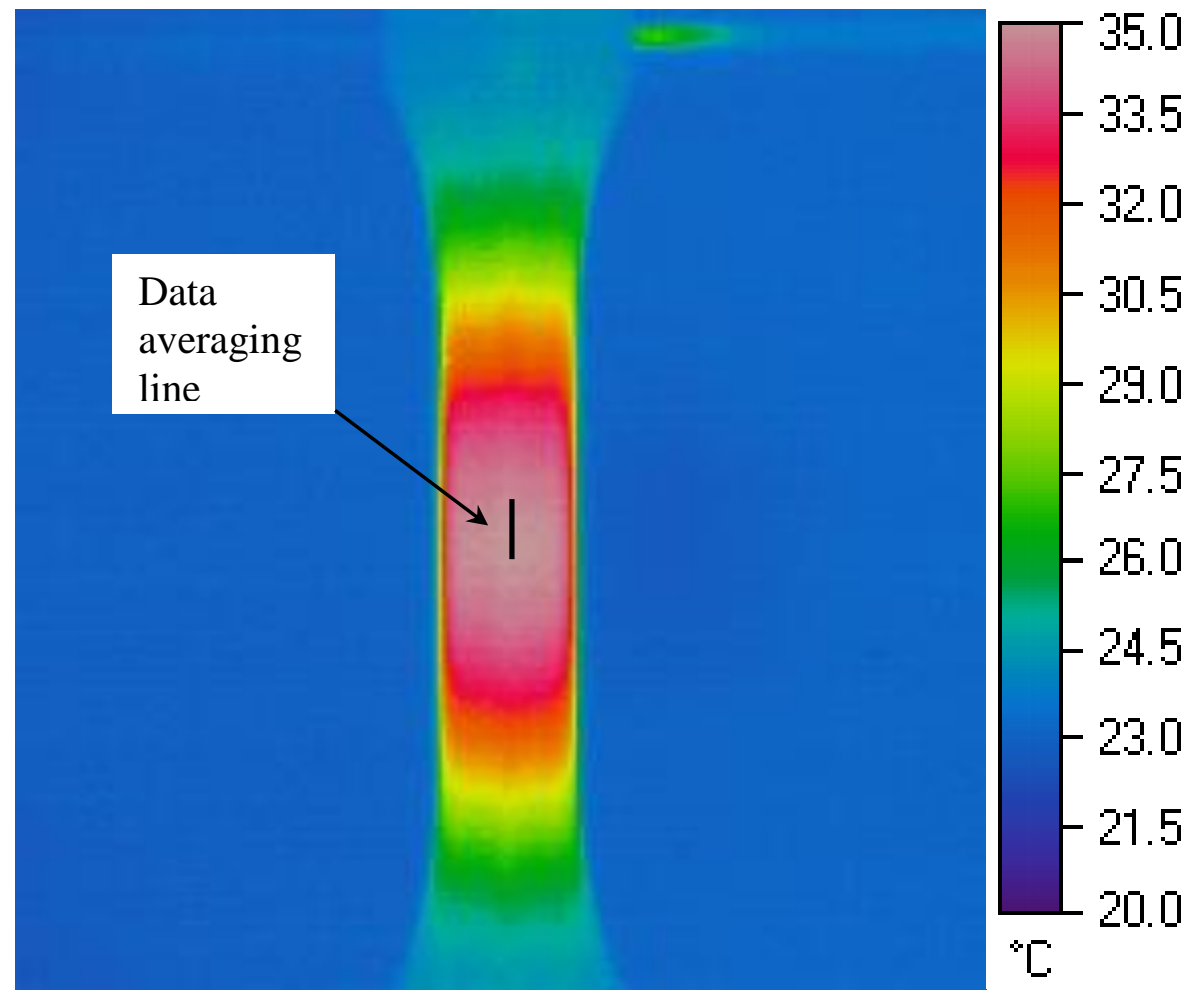

Figure 9: Temperature averaging line on a thermographic Specimen image. 


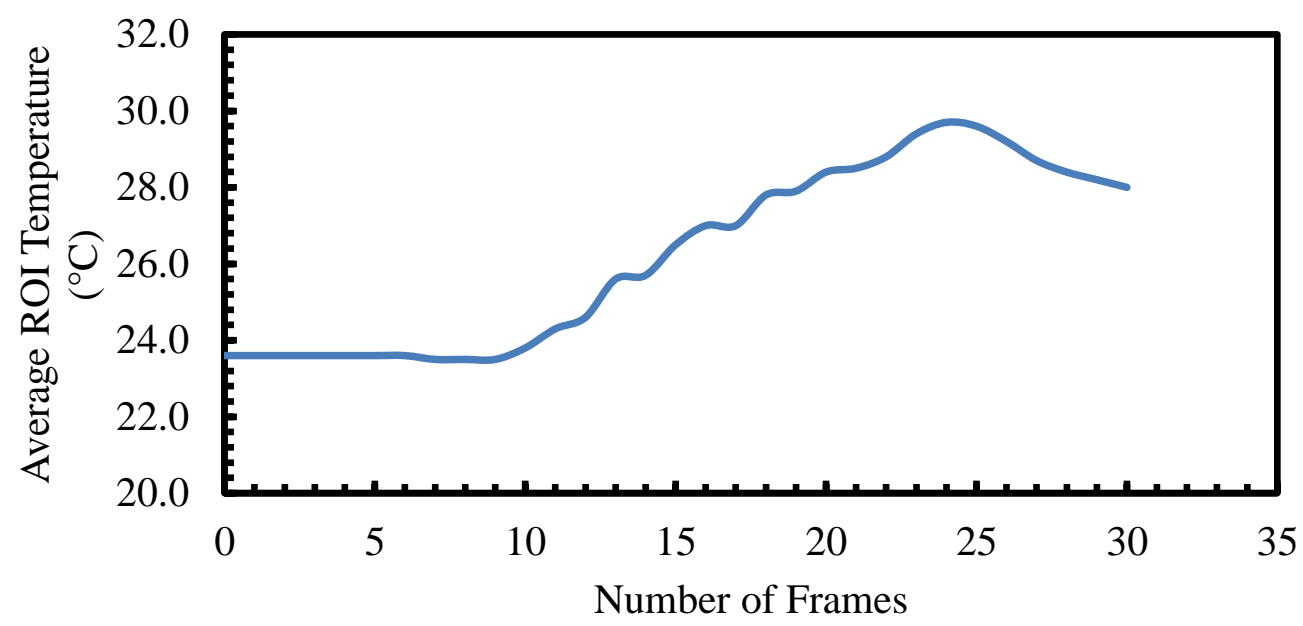

Figure 10: Temperature vs. Frame Number data from the IR Camera software.

From this data, the value of $R_{\theta}$ can be obtained. $R_{\theta}$ is defined as the initial temperature rise from ambient temperature during STE loading. Figure 10 above shows a clear point where the temperature begins to rise when the STE testing begins. This point is taken as the start of the temperature rise, and a further 9 points are selected after this initial point, and a graph plotted using Excel. Applying a linear best fit to the data provides an equation of the form $y=m x+c$ where in this case the gradient value $m$ is equal to $R_{\theta}$. The fitting of a line to the data is shown below in Figure 11.

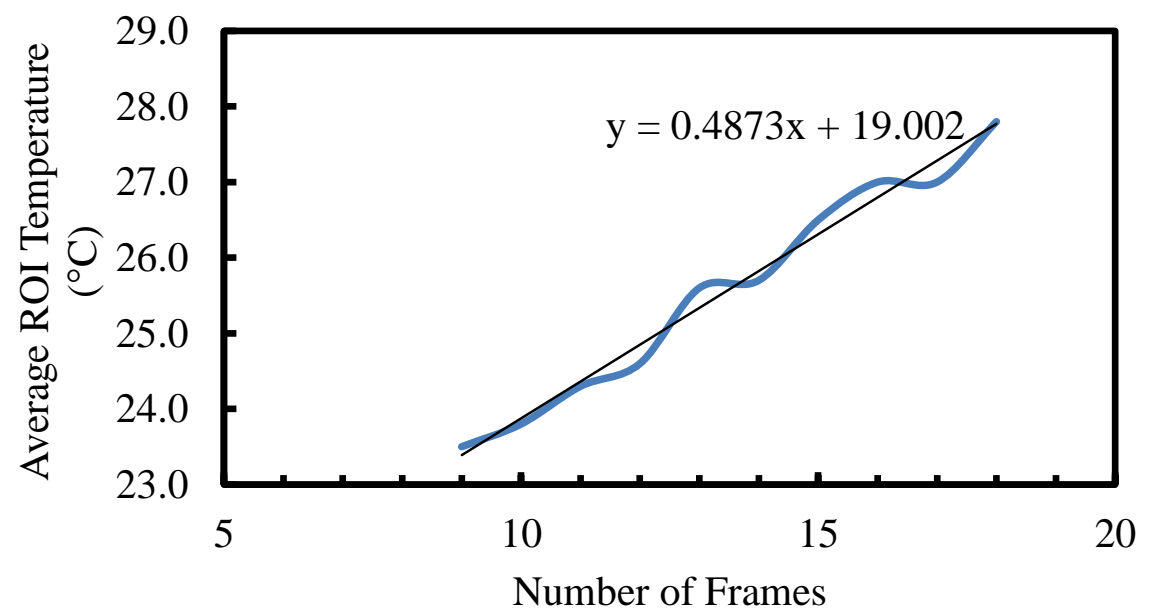

Figure 11: Measurement of $R_{\theta}$ from the thermographic data. 


\subsection{Welded Specimen test procedure}

Welded specimens required a slightly altered approach when running the experiments to measure $R_{\theta}$, due to the behavior of the specimens. Generally welds are considered to be stronger than base metal when the procedure is carried out correctly and appropriate steps are taken to relieve stress and remove excess beading. For the specimens used in the experiments the entire specimen was heat treated following the guidelines detailed in Section 3.1. When undergoing fatigue the welded specimen showed pronounced necking above and below the welded joint. The welded joint maintained the initial specimen geometry, and the base metal reduced in cross section. The stress relieving heat treatment may have been the cause of this larger deformation in the base metal. When viewed with the IR camera used to capture the temperature data, this meant the highest temperature was actually in two different locations, so a simple line marker would not accurately capture the temperature evolution.

To deal with this change in temperature location, a variety of different region of interest (ROI) markers were used to see which would provide a more linear evolution of $R_{\theta}$ which has been seen before in literature [43-45]. Figure 12 below shows $R_{\theta}$ values measured during a welded specimen test, showing the difference between the large rectangle ROI used for the data processing the previously used short line marker. Figure 13 following the graph provides a schematic of each of the ROI shapes used. 


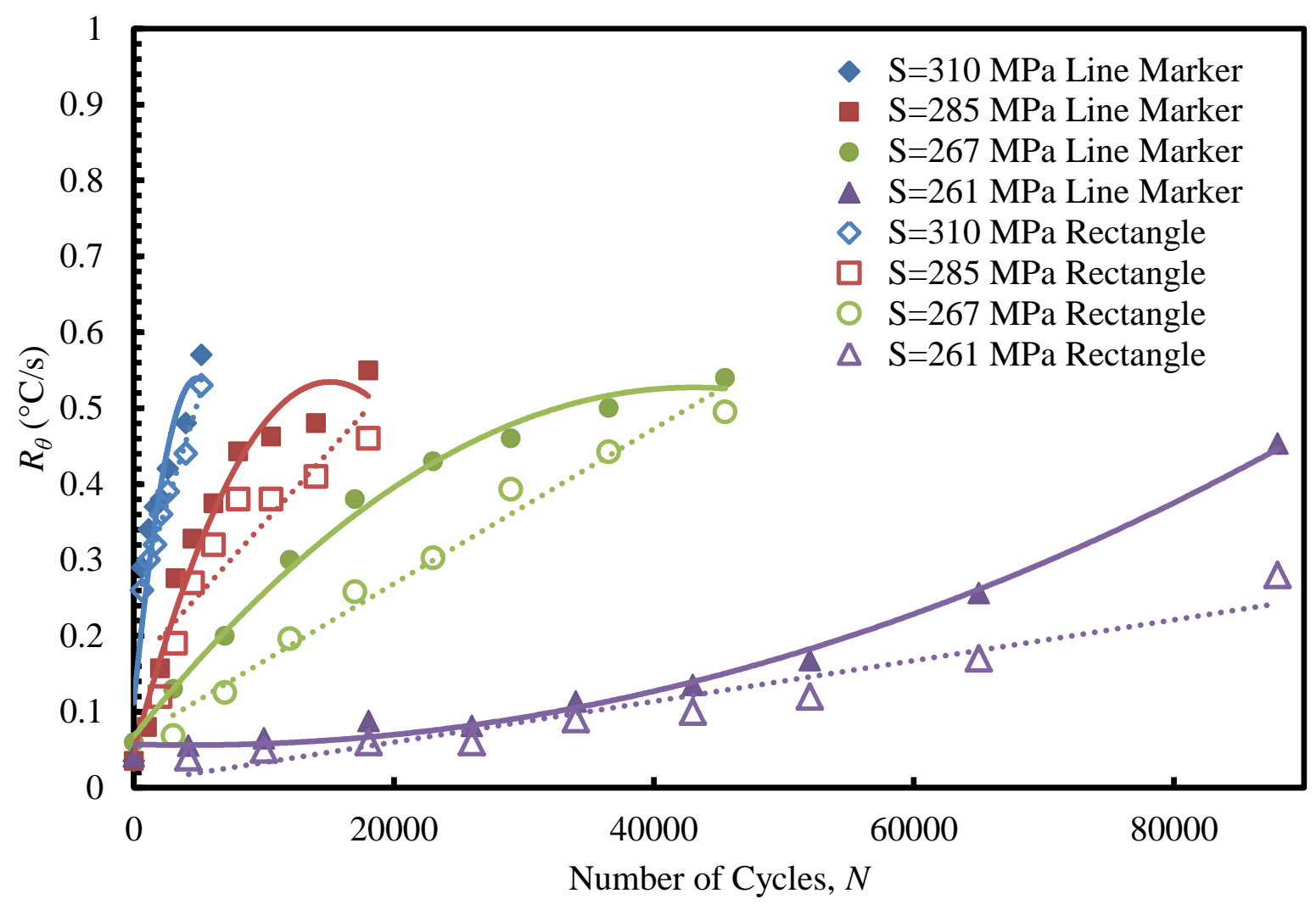

Figure 12: $R_{\theta}$ evolution variation with ROI Marker shape.

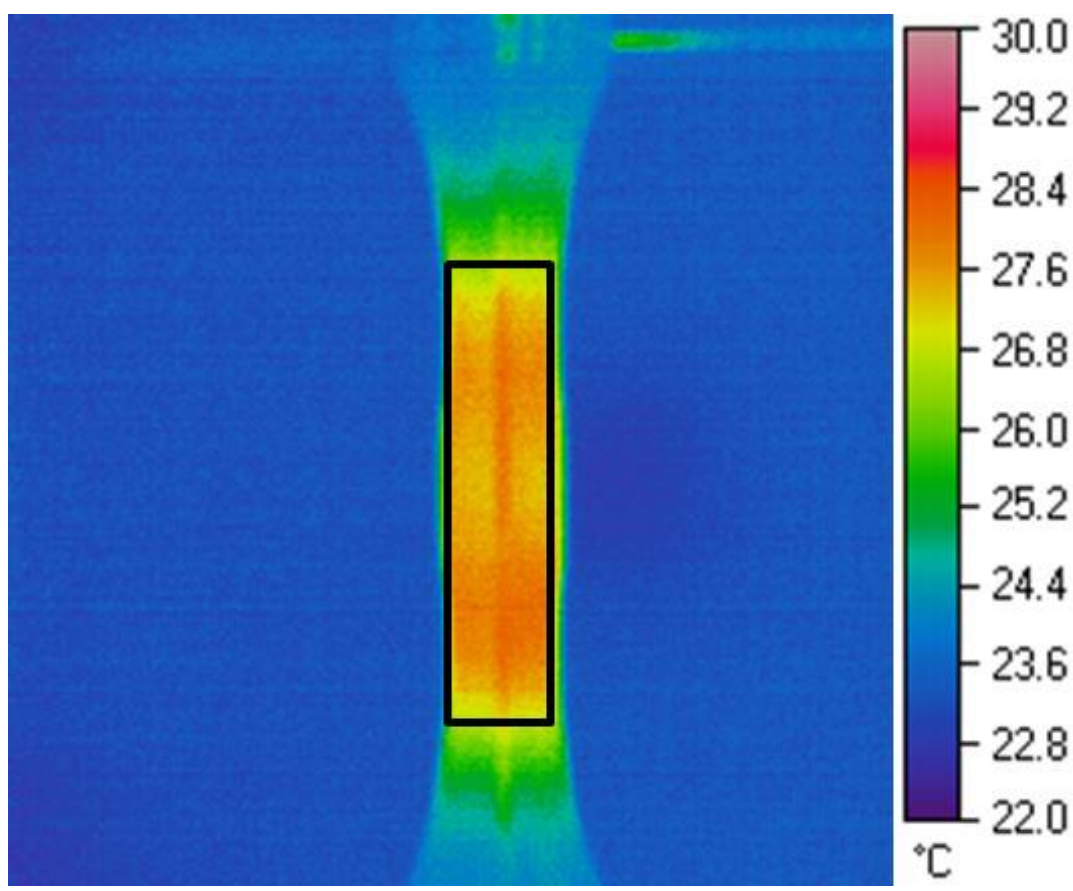

Figure 13: Overlaid schematic of ROI Shapes on a Specimen. 
Figure 13 above shows the variation of $\mathrm{R}$ throughout a specimens fatigue with different markers. It can be clearly seen that a larger rectangle covering the majority of the specimen gauge section produces the most linear evolution. It should also be noted that the hotspots tended to move on the specimen throughout loading. Initially the hotspots appeared in the base metal, above and below the weld, but after a short time undergoing fatigue loading, the hotspots moved closer together towards the center, similar to the phenomena shown by Ummenhofer [91]. Figure 14 shows the hotspot motion during fatigue loading. This appears to be due to the base metal deforming more under load than the stiffer weld metal, thus more hysteresis energy is released. As the energy is released it is conducted from both hot spots towards the center of the specimen making the hotspots move closer.

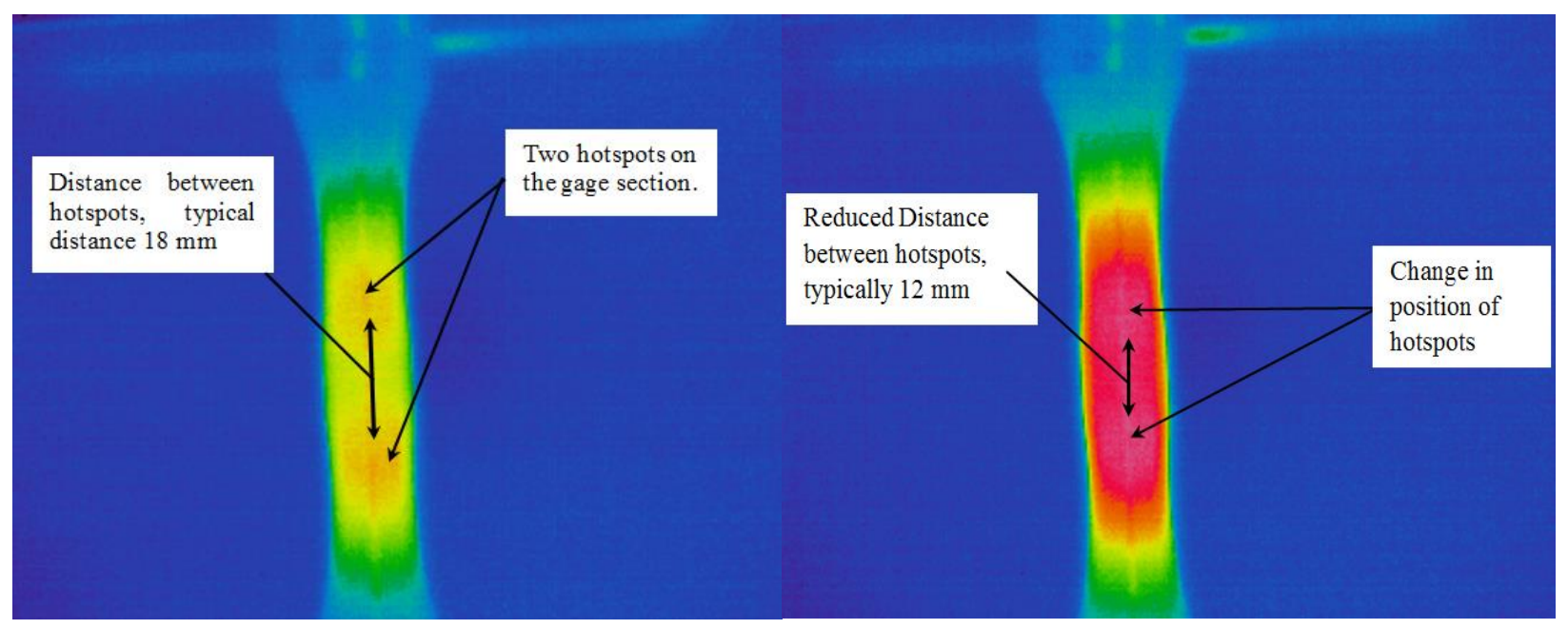

Figure 14: Example of hotspot motion during fatigue loading.

Table 4 below lists the excitation loading conditions for both sets of welded specimens, and the pristine Carbon Steel Buckingham Pi specimens.

Table 4: Excitation Loading Conditions.

\begin{tabular}{cccc}
\hline Material & $\sigma_{\max }(\mathrm{MPa})$ & $L_{R}$ & Frequency, $f(\mathrm{~Hz})$ \\
\hline Welded 1018 & 273 & -0.545 & 10 \\
Welded API5LX52 & 480 & -0.6 & 10 \\
Pristine Carbon Steel & 515 & -0.6 & 10 \\
\hline
\end{tabular}




\subsection{Static test procedure}

Static uniaxial tension tests were briefly mentioned earlier in section 4.1 , and will be briefly covered here for completeness. Static tests are carried out on all materials experimented on, to ensure accurate values are known for important material properties, such as yield strength, elastic modulus and ultimate tensile strength. To get the most accurate values possible the specimens are designed and tested according to ASTM standard E8, with gauge sections of 25.4 $\mathrm{mm}$. The length of the gauge section in particularly important in these tests, as a high precision extensometer, Epsilon Model 3542-0100-050-ST, is utilized to accurately measure the strain and plot a stress strain curve. A strain rate of $0.5 \mathrm{~mm} / \mathrm{sec}$ is used for all the materials tests reported. From the results obtained by the fatigue testing machine, a stress vs. strain plot is obtained and from this the yield strength is measured using a $0.2 \%$ offset, as well as the elastic modulus and ultimate tensile strength. 


\section{Chapter 5: Results and Discussion}

\subsection{Welded Specimen Results}

\subsubsection{Welded Specimen $R_{\theta}$ evolutions}

Figure 15 shows the $R_{\theta}$ evolutions obtained from the welded 1018 Carbon Steel specimens, at a range of different fatigue stress levels.

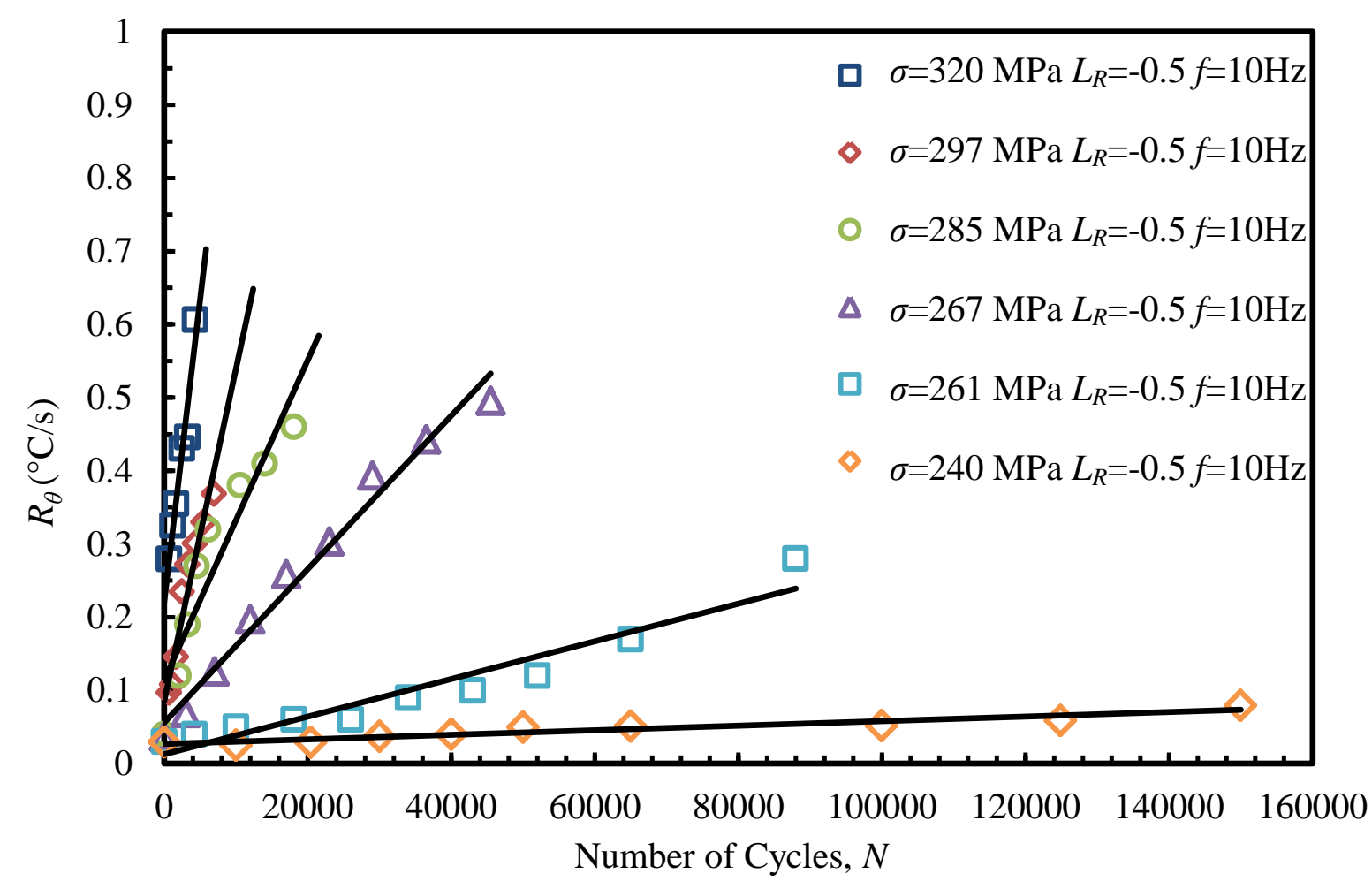

Figure 15: $R_{\theta}$ evolutions for the 1018 Carbon Steel Welded Specimens.

The majority of the test specimens failed in the base metal either above or below the weld in gauge section, as shown in Figure 16. The welded section of the specimen appears as a slight bulge on the gauge section, compared to the narrower necked sections of base metal above and below the welded joint. This could be due to the heat treatment of the specimens causing increased ductility in the base metal, while the stress relief makes the welded joint the strongest section of the specimen. The base metal clearly underwent more deformation during the fatigue 
loading and the temperature hotspots were also located on the base, supporting the theory of increased ductility.

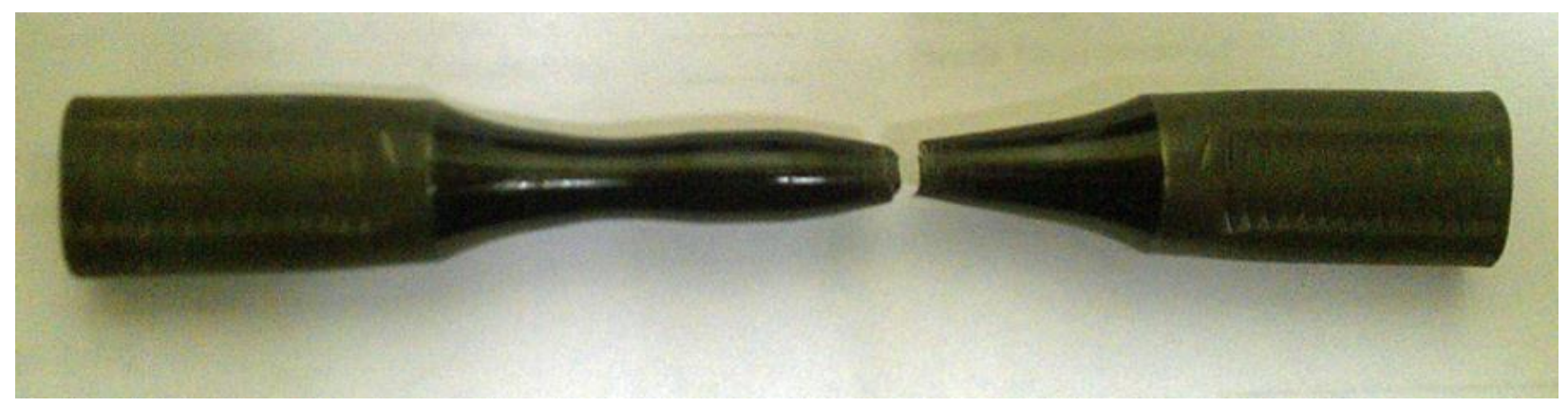

Figure 16: Failed Welded 1018 Specimen.

The test results in Figure 15 only shows specimens that failed in the base metal, suggesting that these welds were high quality and contained no inherent flaws. Due to the size of the specimen, it was not possible to carry out inspections of the welds prior to testing, so flaws in specimens were only detected through test results and unusual specimen failure. Overall the behavior of the specimens was consistent, despite the large of potential variables affecting welds such as microstructure of weld and overall weld quality. The verification tests carried out on the specimens showed close agreement with the experimental results, with no prediction error of over $10 \%$, as shown in Table 5.

Table 5: Verification Test Results for Welded 1018 Specimens.

\begin{tabular}{lllllll}
\hline $\begin{array}{l}\sigma \\
(\mathrm{MPa})\end{array}$ & $\begin{array}{l}R_{\theta} \\
\left({ }^{\circ} \mathrm{C} / \mathrm{s}\right)\end{array}$ & $N$ & $N_{f}$ & $\begin{array}{l}\text { Predicted } \\
\text { Consumed Life, } \\
\text { PCL }(\%)\end{array}$ & $\begin{array}{l}\text { Experimental } \\
\text { Consumed Life, ECL } \\
(\%)\end{array}$ & $\begin{array}{l}\text { Absolute } \\
\text { Error }(\%)\end{array}$ \\
\hline 310 & 0.47 & 3947 & 5101 & 68.4 & 77.37 & 8.97 \\
267 & 0.4594 & 33005 & 49218 & 74.2 & 74 & 0.2 \\
310 & 0.4667 & 3512 & 4741 & 68.0 & 74.07 & 6.07 \\
285 & 0.4194 & 10022 & 15035 & 62.0 & 66.65 & 4.65 \\
\hline
\end{tabular}

The location of the failure, whether above or below the welded joint was recorded after each test, and overall the distribution of fracture locations was fairly even, a few more failing 
below the weld. This indicates the failure location is not due to a stress concentration or loading, but most likely a statistical variation. Previous experiments on welded specimens carried out by Ummerhofer et al. [91] and Crupi et al. [58] show failure close to the weld toe. However, these specimens did not have the weld bead removed or stress relief carried out, suggesting that failure outside the welded region is not uncommon.

Figure 17 shows a comparative S-N for pristine 1018 carbon steel and the specimens containing a welded joint that had been stress relieved.

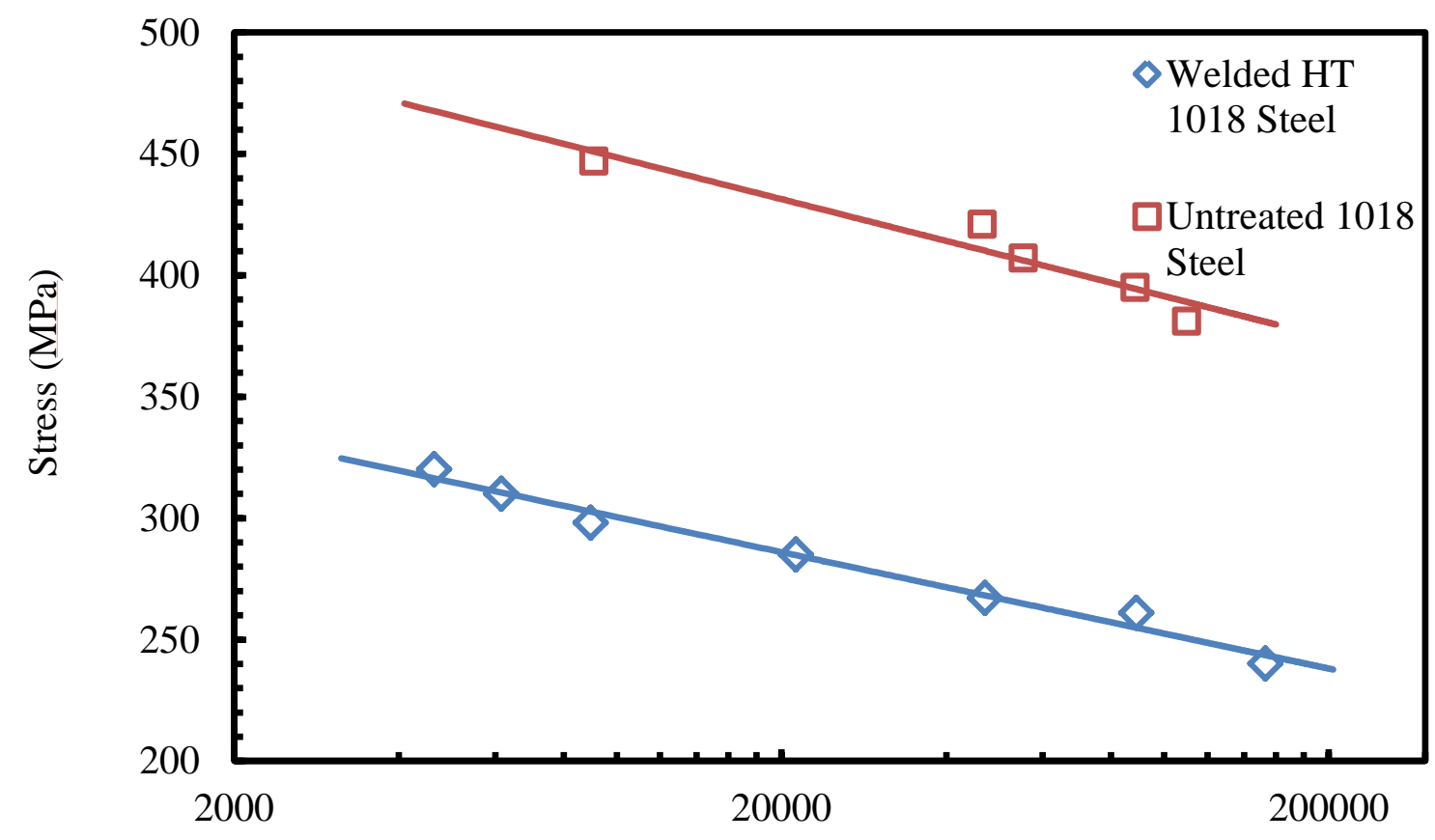

Cycles to Failure, $N f$

Figure 17: S-N Curve for both Welded and Pristine 1018 Specimens.

Both sets of results in the plot show a good linear correlation, the crucial difference between the results is the reduction in the stress level the welded specimen can withstand. A pristine specimen showed a fatigue life of 9091 cycles with a maximum stress of $445 \mathrm{MPa}$, however a similar fatigue life for a welded specimen was obtained at a lower value of $298 \mathrm{MPa}$. 
Despite the applied stress relief, the overall strength of the specimen is significantly reduced, the heat treated base metal was the weakest part of the specimen.

\subsubsection{Welded Specimen Verification Results}

Figures 18 and 19 show performance curves from $R_{\theta}$ tests. $R_{\theta}$ is plotted against the fraction of consumed specimen life. Figure 18 included the initial $R_{\theta}$ value $R_{\theta 0}$, and Figure 19 excludes the initial value.

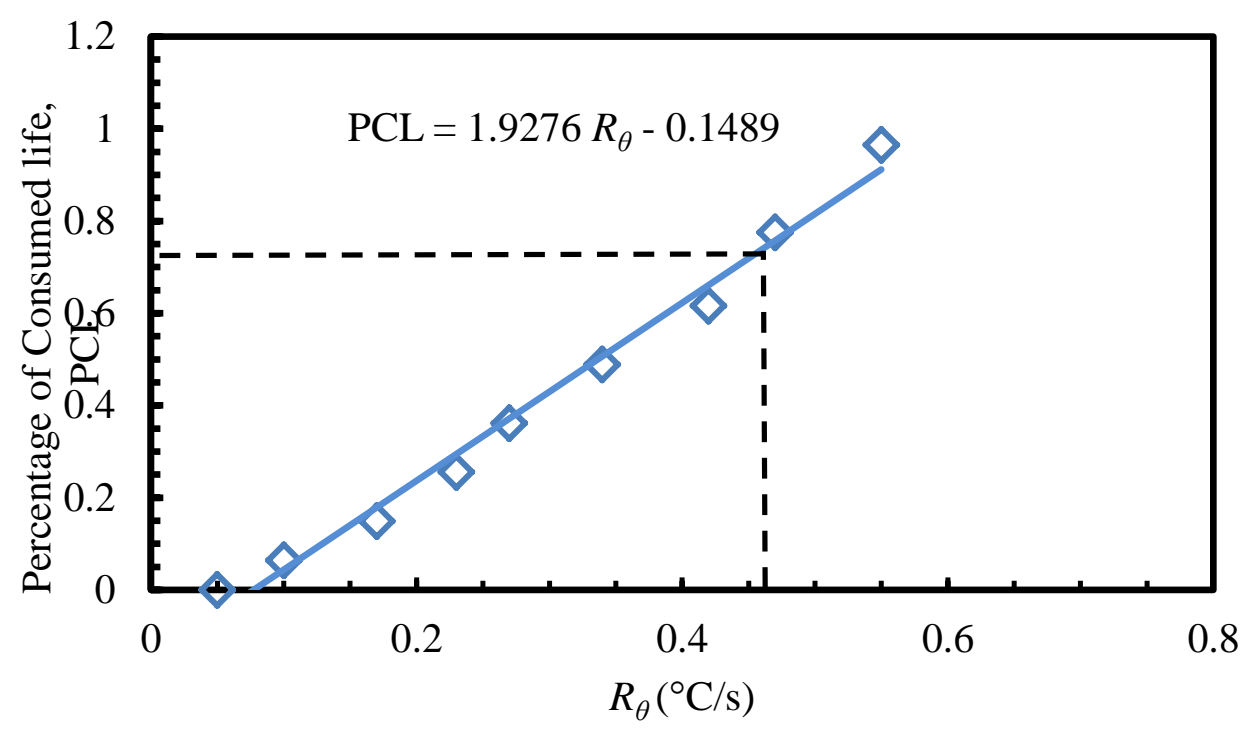

Figure 18: Performance curve for a Welded Specimen, including the $R_{\theta 0}$ value.

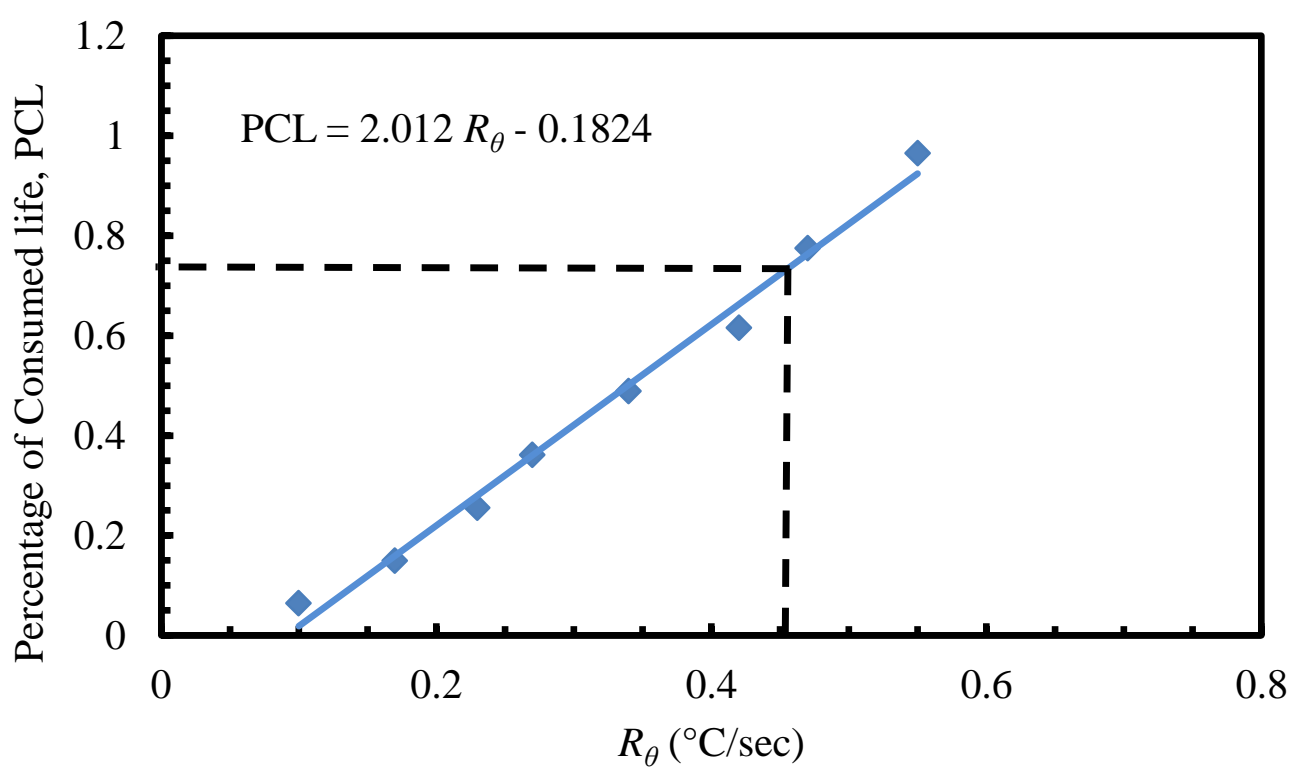

Figure 19: Performance curve for a Welded Specimen with no $R_{\theta 0}$ value. 
It can be seen that the equation for the performance curve varies depending on whether the initial value is included in the curve fit. The verification tests suggest that removing the initial point increases the accuracy of the fatigue life predictions. As the welded specimen cannot be considered truly pristine, the initial point has significant variation, thus removing the initial point is justified.

Figure 20 shows a specimen which failed in the welded section instead of the base metal. Two specimens failed in the manner, both of which were undergoing cyclic loading at $250 \mathrm{MPa}$, which should have provided a high-cycle fatigue regime over 100000 cycles. However during the testing the specimens behaved differently to previous tests. The temperature rise during the fatigue loading was very small, and little deformation was visible in the specimen gauge section, with no characteristic bulge at the welded section. In the two tests where the failure occurred in the weld, the temperature appeared stable until a significant number of fatigue cycles had been completed, 45000 and 70000 the specimen showed sudden significant temperature increases, followed by failure in the weld, approximately in the center of the gauge section. These specimens both showed relatively flat fracture surfaces, generally associated with more brittle materials compared to the more ductile cup and cone fracture surfaces seen in previous tests. Both of the specimens with failures in the welded joint had similar flaws to that shown in Figure 20 , however the size of the flaw varied, with the specimen containing the larger flaw failing earlier. 


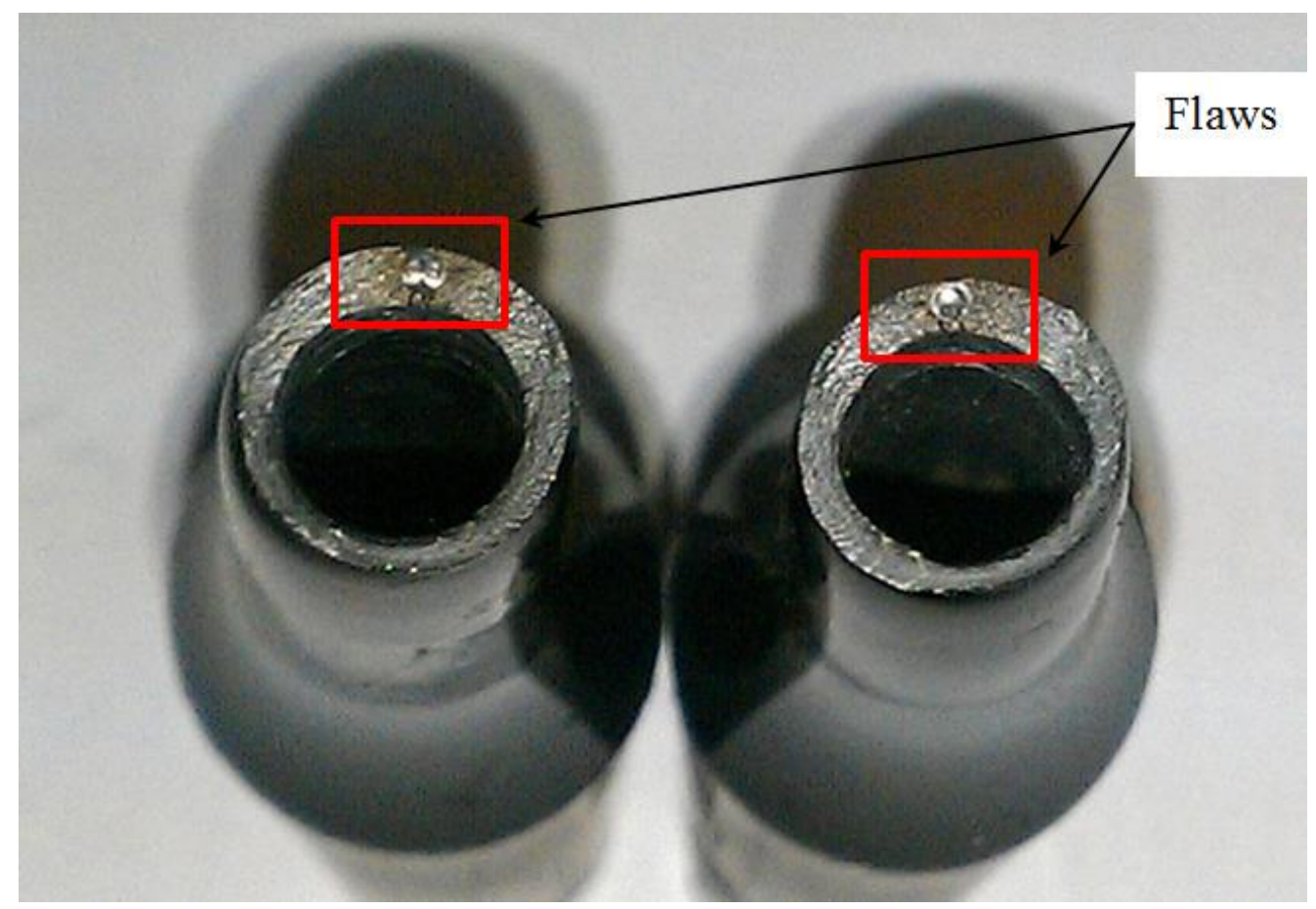

Figure 20: Welded Specimen fracture surface showing apparent flaws.

To accurately confirm whether the failure of these specimens was solely due to the "flawbased" failure as opposed to "plastic deformation" based failure, a further test was carried out at a lower fatigue load of $240 \mathrm{MPa}$. The results obtained from this experiment are shown in Figure 15, with the test lasting for 153000 cycles. The fracture location of this specimen was in the base metal, similar to the majority of the previous tests, with slight bulge created by the welded joint, showing that similar failures occur in both low- and high-cycle fatigue regimes if a flaw is not present.

The failures caused by the flaws in the welded joint, do not provide a true assessment of the strength of the weld, which is evident by the significant reduction in fatigue life in these specimens. The data that was obtained from the specimens which failed early shows good agreement with the other linear progression shown in Figure 15, until the point in the fatigue loading where the flaw became the dominating factor in the failure. Initially during these tests 
the base metal was seen to be deforming more than the weld, however as the flaw continued to grow, it became the main source of heat generation and eventually the failure location.

Following the testing of the 1018 carbon steel welded specimens, further specimens were provided for analysis. These specimens were machined from API5LX52 were tested using the same procedure, and Figure 21 shows the $R_{\theta}$ evolutions of these specimens.

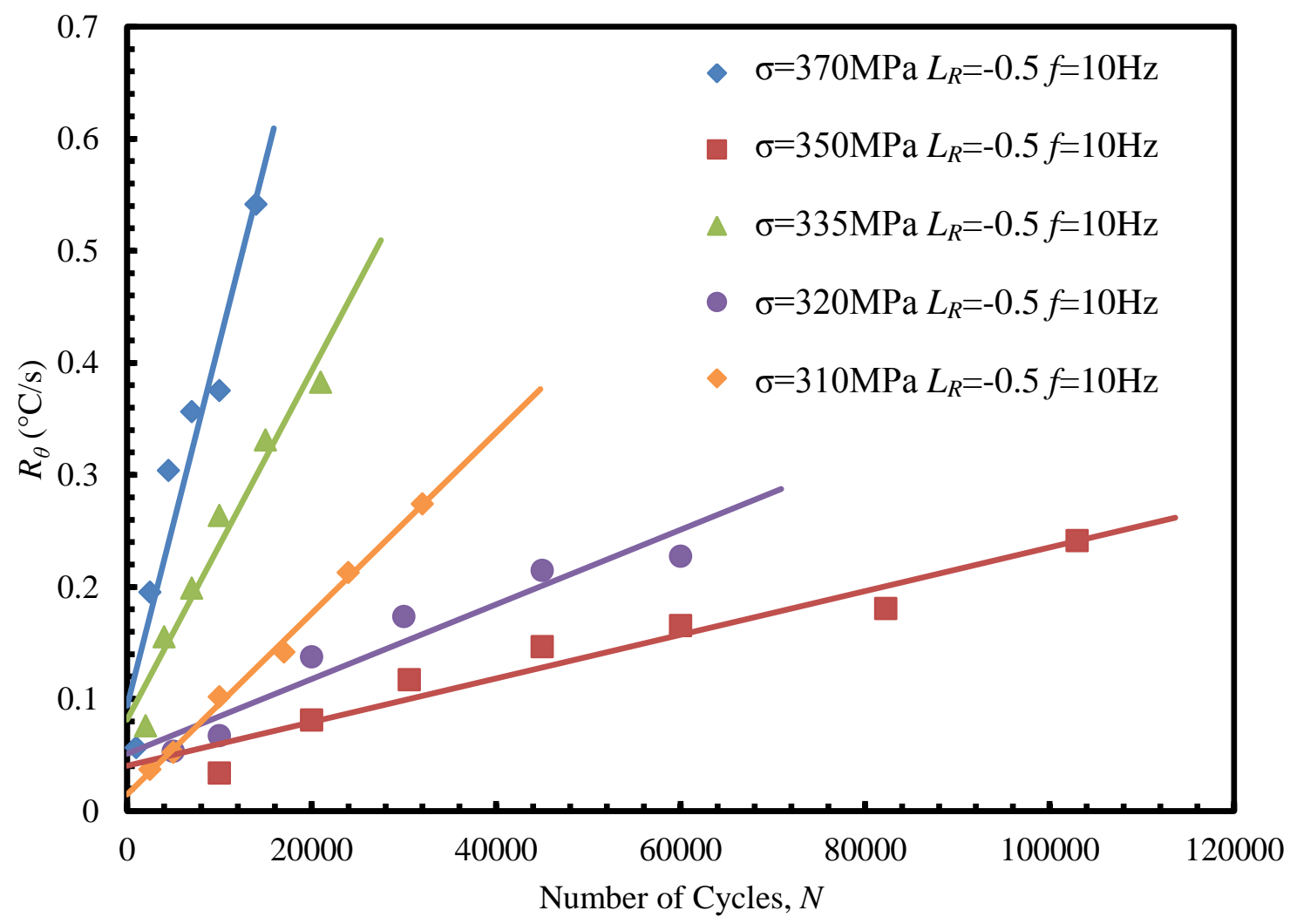

Figure 21: $R_{\theta}$ evolutions for the API5LX52 welded specimens.

The second set of specimens made from API5LX52 also showed good results for $R_{\theta}$ evolutions, with verification tests producing good agreement between the predictions and the experimental results. Using a similar data marker to the previous tests on the tubular welded specimens, the linear evolutions fit the expect trend well. There were several differences between the sets of welded specimens, with the API5LX52 specimens being robotically welded, with an unknown filler material and having no stress relief applied after the procedure. As the specimens 
were machined from the wall of a subsea jumper, it was also possible to know the exact location of the weld in the gauge section, though the specimens were stated to have the weld in the center of the gauge section, and have been cut the same distance from the pipe wall, thus ensuring the maximum consistency in the amount of weld material in the gauge section.

From the results shown in Figure 21, there were no occurrences of flaw based failure as seen previously in the 1018 Carbon Steel specimens. Due to the specimens being manufactured directly from a subsea jumper, the weld was able to be inspected to ensure there were no flaws, providing assurances regarding quality of the weld and ensuring good results. It should also be noted that the specimens had similar fracture locations to the previous specimens, in the base metal above or below the weld, again with the variation in location appearing to have no statistical significance. Overall the ability to obtain accurate predictions as shown in Table 6, as well in specially designed welded specimens shows the strength of the fatigue life prediction technique. Should the technique be applied in a real life setting, there is the likelihood that not all the details of the component will be readily available, thus the testing of specimens prepared externally however still obtaining promising results, emphasizes the techniques utility.

Table 6: Verification Test Results for Welded API5LX52 Specimens.

\begin{tabular}{lllllll}
\hline $\begin{array}{l}\sigma \\
(\mathrm{MPa})\end{array}$ & $R_{\theta}\left({ }^{\circ} \mathrm{C} / \mathrm{s}\right)$ & $N$ & $N_{f}$ & $\begin{array}{l}\text { Predicted } \\
\text { Consumed Life, } \\
\text { PCL }(\%)\end{array}$ & $\begin{array}{l}\text { Experimental } \\
\text { Consumed Life, ECL } \\
(\%)\end{array}$ & $\begin{array}{l}\text { Absolute } \\
\text { Error }(\%)\end{array}$ \\
\hline 370 & 0.5703 & 10299 & 12526 & 92.4 & 82.2 & 10.18 \\
335 & 0.2636 & 29998 & 45726 & 68.75 & 65.6 & 3.15 \\
350 & 0.3067 & 16003 & 29289 & 52.6 & 54.6 & 2.00 \\
\hline
\end{tabular}




\subsection{Buckingham Pi Results}

\subsubsection{Buckingham Pi $R_{\theta}$ evolutions}

Table 7 contains the results of the fatigue tests carried out, at a range of stress levels, fatigue loading frequencies, load ratios and geometries.

Table 7: Test Results for Buckingham Pi.

\begin{tabular}{|c|c|c|c|c|c|}
\hline $\begin{array}{l}\text { Test } \\
\text { Number }\end{array}$ & $\begin{array}{l}\text { Max. Applied } \\
\text { Stress (MPa) }\end{array}$ & $\begin{array}{l}\text { Load } \\
\text { Ratio }\end{array}$ & $\begin{array}{c}\text { Fatigue } \\
\text { Frequency } \\
(\mathrm{Hz})\end{array}$ & $\begin{array}{l}\text { Gauge Length } \\
(\mathrm{mm})\end{array}$ & $\begin{array}{c}\text { Cycles to } \\
\text { failure } \\
\left(N_{f}\right)\end{array}$ \\
\hline \multicolumn{6}{|c|}{ Varying Maximum Applied Stress } \\
\hline 1 & 515 & -0.5 & 10 & 14 & 12499 \\
\hline 2 & 500 & -0.5 & 10 & 14 & 25267 \\
\hline 3 & 485 & -0.5 & 10 & 14 & 32376 \\
\hline 4 & 465 & -0.5 & 10 & 14 & 68611 \\
\hline 5 & 450 & -0.5 & 10 & 14 & 105248 \\
\hline \multicolumn{6}{|c|}{ Varying Load Ratio } \\
\hline 6 & 500 & -0.25 & 10 & 14 & 84301 \\
\hline 7 & 500 & -0.4 & 10 & 14 & 42067 \\
\hline 8 & 500 & -0.6 & 10 & 14 & 8101 \\
\hline 9 & 500 & -0.75 & 10 & 14 & 3259 \\
\hline \multicolumn{6}{|c|}{ Varying Fatigue Loading Frequency } \\
\hline 10 & 500 & -0.5 & 5 & 14 & 27543 \\
\hline 11 & 500 & -0.5 & 7.5 & 14 & 34505 \\
\hline 12 & 500 & -0.5 & 12.5 & 14 & 27442 \\
\hline 13 & 500 & -0.5 & 15 & 14 & 35834 \\
\hline \multicolumn{6}{|c|}{ Varying Gauge Length } \\
\hline 14 & 500 & -0.5 & 10 & 5 & 27876 \\
\hline 15 & 500 & -0.5 & 10 & 10 & 30497 \\
\hline 16 & 500 & -0.5 & 10 & 20 & 18725 \\
\hline 17 & 500 & -0.5 & 10 & 25 & 19419 \\
\hline
\end{tabular}

From the presented results, it is possible to study how $R_{r}$ varies with the change of an individual parameter from a Pi group. The Figures 22-27 below show $R_{r}$ plotted against the changing variable, and the relation that the results show. 


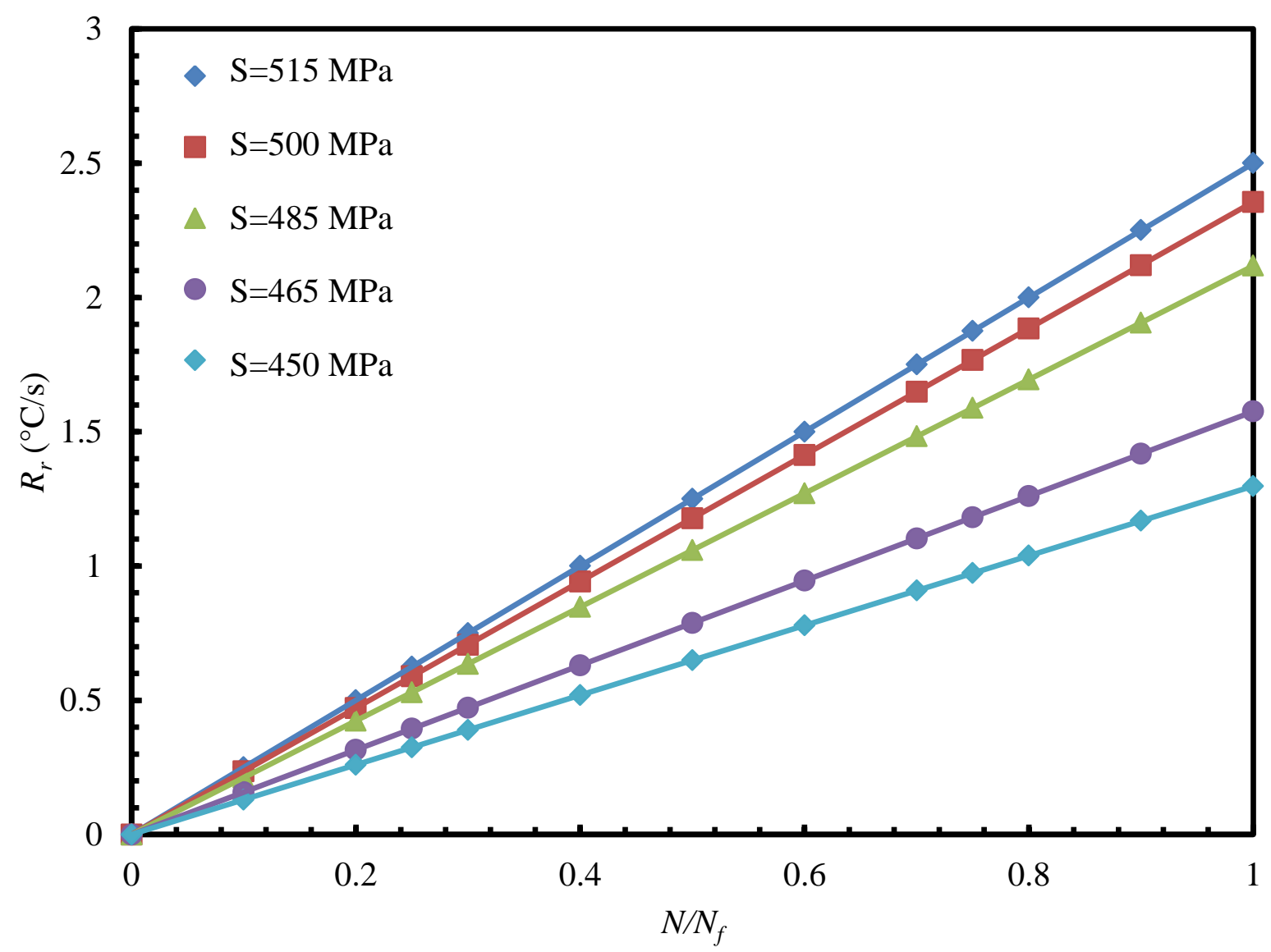

Figure 22: $R_{r}$ vs. $N / N_{f}$.

The relation between $R_{r}$ and $N / N_{f}$ was mentioned previously in Section 3.2 and was presented as equation 12 .

$$
R_{r}=\left(n \frac{N}{N f}\right)
$$

where $n$, is the slope of the $R_{r}$ evolution. Using this group, if all parameters regarding the test remain constant, other than the proportion of consumed fatigue life, $N / N_{f}$, then it is possible to generate points of the $R_{r}$ evolution to show a full evolution from $N / N_{f}=0$ to $N / N_{f}=1$. 


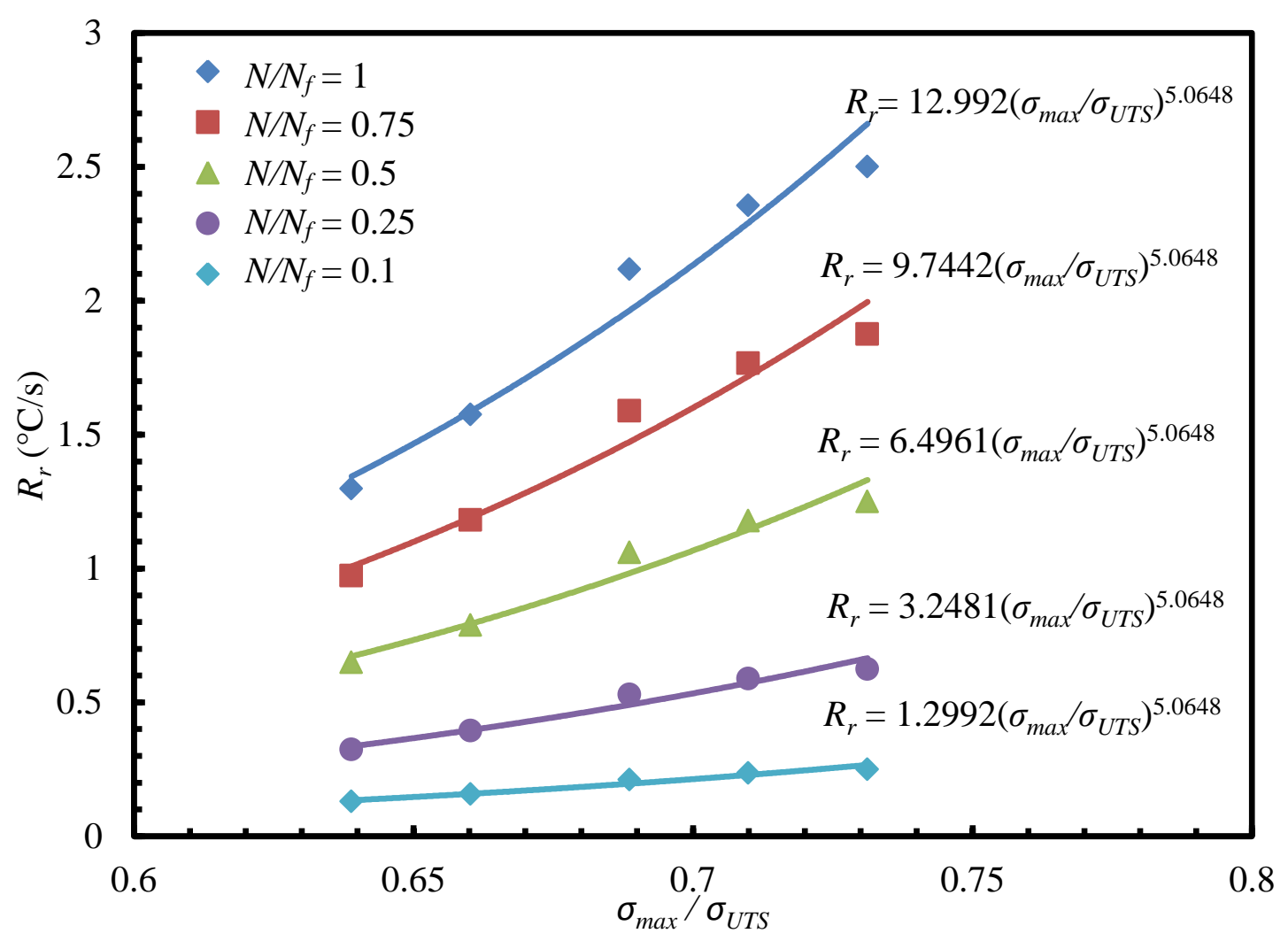

Figure 23: $R_{r}$ vs. Maximum Applied Stress/ Ultimate Tensile Strength.

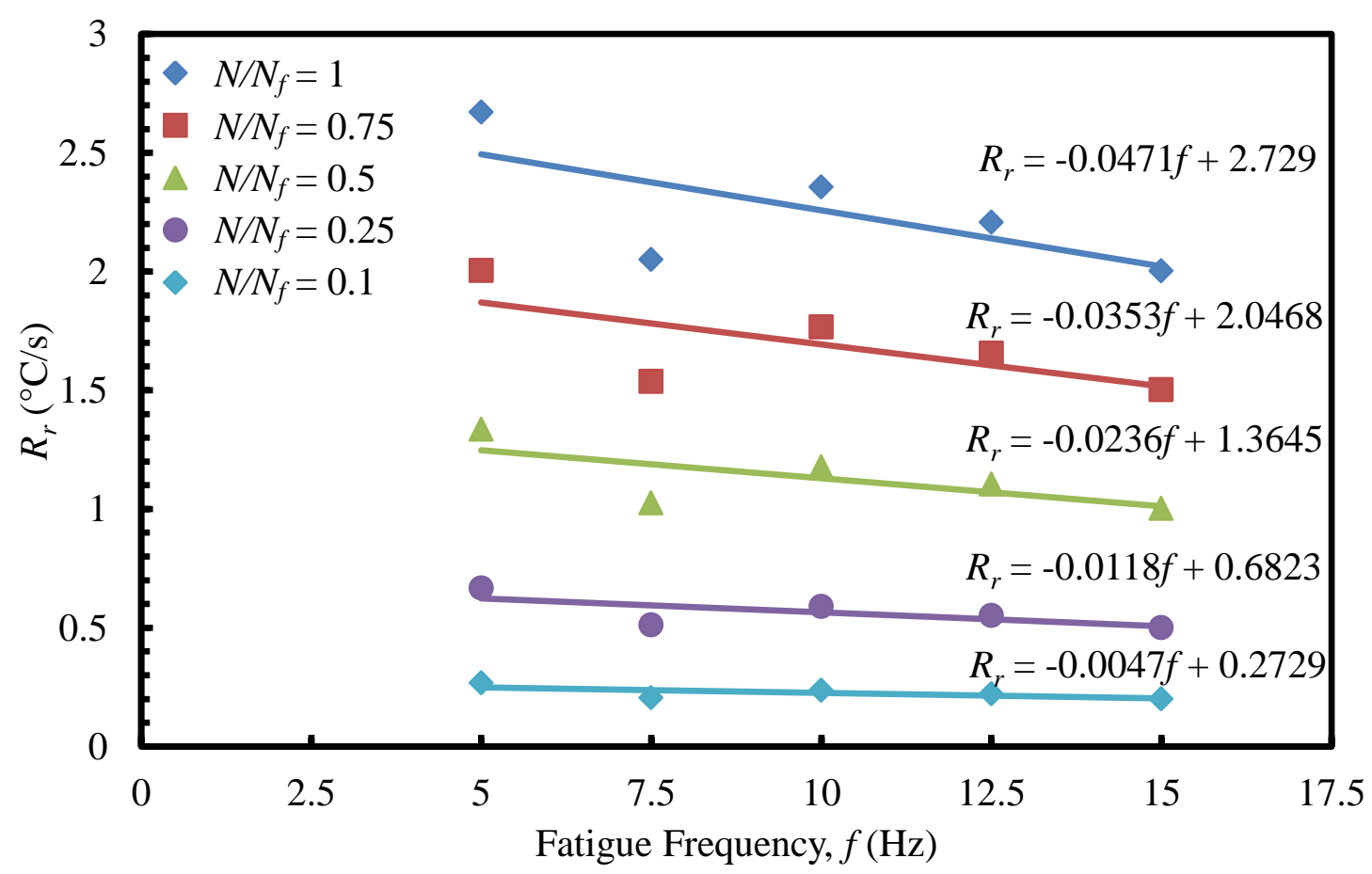

Figure 24: $R_{r}$ vs. Fatigue Loading Frequency. 


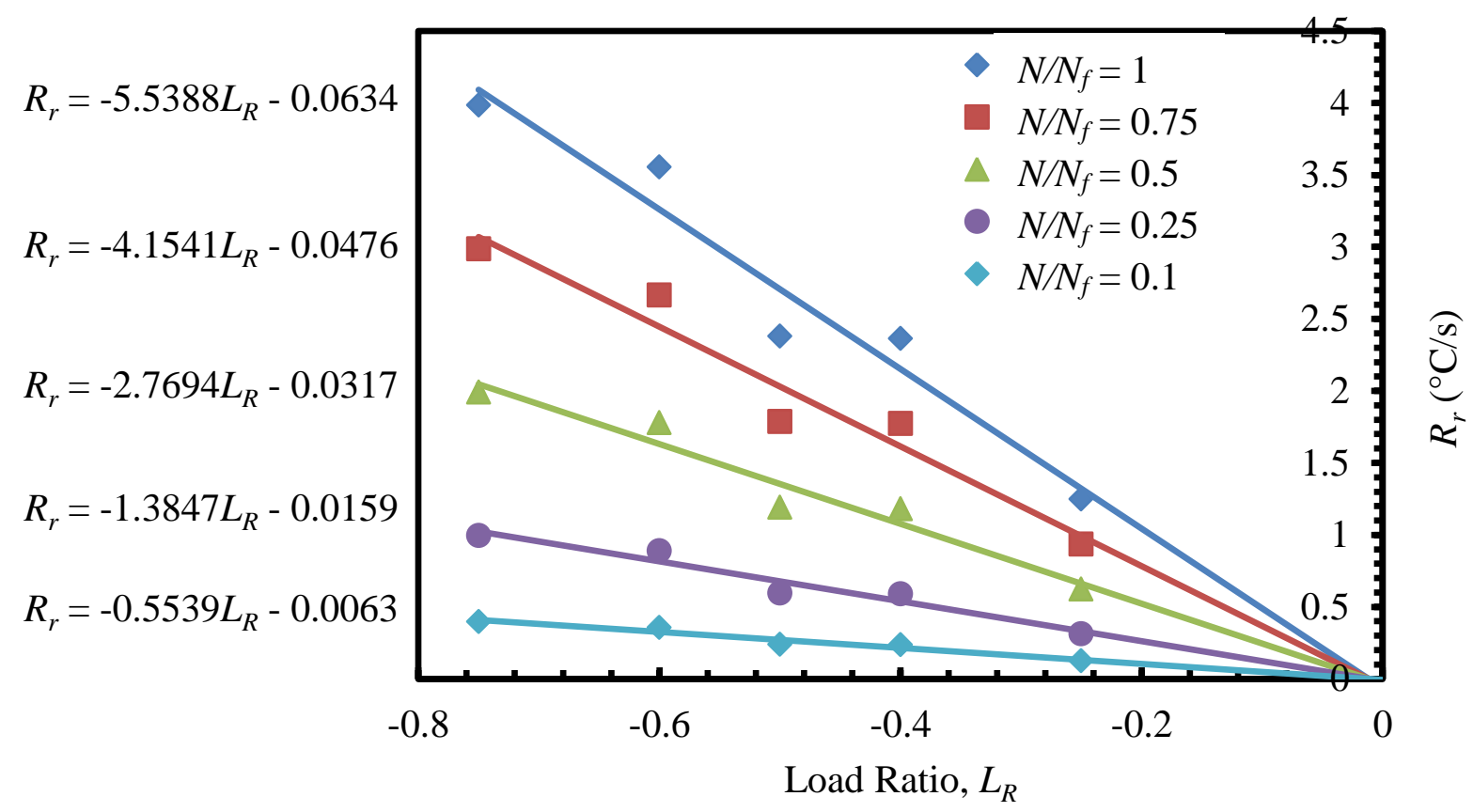

Figure 25: $R_{r}$ vs. $L_{R}$.

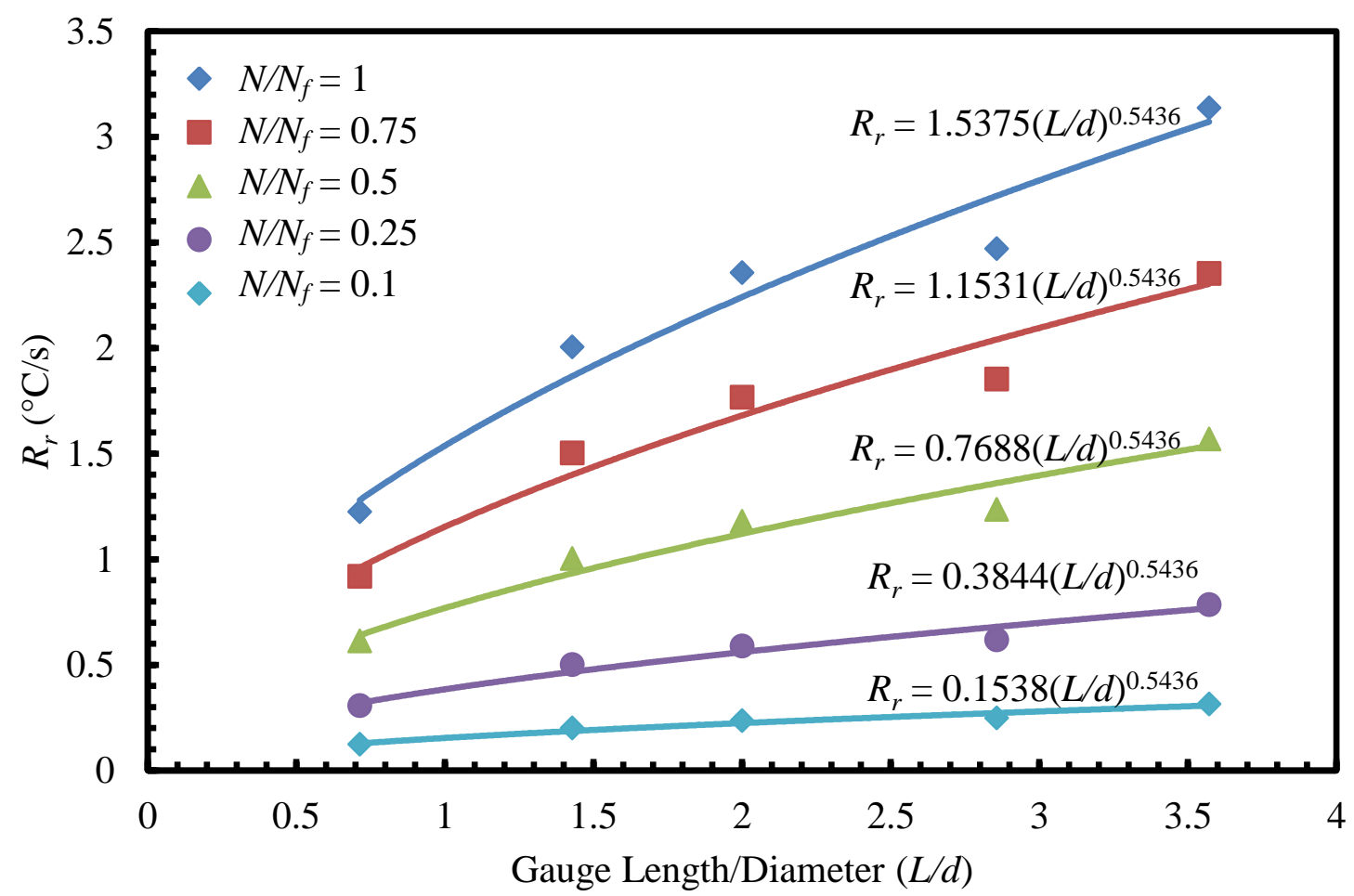

Figure 26: $R_{r}$ vs. $L / d$ ratio. 


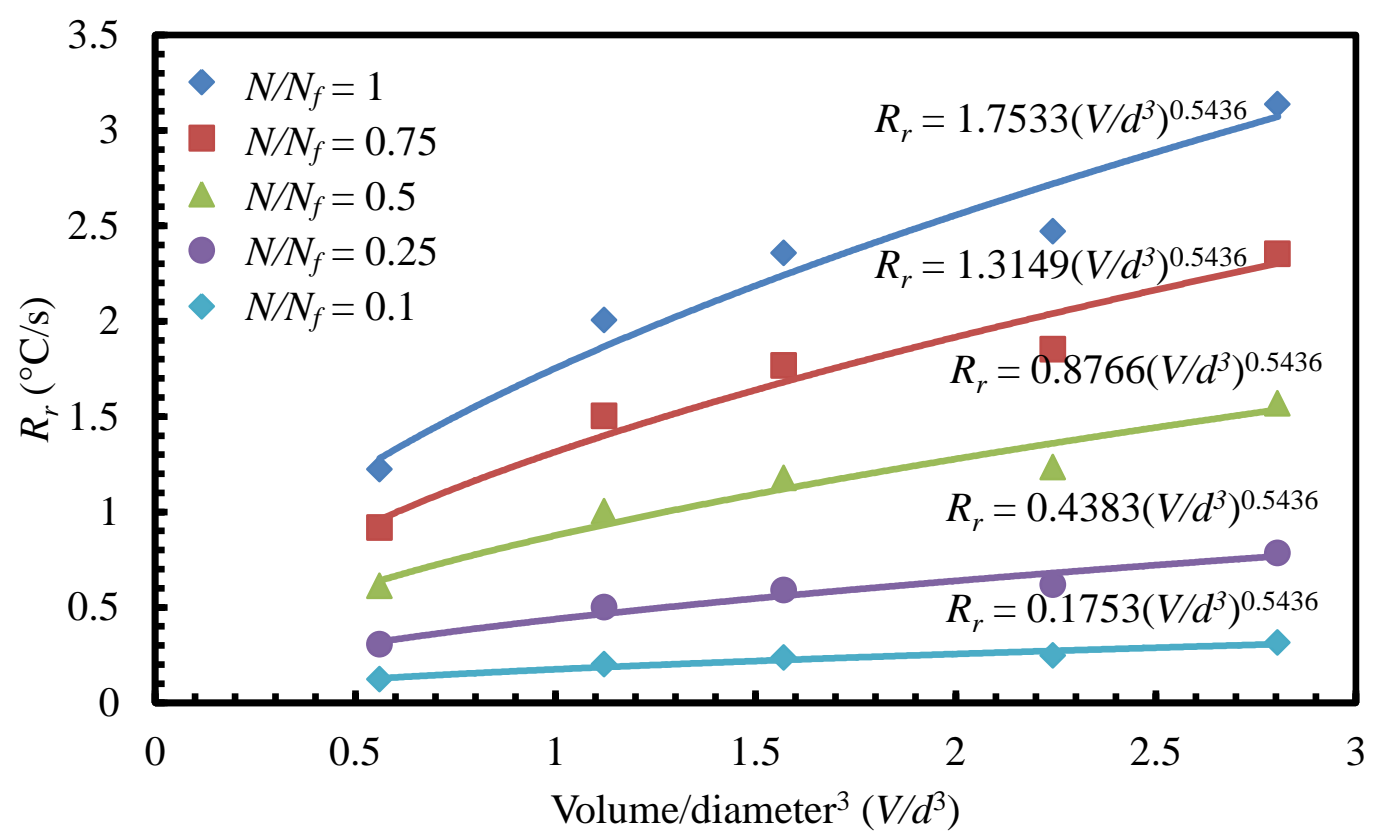

Figure 27: $R_{r}$ vs. $V / d^{3}$ ratio.

\subsubsection{Application of Results to Pi Theorem}

The results shown in Figures 22-27 provide a useful insight to the variation of $R_{r}$ with each Pi group. From inspection of the computational fitting expressions, it can be seen that the coefficient of the Pi groups plotted is also a function of the fraction of consumed life, in the form shown below in equation 25 :

$$
R_{r}=\frac{N}{N_{f}} \cdot C_{i} \cdot\left(\Pi_{i}\right)^{Z_{i}}
$$

Particular results of note are the $L / d$ and $V / d^{3}$ results, which have the same exponent for the power law fit, with slightly different coefficient values, suggesting that either nondimensional group could be utilized. However, for this data $V / d^{3}$ will continue to be used, as this allows for the application of the group to tubular specimens. Equations 26 and 27 show the data fit expressions for both the geometry ratios. 


$$
\begin{aligned}
& R_{r}=\frac{N}{N_{f}} \cdot C_{1} \cdot\left(\frac{V}{d^{3}}\right)^{0.5436} \\
& R_{r}=\frac{N}{N_{f}} \cdot C_{2} \cdot\left(\frac{L}{d}\right)^{0.5436}
\end{aligned}
$$

Another group of interest is the fatigue frequency Pi group, which has a reasonably linear fit, with a very small slope value. Due to this small slope value and given that the fatigue life results suggest a negligibly small variation due to fatigue frequency, this group does not appear to be relevant to study in any greater detail between the values tested.

Now, the relation between each of the Pi groups and $R_{r}$ is known and predictions can be made at different stress levels, or different specimen geometries through the use of a base line test. These results will be used to determine the appropriate coefficients for a set group. For example using a test at $500 \mathrm{MPa}$ maximum applied stress, $L_{R}$ of -0.5 , fatigue frequency of $10 \mathrm{~Hz}$ and $V / d^{3}$ ratio of, the coefficients can be calculated for this material and set of excitation loading conditions. Table 8 below shows the coefficient values for the Carbon Steel calculated from the base line test described above.

Table 8: Coefficients for Carbon Steel.

\begin{tabular}{ccc}
\hline Stress Coefficient & Load Ratio Coefficient & Volume Ratio Coefficient \\
\hline 12.992 & -5.5388 & 1.7533 \\
\hline
\end{tabular}

Using these coefficients, with the appropriate Pi groups, predictions can be made of the $R_{r}$ evolutions, for untested levels. To confirm the accuracy of these groups, Figures 28-30 below shows predicted evolutions from the Pi groups compared with the experimentally obtained values. 


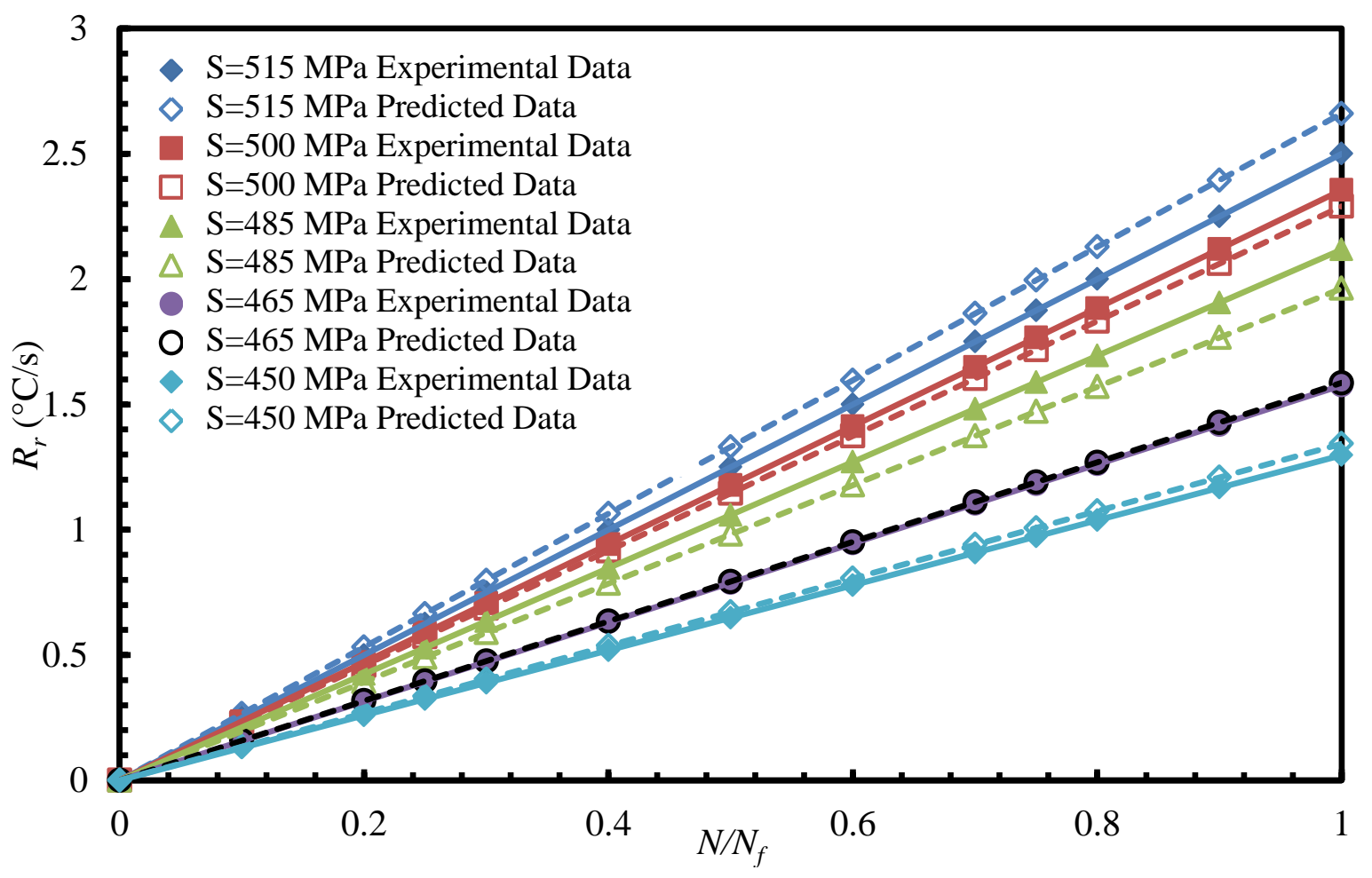

Figure 28: Comparison of Experimental and Predicted $R_{r}$ evolutions and different stress levels.

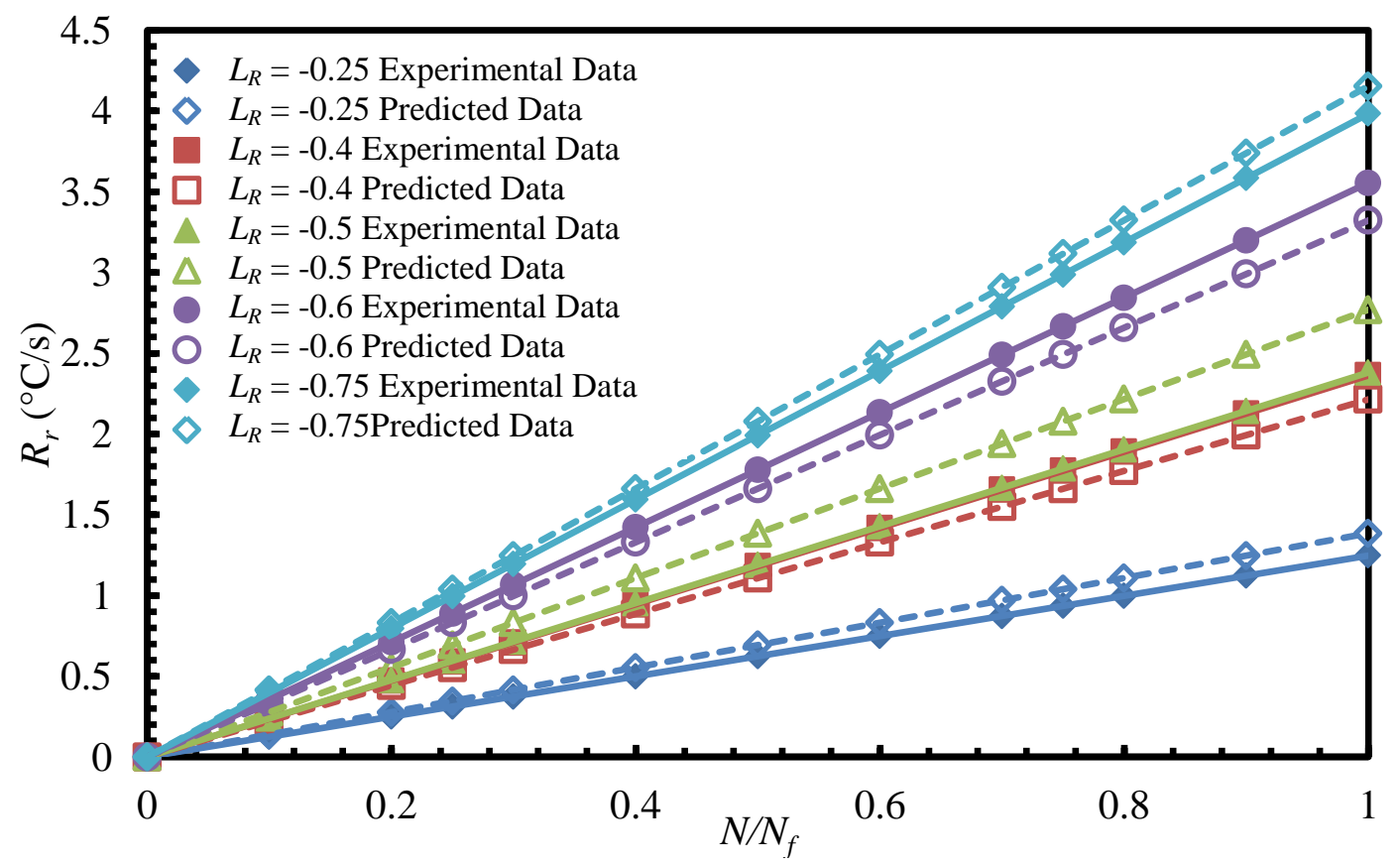

Figure 29: Comparison of Experimental and Predicted $R_{r}$ evolutions at different load ratios. 


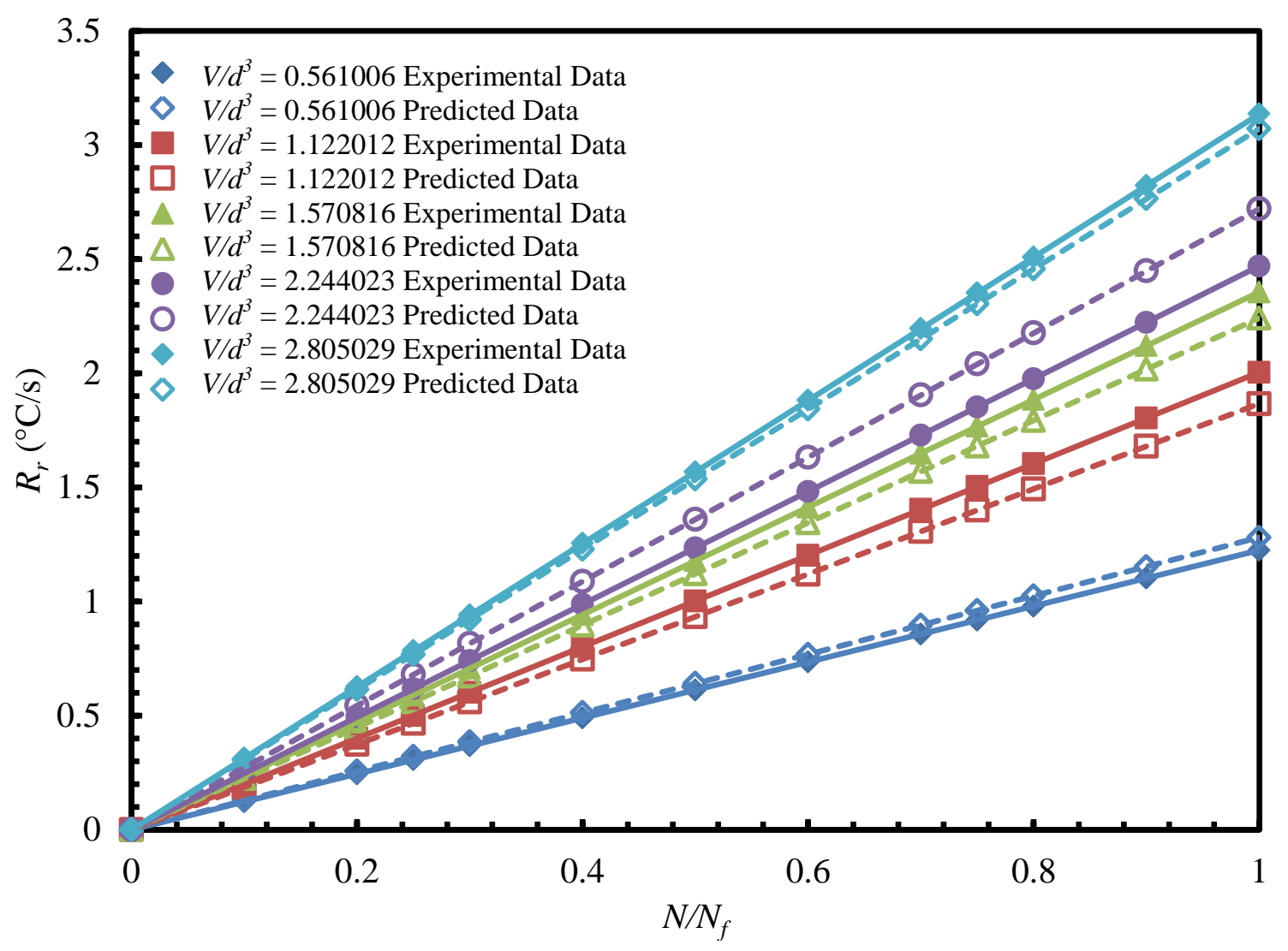

Figure 30: Comparison of Experimental and Predicted $R_{r}$ evolutions at different $V / d^{3}$ ratios.

Figures 25-27 show a good agreement between the experimental $R_{r}$ evolutions and the generated evolutions using the coefficients from the base line test, and the groups determined through Pi theorem and experiment. To further test the strength of these groups and coefficient values, predictions need to be made for test conditions which have not yet been carried out, to confirm the expressions hold for other conditions. These results are shown in Section 5.2.2.

\subsubsection{Predictions for previously untested $R_{r}$ evolutions}

Using the Pi groups obtained in Section 2.3, and the experimental relations determined in Section 5.2.1, predictions were made for stress levels and a load ratio which were previously untested. Figure 31 shows the predicted $R_{r}$ evolutions for these tests. 


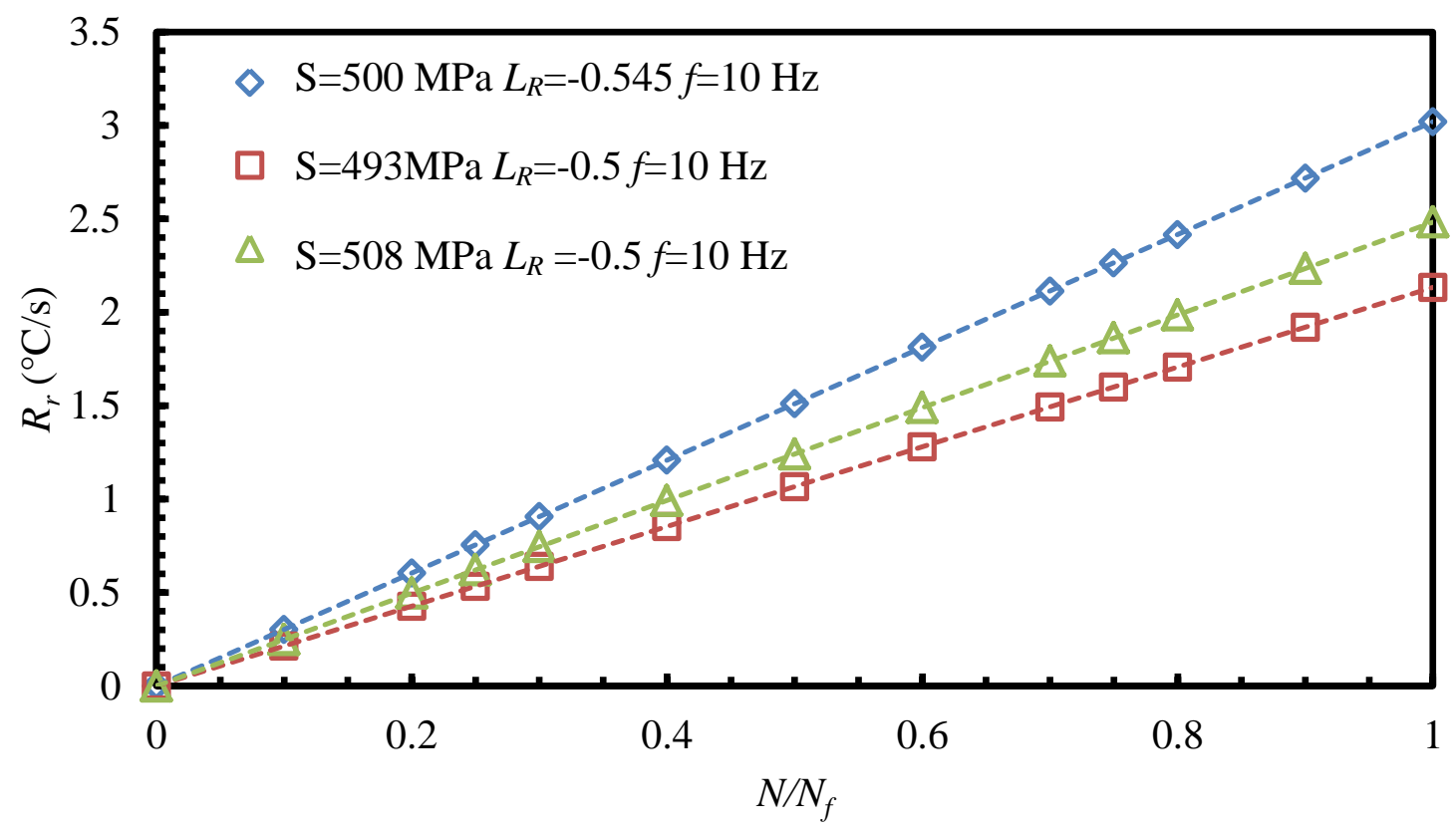

Figure 31: Predicted $R_{r}$ evolutions.

Following the predictions, experiments were carried out to determine the actual $R_{r}$ evolutions of the material, and these are presented in Figure 32, with the predicted evolutions also shown for comparison.

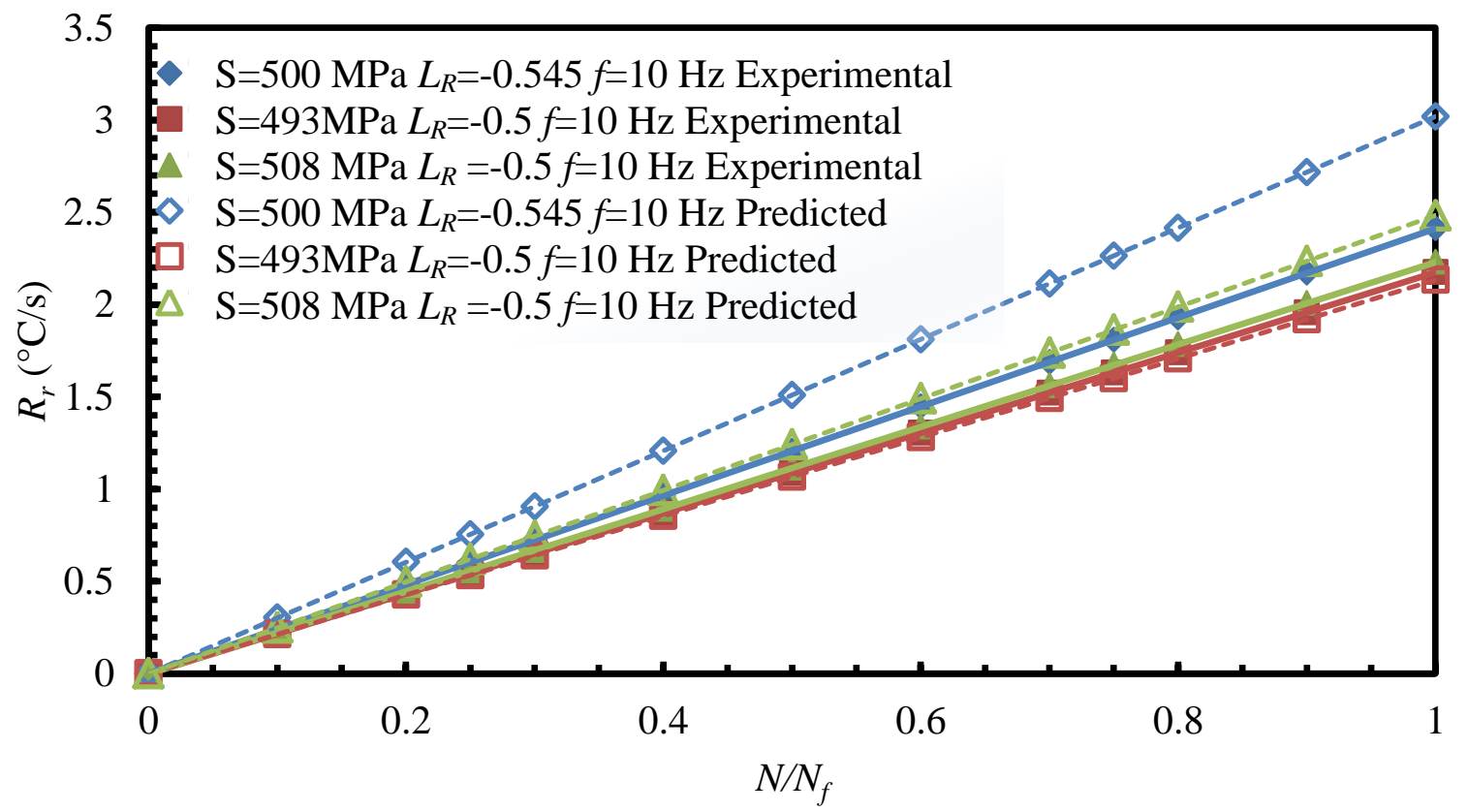

Figure 32: Comparison of Predicted and Experimental $R_{r}$ evolutions. 
The initial experimental results for the Pi groups determined via the Buckingham Pi theorem show reasonably strong trends when plotted against the relative temperature rise, $R_{r}$. Perhaps the weakest trend is shown by the frequency plot, however based on the very small slope values of this relation at all fractions of fatigue life, it appears to have a negligibly small effect on $R_{r}$. This result is expected, as the frequency at which the fatigue is carried out should not have a significant effect on the STE test temperature evolutions.

Figures 28-30 show the experimental evolutions of $R_{r}$, and for comparison also show the $R_{r}$ evolutions calculated using the coefficients, and exponents generated through the Pi theorem. Overall the predictions appear to hold relatively well within the envelope of the testing conditions.

Figures 31 and 32 show test results using only the Pi groups to generate the $R_{r}$ evolutions, prior to carrying out the experiments, and then again show comparisons between the predictions and the experimental data. For the Stress level of $493 \mathrm{MPa}$, the prediction shows a very close agreement with an error of around 2\%, however the higher stress level tested in this manner, 508 MPa had a larger deviation of $11 \%$. The final prediction made using a different load ratio of 0.545 shows the largest error of $25 \%$, far greater than acceptable. Some deviation in these predictions is expected as the coefficients and exponents for the Pi groups are based across several tests, and thus the result will potentially fit some experimental points more accurately than others. Further experimentation to refine the groups and study the parameters appears necessary to improve the accuracy.

Ideally further tests would be carried out, at stress levels not included within the current range, but due to the range of fatigue lives of the tests carried, from the low-cycle regime to high-cycle fatigue over 100000 cycles. These tests would either be extremely short, where STE 
tests can actually begin to affect the fatigue life, or extremely long with small temperature rises due to the small amounts of plastic strain experienced. Additional materials testing too would further help to study the groups, although it should be noted that the coefficients and exponents for each group appear to be based on the material properties, and the excitation loading conditions, thus they are likely to vary between different materials. Other research at CeRoM has provided data for varying stress levels on API5LX52 specimens, where the form of the curve fit is that same, a power law, this data is provided in Appendix 6. However the exponent and coefficient do vary, as shown in Figure 33. The coefficient and exponent from the curve fit are different for the welded specimen data compared to the pristine API5LX52 data shown in the Appendix 6, but the form of the stress ratio Pi group remains the same.

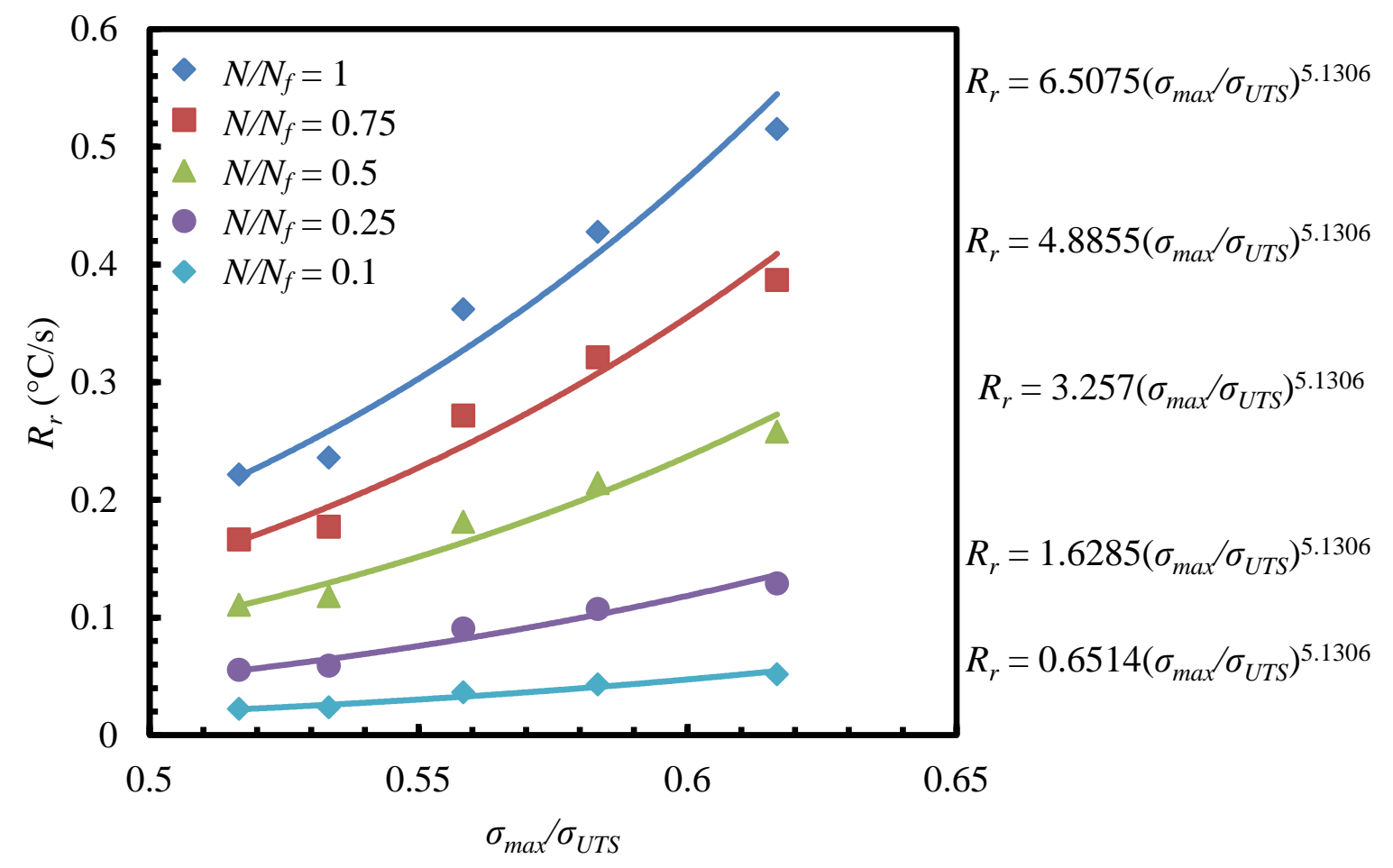

Figure 33: $R_{r}$ vs. maximum applied stress/ ultimate tensile strength ratio for Welded API5LX52 Specimen. 
Between different materials, the Pi groups themselves should remain the same, and the form of the equation as shown in Equation 22. For completeness these results have been included in the Appendix. The current results shown for the Buckingham Pi analysis, show potential, and further work is planned to determine more information regarding the relationships shown in this section.

\subsection{Damage Parameter Results}

\subsubsection{Damage Evolutions from $R_{r}$}

The concept of the damage parameter, $D$, was introduced in Section 1.6 as a method for studying the degradation of a material undergoing loading cycles. The initial paper discussing this parameter showed a range of different material properties which could be measured throughout the fatigue loading process to determine the evolution of damage in the material. The parameter $R_{r}$ is also shown to vary continuously throughout the fatigue life of a specimen, which allowed for Liakat and Khonsari at the CeRoM laboratory [87] to develop a formulation to calculate the damage parameter using the thermographic data, which can also be utilized to make fatigue life predictions, and to determine a critical point, where the evolution of damage increases dramatically. Using the equation from the literature relating damage parameter and the $R_{r}$ :

$$
D=\frac{-1}{\ln \left(\frac{R_{r f}}{n}\right)} \cdot \ln \left(1-\frac{R_{r}}{R_{r f}}\right)
$$

Where $R_{r f}$ is the final $R_{r}$ value at failure and $n$, is the slope of the $R_{\theta}$ curve. The damage evolution of the welded specimens was calculated and compared to that of a pristine specimen made from the same material. Figure 34 below presents the results of these calculations using the temperature evolutions measured experimentally. 


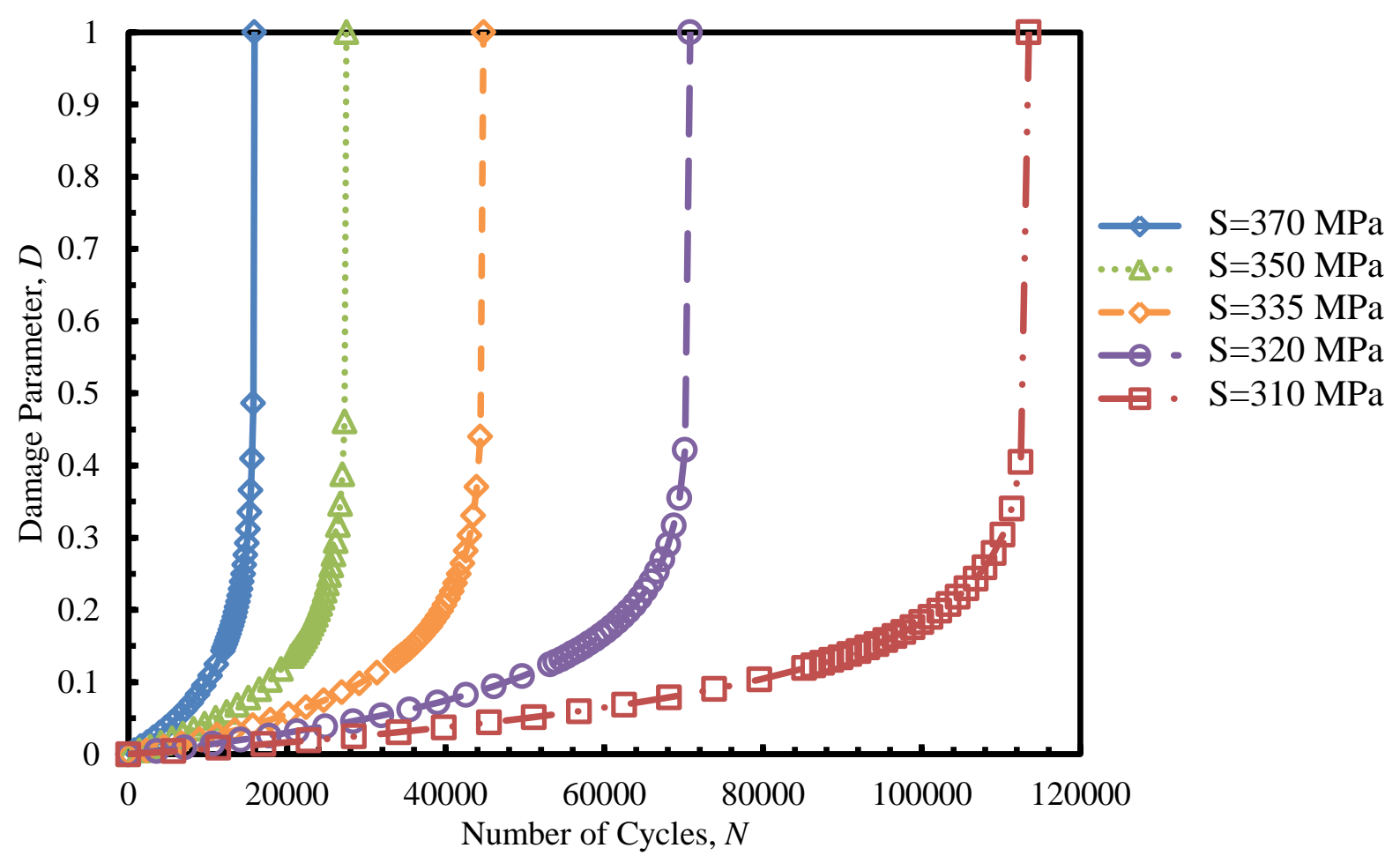

Figure 34: Damage Evolution for API5LX52 Welded Specimens.

\subsubsection{Remaining Fatigue Life Prediction using $D$}

Using the $R_{\theta}$ evolution curves for the API5LX52 specimens, and the $R_{\theta}$ values obtained from the STE tests at the stopping point, $D$ was calculated. These values are shown in Table 9 below. The values of $D$ were used to obtain a value of consumed life from a $D$ vs. $N / N_{f}$ plot, and the results presented below show good agreement with the $R_{\theta}$ results.

Using the formula presented by Liakat and Khonsari [87] the $D$ evolutions are shown in Figures 34 and 35 . The form of the evolution fits very well with damage evolution shown in a range of different literature sources. Using the $R_{\theta}$ values from the verification tests, and subtracting the y intercepts value $R^{\prime}{ }_{\theta 0}$ allows for the calculation of the damage parameter at that particular moment in time. These values are then used to read from the $D$ vs. $N / N_{f}$ plot and make promising predictions of the consumed fraction of fatigue life. 
Table 9: Damage Verification Test Results for Welded API5LX52 Specimens.

\begin{tabular}{|c|c|c|c|c|c|c|c|}
\hline $\begin{array}{c}\sigma \\
(\mathrm{MPa})\end{array}$ & $\begin{array}{c}R_{\theta} \\
\left({ }^{\circ} \mathrm{C} / \mathrm{s}\right)\end{array}$ & $\begin{array}{c}R_{r} \\
\left({ }^{\circ} \mathrm{C} / \mathrm{s}\right)\end{array}$ & $N$ & $D$ & $\begin{array}{l}\text { Predicted } \\
\text { Consumed } \\
\text { Life, PCL } \\
(\%)\end{array}$ & $\begin{array}{l}\text { Experimental } \\
\text { Consumed } \\
\text { Life, ECL } \\
(\%)\end{array}$ & $\begin{array}{l}\text { Absolute } \\
\text { Error (\%) }\end{array}$ \\
\hline 370 & 0.5703 & 0.4763 & 10299 & 0.2677 & 92 & 82.22 & 9.78 \\
\hline 335 & 0.2636 & 0.2489 & 29998 & 0.1088 & 70 & 65.6 & 4.40 \\
\hline 350 & 0.3067 & 0.2252 & 16003 & 0.073 & 53 & 54.6 & 1.60 \\
\hline
\end{tabular}

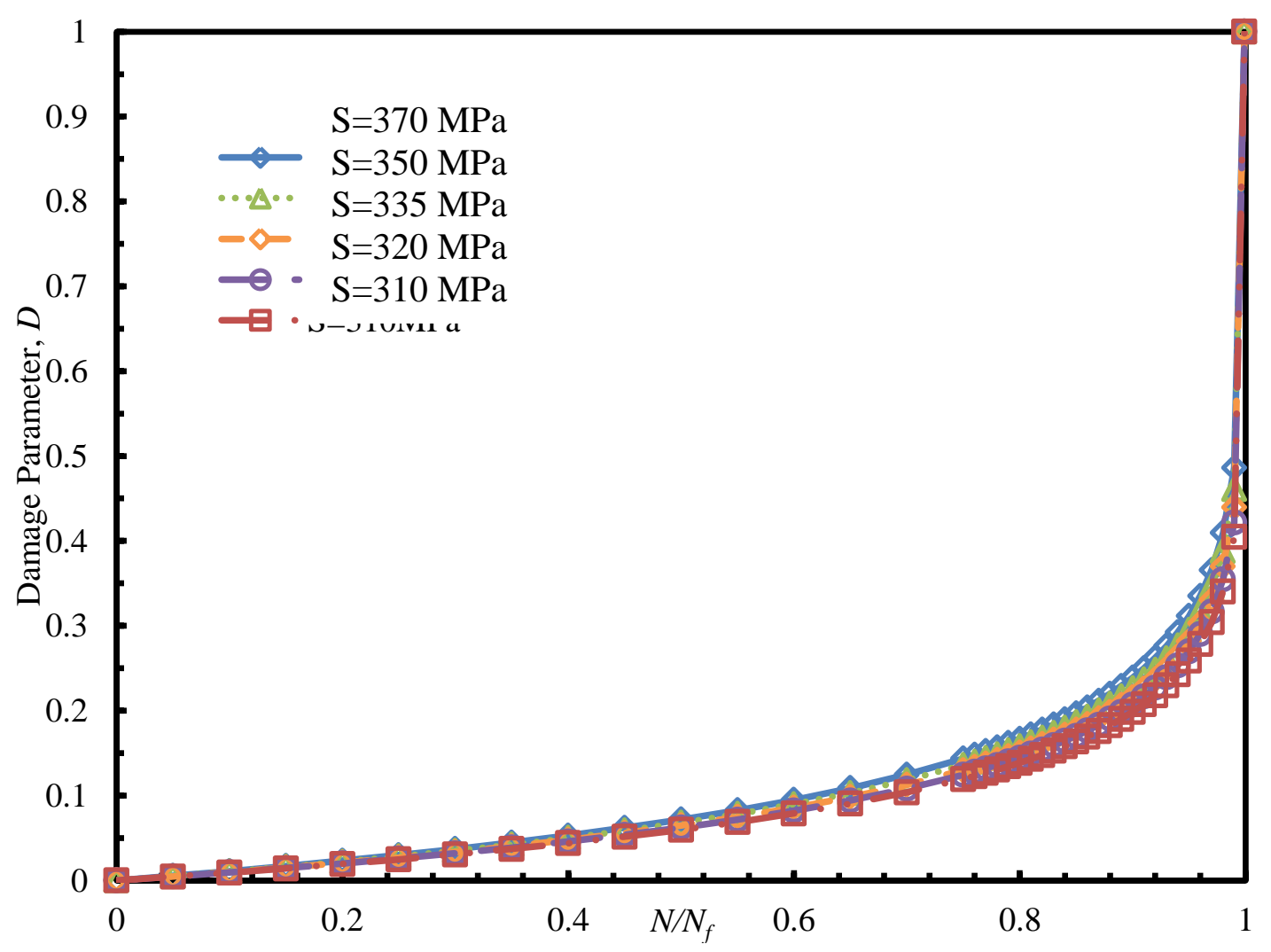

Figure 35: Damage Parameter, $D$ vs. $N / N_{f}$.

As only one brief set of experiments have been carried out using this methodology, some further experimentation to confirm the accuracy of these predictions would help significantly in developing the procedure for prediction of remaining fatigue lives. Due to the difference in strength between welded specimens and pristine API5LX52 specimens, it was not possible to directly compare the damage evolution of welded and pristine specimens. This would allow for interesting analysis on the strength of damage parameter in studying the different failure mechanisms, such as the different microstructures in HAZ and weld compared to the more 
uniform microstructure that would be expected in pristine materials. Plotting both pristine and welded damage vs. $N / N_{f}$ would allow for a comparison between the two. 


\section{Chapter 6: Conclusions}

Overall, the work presented in this thesis shows promise for the $R_{\theta}$ technique in making predictions for not only pristine materials, but also welded specimens. Applying the technique in this manner pushes the technique closer towards being successfully applied to real-life components in industrial scenarios. Although a few potentials issues still remain such as generating temperature rises in larger specimens or full size components, as well as dealing with welded that fail due to flaws. It can be expected that welded joints would be inspected either ultrasonically, by X-Ray examination or by dye penetrant testing, thus failure through inherent flaws should not be common. However, ideally the technique would work regardless.

The results for the API5LX52 welded specimens also provides support for the promise of the $R_{\theta}$ technique, as these specimens were externally prepared, and very little about the manufacturing and welding was known, but the mapping methodology worked showing good accuracy despite that lack of knowledge in this case, of material taken directly from an engineering application.

Application of Buckingham Pi theorem to study this phenomenon has shown some initial promise, although it appears that further work is required to fully understand how each variable affects $R_{r}$, and to potentially be able to form a full non-dimensional equation capable of making predictions without the need to run long series of experiments. Experimentation to study how the variation in material properties and excitation loading conditions affect the coefficients and exponents would also help to vastly improve the understanding, and confirm the curve fits found from the experimental data carried out on the Carbon Steel.

The use of $D$ to make promising fatigue life predictions also has room for further development in the study of welded specimens. The general form of the $D$ vs. $N / N_{f}$ curve shows 
potential to make predictions of even this complicated failure relatively straight forward, regardless of stress, geometry or load ratio, and being the most generalized methodology for this type of prediction. 


\section{Chapter 7: Further Work}

The work presented all shows promise for further developments, to improve and refine the work, and aid in the application to more scenarios. The work on welded joint fatigue life prediction has been carried out on two different steels, with known weld locations. Ideally further work would be carried out where a weld was located within the gauge section of the specimen, but the location was not consistent. Proving the concept could be applied for the study of the technique for analyzing a more unknown specimen. Steel itself is a very common material in engineering, but many others materials are used, and welded such as aluminum or titanium alloys. $R_{\theta}$ has been applied to a range of materials including composites. However, welding causes changes within the material so confirmation of the applicability to other welded materials would strengthen the technique.

Another area pertaining to the welded specimens is the method of welding. Weld quality can vary significantly depending on the welding technique used, or experience of the weld, even the choice of weld metal, as in some scenarios there may be more than one possible choice. Stress relief techniques should also be considered, as these could change the material response. The two different specimens tested in this presented work were in two different stress relief conditions, the tubular 1018 carbon steel specimens were heat treated according to literature techniques to remove as much stress as possible, and the API5LX52 specimens did not require stress relief, however other methods remain which could be examined. Both the 1018 and API5LX52 welded specimens also had the weld bead removed to reduce any potential stress concentration, however this is not always the case in real life applications, and so testing of an as-welded specimen could provide useful information. 
The Buckingham Pi theorem results from the carbon steel also provide a good starting point for understanding the effect of individual variables on the thermographic $R_{\theta}$ life prediction method, but more work is required to truly complete the understanding of the phenomena. The groups developed through the theorem are able to make relatively accurate prediction or the $R_{r}$ evolution for a material, provided that a baseline test is carried out. From this baseline test, using the y intercept it is possible to predict an $R_{\theta}$ evolution that can be used for making a fatigue life prediction. However, the Pi groups all contain coefficients which must be calculated from the baseline test, thus any material must have at least one experiment carried out on it to ensure any prediction can be made. Further study in to the development of these coefficients could find a way to determine them based on STE loading conditions and material properties. 


\section{References}

[1] Anonymous, 1981, The Alexander L. Kielland accident, report of a Norwegian public commission appointed by royal decree of March 28, 1980, presented to the Ministry of Justice and Police, ISBN B0000ED27N.

[2] Report of the Public Inquiry into the causes and circumstances of the accident which occurred on the 10th January, 1954, to the Comet aircraft G-ALYP.

[3] Reed, R.P., Smith J.H. and Christ B.W., 1983, US Department of Commerce, National Bureau of Standards, Gaithersburg, MD, Special Publication 647.

[4] Bhaumik, S. K., Sujata M. and Ventataswamy M.A., 2008, Fatigue failure of aircraft components, Engineering Failure Analysis, Vol. 15, pp. 675-894.

[5] Paris, P.C. and Erdogan, F., 1963, A critical analysis of crack propagation laws, J. Basic Engineering Trans. ASME, Ser. D. Vol. 85, pp. 528-534.

[6] Wöhler, A., 1870, Über die Festigkeitsversuche mit Eisen und Stahl, Zeitschrift für Bauwesen, Vol. 20 pp. 73-106.

[7] Basquin O.H., 1910, The Exponential Law of Endurance Tests, American Society for Testing and Materials Proceedings, Vol. 10.

[8] Stephens, R., Fatemi, A., Stephens, R. R., and Fuchs, H., 2001, Metal Fatigue in Engineering, Wiley Publications, $2^{\text {nd }}$ Edition, New York, USA.

[9] Gaussorgues, G., Infra-red Thermography. Springer, 1994. p. xv. ISBN: 0412479001.

[10] Meola, C., Carlomagno, G. M., Squillace, A. and Gioleo. G., 2004, The use of infrared thermography for nondestructive evaluation of joints. Infrared Physics and Technology, Vol. 46. pp. 93-99.

[11] Maldague, X. F. M., 1994, Infrared Methodology and Technology. McGonnagle, W. J., (Ed.), Nondestructive Testing Monographs and Tracts, Gordon and Breach Science Publishers, 1994.

[12] Stanley, P. and Chan, W. K., 1985, Quantitative stress analysis by means of the thermoelastic effect. Journal of Strain Analysis, Vol. 20, Issue 3, pp. 129-137.

[13] Offermann, S., Beaudoin, J. L., Bissieux, C., and Frick, H., 1997, Thermoelastic Stress Analysis Under Nonadiabatic Conditions, Experimental Mechanics, Vol. 37, Issue 4, pp. 409-413. 
[14] Stanley, P., and Chan, W. K., 1986, The determination of stress intensity factors and crack tip velocities from thermoelastic infra-red emissions. Proc. of International conference of fatigue of engineering materials and structures, c262, IMechE, Sheffield, UK, pp. 105-114.

[15] Tomlinson, R. A., Nurse, A. D. and Patterson, E. A., 1997, On determining stress intensity factors for mixed mode cracks from thermoelastic data. Fatigue and fracture of engineering materials and structures, Vol. 20, Issue 2, pp. 217-226.

[16] Guduru, P. R., Zehnder, A. T., Rosakis, A. J., and Ravichandran, G., 2001, Dynamic full field measurements of crack tip temperatures. Engineering Fracture Mechanics, Vol. 68, pp. 1535-1556.

[17] Reifsnider, K. L. and Williams, R. S., 1974, Determination of fatigue-related heat emission in composite materials. Experimental Mechanics, pp. 479-485.

[18] Charles, J.A., Appl, F. J. and Francis, J. E., 1975, Using the scanning infrared camera in experimental fatigue studies. Experimental Mechanics, pp.479-485.

[19] Naderi, M., Amiri, M. and Khonsari. M. M., 2010, On the Thermodynamic Entropy of Fatigue Fracture. Proc. R. Soc. A, Vol. 466, Issue 2114, pp. 423-438.

[20] Dulieu-Barton, J. M. and Stanley, P., 1999, Applications of thermoelastic stress analysis to composite materials. Strain, pp. 41-48.

[21] Naderi, M. and Khonsari, M. M., 2012, Thermodynamic Analysis of fatigue failure in a composite laminate. Mechanics and Materials, Vol. 46, pp. 113-122.

[22] Woodward, R. J., Cunninghame, J. R. and Gresty, J. L., 1984, Application of Thermoelastic Stress Analysis to Concrete. 1st Int. Conf. Stress Anal. Thermoelastic Tech., London, pp. 27-28.

[23] Büyüköztürk, O., 1998, Imaging of Concrete Structures. NDT \& E International, Vol. 31 Issue 4, pp. 233-243.

[24] Clark, M. R., McCann, D. M. and Forde, M. C., 2003, Application of infrared thermography to the non-destructive testing of concrete and masonry bridges. NDT \& E International, Vol. 36, Issue 4, pp. 265-275.

[25] Meola, C., Carlomagno, G. M., Squillace, A. and Gioleo. G., 2004, The use of infrared thermography for nondestructive evaluation of joints. Infrared Physics and Technology, Vol. 46, Issue 1-2, pp.93-99.

[26] Breitenstein, O., Schmidt, C., Altmann, F. and Karg, D., 2011, Thermal Failure Analysis by IR Lock-in Thermography. Microelectronics Failure Analysis Desk Reference, $6^{\text {th }}$ Edition, ASM International 2011. 
[27] Lahiri, B. B., Bagavathiappan, S., Jayakumar, T. and Philip, J., 2012, Medical Applications of infrared thermography. Infrared Physics \& Technology, Vol. 55, Issue 4, pp. 221-235.

[28] Thomson, W. X. V., 1853, On the Dynamical Theory of Heat, with numerical results deduced from Mr. Joule's Equivalent of a Thermal Unit, and M. Regnault's Observations on Steam. Transactions of the Royal Society of Edinburgh, Philosophical Magazine, Vol. 20, pp. 261-288.

[29] Thomson, W., 1878, On the Thermoelastic, Thermomagnetic and Pyro-electric Properties of Matters, Transactions of the Royal Society of Edinburgh, Philosophical Magazine, Vol. 5, pp. 4-27.

[30] Biot, M. A., 1956, Thermoelasticity and Irreversible Thermodynamics. Journal of Applied Physics, Vol. 27, Issue 3, pp. 240-253.

[31] Morrow, J. D., 1965, Cyclic Plastic Strain Energy and Fatigue of Metals, ASTM STP 378, pp. 45-87.

[32] Kliman, V. and Bílý, M., 1984, Hysteresis energy of cyclic loading. Materials Science and Engineering, Vol. 68, Issue 1, pp. 11-18.

[33] Radhakrishnan, V. M., 1980, An analysis of low cycle fatigue based on hysteresis energy. Fatigue \& Fracture of Engineering Materials \& Structures, Vol. 3, Issue 1, pp. 75-84.

[34] Tchankov, D. S. and Vesselinov, K. V., 1998, Fatigue life prediction under random loading using total hysteresis energy. International Journal of Pressure Vessels and Piping, Vol. 75, Issue 13, pp. 955-960.

[35] Park, J. and Nelson, D., 2000, Evaluation of an energy-based approach and a critical plane approach for predicting constant amplitude multiaxial fatigue life. International Journal of Fatigue, Vol. 22, Issue 1, pp. 23-39.

[36] Meneghetti, G., 2007, Analysis of the fatigue strength of a stainless steel based on the energy dissipation, International Journal of Fatigue, Vol. 29, Issue 1, pp. 81-94.

[37] Prigogine I., 1967, Introduction to thermodynamics of irreversible processes, Interscience Publishers, NY, USA.

[38] Naderi, M. and Khonsari, M. M., 2011, A comprehensive fatigue failure criterion based on thermodynamic approach. Journal of Composite Materials, Vol. 46, pp. 437-447.

[39] Naderi, M. and Khonsari, M. M., 2010, An experimental approach to low-cycle fatigue damage based on thermodynamic entropy. International Journal of Solids and Structures, Vol. 47, pp. 875-880. 
[40] Naderi, M. and Khonsari, M. M., 2010, A thermodynamic approach to fatigue damage accumulation under variable loading. Journal of Materials Science and Engineering A, Vol. 527, pp. 6133-6139.

[41] Amiri, M., Naderi, M. and Khonsari, M. M., 2011, An experimental approach to evaluate the critical damage. International Journal of Damage Mechanics, Vol. 20, pp. 89-112.

[42] Naderi, M., Kahirdeh, A. and Khonsari M. M., 2012, Dissipated thermal energy and damage evolution of Epoxy/Glass composite material using infrared thermography and acoustic emission techniques. Composite Part B, Vol. 43, pp. 1613-1620.

[43] Amiri, M. and Khonsari, M. M., 2010, Life prediction of metals undergoing fatigue load based on temperature evolution. Materials Science and Engineering A, Vol. 527, Issue 6, pp. 1555-1559.

[44] Amiri, M. and Khonsari, M. M., 2010, Rapid determination of fatigue failure based on temperature evolution: Fully reversed bending load. International J Fatigue, Vol. 32, pp. $382-89$.

[45] Amiri, M. and Khonsari, M. M., 2012, Non-destructive estimation of remaining fatigue life: Thermography technique. Journal of Failure Analysis and Prevention, Vol. 12, pp. 683-688.

[46] Ali, M. D., Naderi, M., Khonsari, M. M. and Kabir, O. M., 2013, Non-destructive testing and prediction of remaining fatigue life of metals. Journal of Nondestructive Testing and Evaluation, pp. 1-8.

[47] Khonsari, M. M. and Amiri, M., 2013, Introduction to Thermodynamics of Mechanical Fatigue. CRC Press; Taylor and Francis Group.

[48] Meneghetti, G., 2007, Analysis of the fatigue strength of a stainless steel based on the energy dissipation. International J Fatigue, Vol. 29, pp. 81-94.

[49] Rösner, H., Sathish, S. and Meyendorf, N., 2001, Thermographic characterization of fatigue. Review of Progress in Quantitative Nondestructive Evaluation, Vol. 20, pp. 17021709.

[50] Matsumoto, E., 2011, Non Destructive Evaluation of Fatigue by thermal, acoustic and electromagnetic techniques. Procedia Engineering, Vol. 10, pp. 3656-3661.

[51] Crupi, G., Crupi, V., Guglielmino, E. and Taylor, D., 2005, Fatigue Assessment of Welded Joints using critical distance and other methods. Engineering Failure Analysis, Vol. 12, pp. $129-142$.

[52] Bilous, P. and Lagoda, T., 2009, Structural notch effect in steel welded joints. Materials and Design, Vol. 30, pp. 4562-4564. 
[53] Alam, M. M., Karlsson, J. and Kaplan, A. F. H., 2011, Generalising fatigue stress analysis of different laser weld geometries. Materials and Design, Vol. 32, pp. 1814-1843.

[54] Jiang, W. C., Wang, B. Y., Gong, J. M. and Tu, S. T., 2011, Finite element analysis of the effect of welding heat input and layer number on residual stress in repair welds for a stainless steel clad plate. Materials and Design, Vol. 32, pp. 2851-2857.

[55] Kang, H. T., 2007, Fatigue prediction of spot welded joints using equivalent structural stress. Materials and Design, Vol. 28, pp. 837-843.

[56] Park, J. M. and Kang, H. T., 2007, Prediction of fatigue life for spot welds using backpropagation neural networks. Materials and Design, Vol. 28, pp. 2577-2584.

[57] Fan, J., Guo, X., Wu, C. and Ma, G., 2012, Rapid Measurement of Fatigue Behavior of Welded Joints Using the Lock-in Infrared Thermography. $11^{\text {th }}$ International Conference on Quantitative Infrared Thermography, 11-14 June, Naples, Italy.

[58] Crupi. V., Chiofalo, G. and Guglielmino, E., 2010, Using Infrared Thermography in LowCycle Fatigue Studies of Welded Joints. Welding Journal, Vol. 89, pp. 195-200.

[59] Buckingham, E., 1914, On physically similar systems; Illustrations of the use of dimensional equations. Physical Review, Vol. 4, Issue 4, pp. 345-376.

[60] Sommerfeld, A, 1909, Ein Beitrag zur hydrodynamischen Erklärung der turbulenten Flüssigkeitsbewegung, in: Proceedings of the 4th International Mathematical Congress, Rome 1908, Vol. 3, pp. 116-124.

[61] Barenblatt, G. I. and Botvina, L. R., 1981, Incomplete self-similarity of fatigue in the linear range of crack growth. Fatigue of Engineering Materials and Structures, Vol. 3, pp. 193-202.

[62] Motte, A., 1729, The mathematical principles of Natural Philosophy, 1729. English Translation of Sir Isaac Newton's "Philosophice Naturalis Principia Mathematica" $3^{\text {rd }}$ Edition 1726.

[63] Bolster, D., Hershberger, R. E., and Donnelly, R. J., 2011, Dynamic similarity, the dimensionless science. Physics Today, pp. 42-47.

[64] Fourier, J., 1878, The analytical theory of heat. Cambridge University Press 1878. Translated by Alexander Freeman.

[65] Lord Rayleigh, 1945, The Theory of Sound London, pp. 1877-1896.

[66] Lord Rayleigh, 1915, Letters to Editor. Nature, Vol. 95, p.644. 
[67] Stahl, W. R., 1961, Dimensional analysis in mathematical biology: I. General Discussion. Bulletin of Mathematical Biophysics, Vol. 23, pp. 355-375.

[68] Hersey, M. D., 1919, A relation connecting the derivatives of physical quantities. US Dept. of Commerce, Bureau of Standards.

[69] Buckingham, E., 1915, The principle of similitude. Nature, Vol.96, pp.396-397.

[70] Hersey, M. D., 1932, Dimensional analysis of plastic flow. Journal of Rheology, Vol. 3, Issue 1, pp. 23-29.

[71] Bridgman, P. W., 1922, Dimensional Analysis. Yale University Press.

[72] Barenblatt, G. I., 2006, Scaling Phenomena in fatigue and fracture. International Journal of Fracture, Vol. 138, pp. 19-35.

[73] Shirani, M. and Härkegård, G., 2011, Fatigue life distribution and size effect in ductile cast iron for wind turbine components. Engineering Failure Analysis, Vol. 18, pp. 12-24.

[74] Nakai, Y., Hashimoto, A., Imanishi, T. and Hiwa, C., 1999, Size effect on fatigue strength of metallic micro-materials. Proceedings of Asian-Pacific Conference on Fracture and Strength, Vol. 99.

[75] Flaceliere, L. and Morel, F., 2001, Probabilistic approach in high-cycle multiaxial fatigue: volume and surface effects. Fatigue and Fracture of Engineering Materials and Structures, Vol. 27, pp. 1123-1135.

[76] Ciavarella, M., Paggi, M. and Carpinteri, A., 2008, One, no one and one hundred thousand crack propagation laws: A generalized Barenblatt and Botvina dimensional analysis approach to fatigue crack growth. Journal of the Mechanics and Physics of Solids, Vol. 56, pp. 3416-3432.

[77] Paggi, M., 2011, Modelling fatigue in quasi-brittlematerials with incomplete self-similarity concepts. Materials and Structures, Vol. 44, Issue 3, pp. 659-670.

[78] Plekhov, O., Paggi, M., Naimark, O. and Carpinteri, A., 2011, A dimensional analysis interpretation to grain size and loading frequency dependencies of the Paris and Wöhler curves. International Journal of Fatigue, Vol. 33, pp. 477-483.

[79] Chou, P. C. and Croman, R., 1979, Scale effect in fatigue of composite materials. Journal of Composite Materials, Vol. 13, pp. 178-194.

[80] Nguyen, T. N. and Wahab, M. A., 1998, The effect of weld geometry and residual stresses on the fatigue of welded joints under combined loading. Journal of Materials Processing Technology, Vol. 77, pp. 201-208. 
[81] Hirose, T., Sakasegawa, H., Kohyama, A., Katoh, Y. and Tanigawa, H., 2000, Effect of specimen size on fatigue properties of reduced activation ferritic/martensitic steels. Journal of Nuclear Materials, pp. 283-287.

[82] Hashin, Z. and Rotem, A., 1978, A cumulative damage theory of fatigue failure. Materials Science and Engineering, Vol. 34, Issue 2, pp. 147-160.

[83] Lemaitre, J. and Dufailly, J., 1987, Damage measurements. Engineering Fracture Mechanics, Vol. 28, Issue 5, pp. 643-661.

[84] Cheng, G. X., Lou, Z. W. and Kuang, Z. B., 1994, A new damage variable for low-cycle fatigue of metallic materials. Engineering Fracture Mechanics, Vol. 48. pp. 281-287.

[85] Duyi, Y. and Zhenlin, W., 2001, Change characteristics of static mechanical property parameters and dislocation structures of 45 medium carbon structural steel during fatigue failure process. Materials Science and Engineering: A, Vol. 297, Issue 1, pp. 54-61.

[86] Duyi, Y. and Zhenlin, W., 2001, A New Approach to Low Cycle Fatigue Damage Based on Exhaustion of Static Toughness and Dissipation of Cyclic Plastic Strain Energy during Fatigue, Int. J. Fatigue, Vol. 23, pp. 679- 687.

[87] Liakat, M. and Khonsari, M. M., 2014, An experimental approach to estimate damage and remaining life of metals under uniaxial fatigue loading. Journal of Materials and Design, Vol. 57, pp. 289-297.

[88] Meyendorf, N., Rösner, H., Kramb, V. and Sathish, S., 2002, Thermo-acoustic fatigue characterization. Ultrasonics, Vol. 40, pp. 427-434.

[89] Williams, P., Liakat, M. D., Khonsari, M. M. and Kabir, O. M., 2013, A thermographic method for remaining fatigue life prediction of welded joints. Journal of Materials and Design, Vol. 51, pp. 916-923.

[90] Bramson, M. A., 1968, Infrared Radiation, a Handbook for Applications. Springer. ISBN: 1475709137.

[91] Ummenhofer, T. and Medgenberg, J., 2009, On the use of infrared thermography for the analysis of fatigue damage processes in welded joints. International J Fatigue, Vol. 31, pp. 130-137. 


\section{Appendix A: Additional Experimental Data for welded $\boldsymbol{R}_{\theta}$ testing and}

Buckingham Pi testing

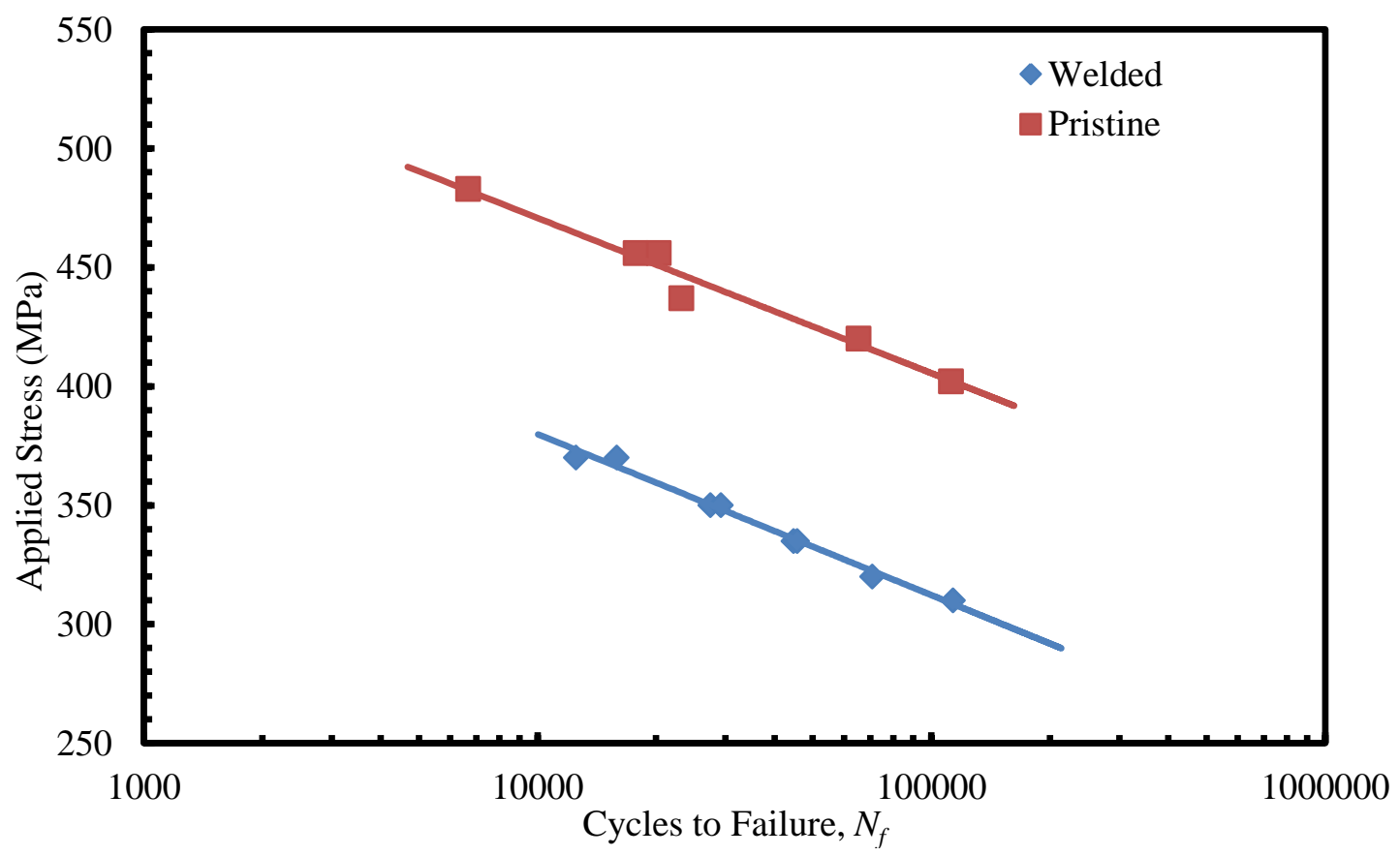

Figure A-1: $S-N$ curve for Welded and Pristine API5LX52.

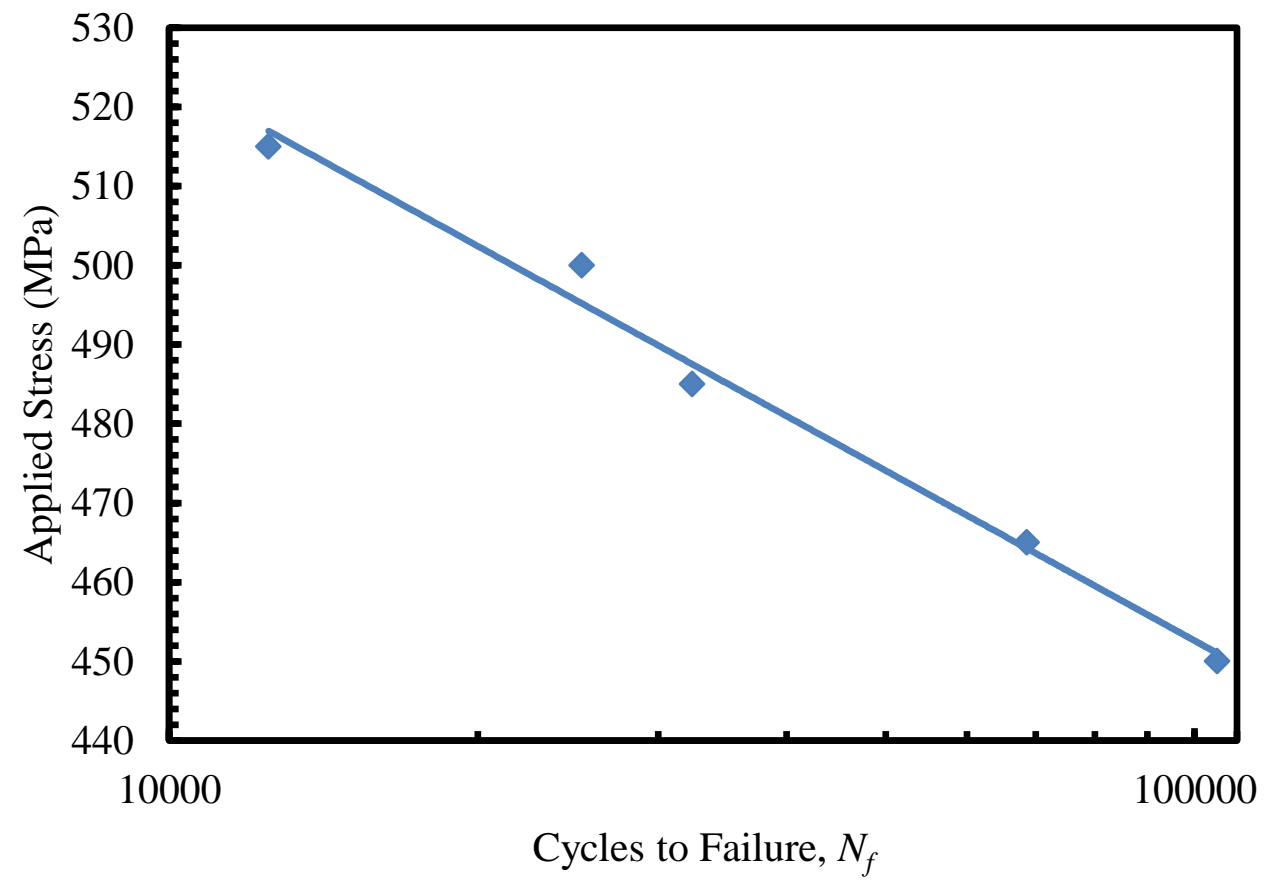

Figure A-2: $S-N$ Curve for Buckingham Pi Specimens. 


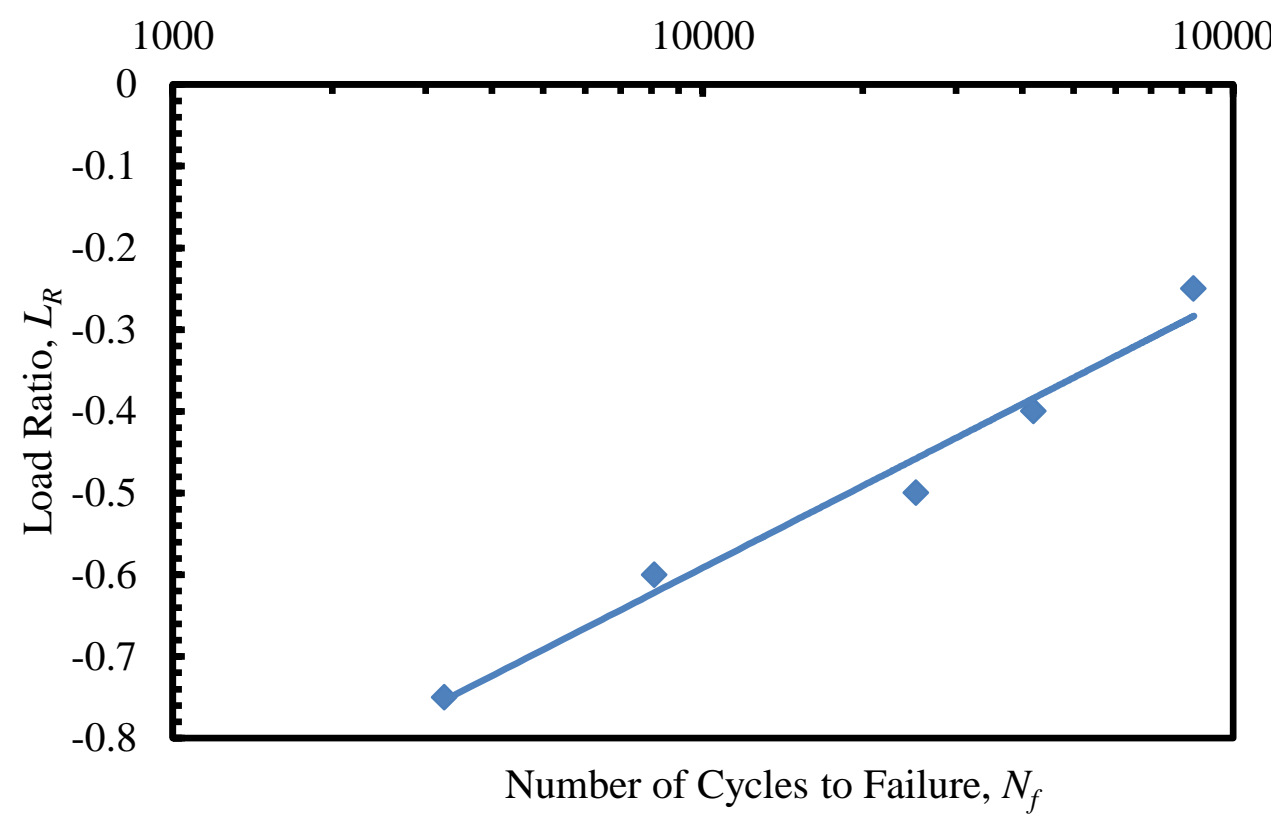

Figure A-3: $L_{R}-N$ Curve for Buckingham Pi Specimens.

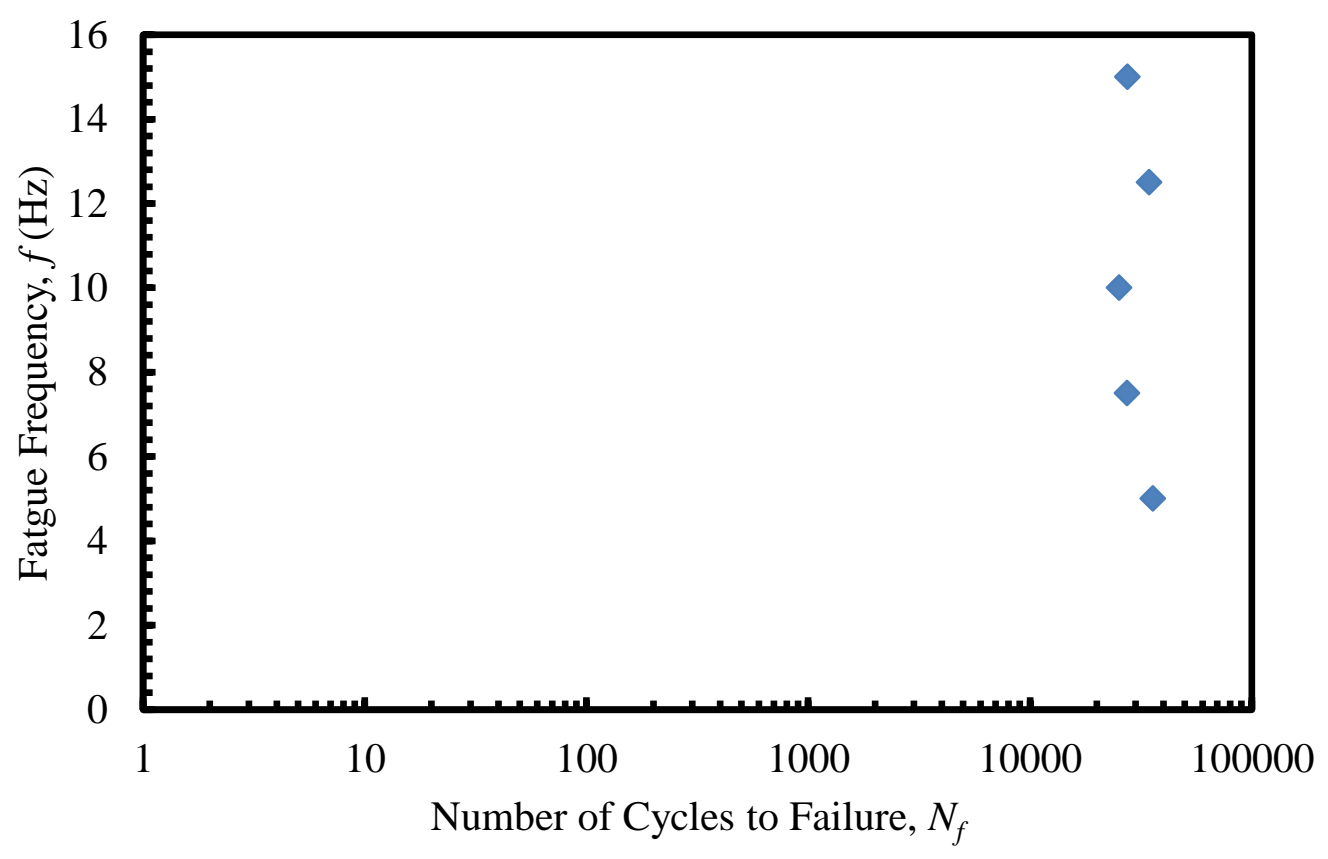

Figure A-4: $f-N$ Curve for Buckingham Pi Specimens. 


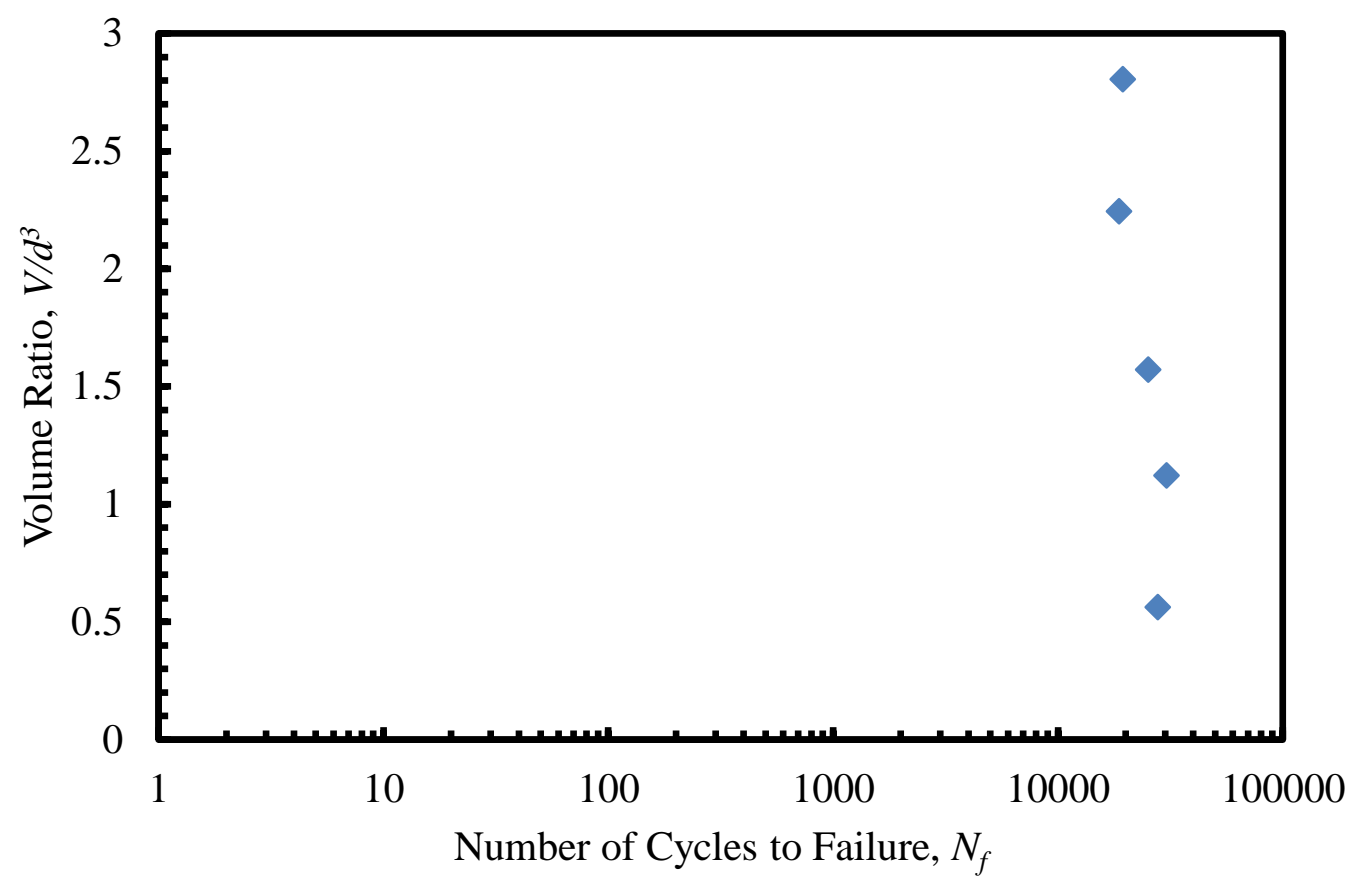

Figure A-5: Volume Ratio - N Curve for Buckingham Pi Specimens.

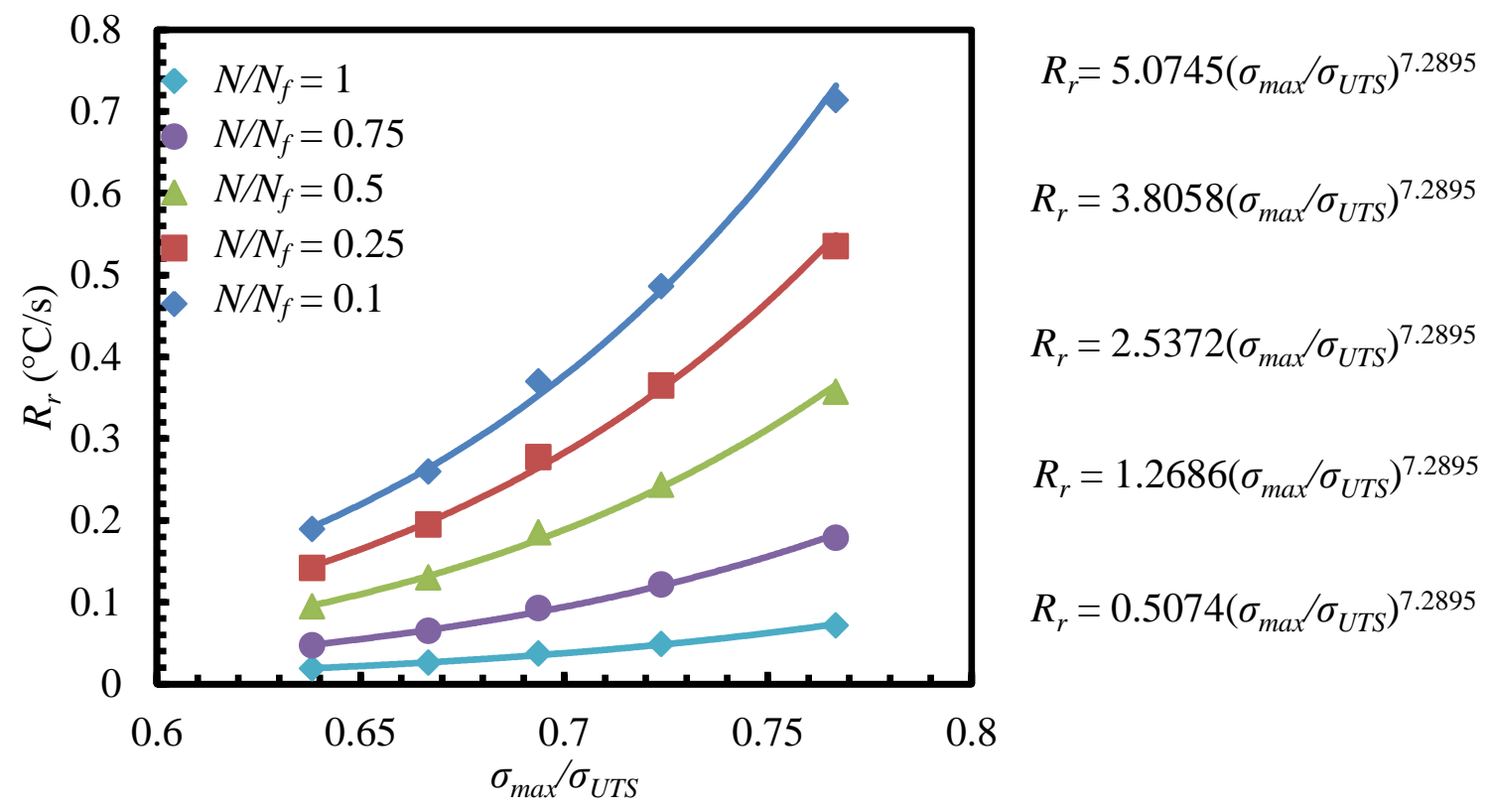

Figure A-6: $R_{r}$ vs. Maximum Applied Stress/ Ultimate Tensile Strength for API5LX52. 


\section{Appendix B: Letter of permission for reuse of images and text}

This is a License Agreement between Paul T Williams ("You") and Elsevier ("Elsevier"). The license consists of your order details, the terms and conditions provided by Elsevier, and the pavment terms and conditions.

Get the printable license.

\begin{tabular}{|c|c|}
\hline License Number & 3364840742956 \\
\hline License date & Apr 09, 2014 \\
\hline Licensed content publisher & Elsevier \\
\hline Licensed content publication & Materials \&. Design \\
\hline Licensed content title & A thermographic method for remaining fatigue life prediction of welded joints \\
\hline Licensed content author & P. Williams,M. Liakat,M.M. Khonsari,O.M. Kabir \\
\hline Licensed content date & October 2013 \\
\hline $\begin{array}{l}\text { Licensed content volume } \\
\text { number }\end{array}$ & 51 \\
\hline Number of pages & 8 \\
\hline Type of Use & reuse in a thesis/dissertation \\
\hline Portion & full article \\
\hline Format & both print and electronic \\
\hline $\begin{array}{l}\text { Are you the author of this } \\
\text { Elsevier article? }\end{array}$ & Yes \\
\hline Will you be translating? & No \\
\hline $\begin{array}{l}\text { Title of your } \\
\text { thesis/dissertation }\end{array}$ & A thermographic method for remaining fatigue life prediction of welded joints \\
\hline Expected completion date & Apr 2014 \\
\hline $\begin{array}{l}\text { Estimated size (number of } \\
\text { pages) }\end{array}$ & 90 \\
\hline Elsevier VAT number & GB 494627212 \\
\hline Permissions price & 0.00 USD \\
\hline VAT/Local Sales Tax & 0.00 USD / 0.00 GBP \\
\hline Total & 0.00 USD \\
\hline
\end{tabular}

Figure B-1: Letter of permission for reuse of images and text from the paper "A thermographic method remaining fatigue life prediction of welded joints". 


\section{Vita}

Paul Thomas Williams, originally from Leatherhead, Surrey in the United Kingdom, received his Master of Engineering (MEng), in Mechanical Engineering from the University of Sheffield in 2010. Following the completion of this program he worked and applied to Graduate Schools in the United States, while obtaining his Associate Membership (AM) in the Institute of Mechanical Engineers (IMechE). In the Fall of 2011 he began studying Mechanical Engineering at Louisiana State University. He hopes to graduate with his Master of Science in Mechanical Engineering (MSME) in 2014, with the intent to work in industry and gain practical experience, with the ambition to pursue Doctoral Study at a later date. 